\title{
The Implementation of the Korean Green Growth Strategy in Urban Areas
}
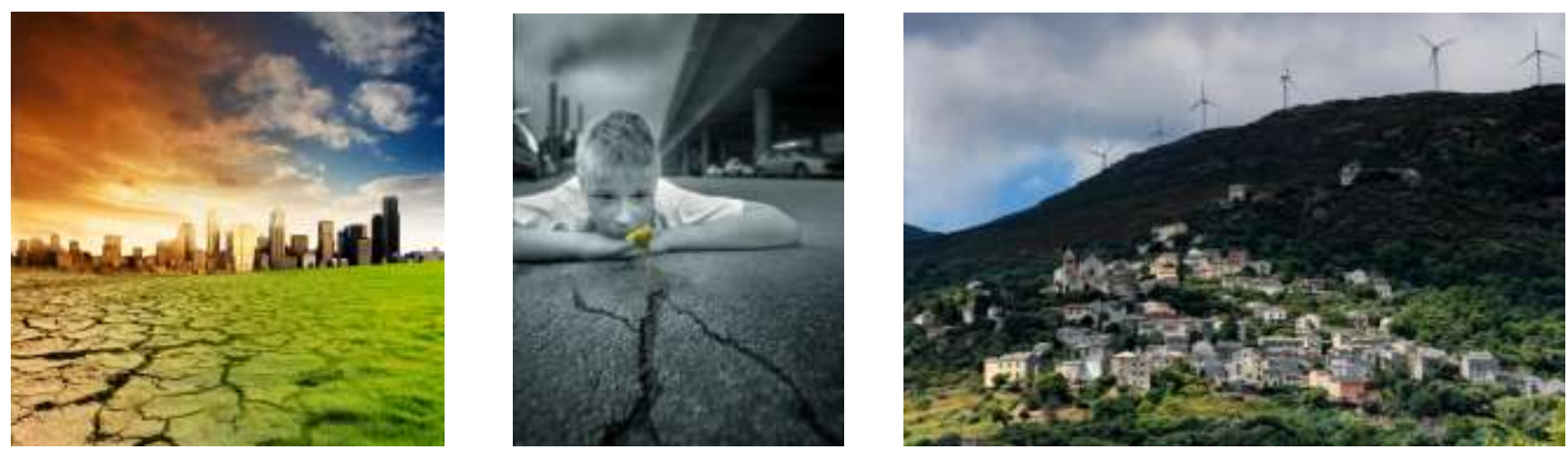

Please cite this paper as:

Kamal-Chaoui, L., et al. (2011), "The

Implementation of the Korean Green Growth

Strategy in Urban Areas", OECD Regional

Development Working Papers 2011/02, OECD

Publishing.

http://dx.doi.org/10.1787/5kg8bf4l4lvg-en

OECD Regional Development Working Papers 2011/02

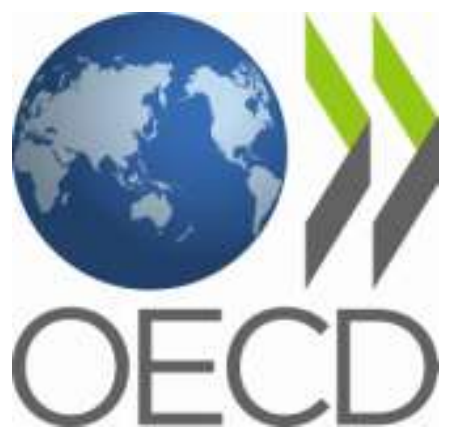

Lamia Kamal-Chaoui, Fabio Grazi, Jongwan Joo and Marissa Plouin

JEL Classification: Q2, Q3, Q4, Q5, R1, R4, R5 


\section{OECD REGIONAL DEVELOPMENT WORKING PAPERS}

This series is designed to make available to a wider readership selected studies on regional development issues prepared for use within the OECD. Authorship is usually collective, but principal authors are named. The papers are generally available only in their original language, English or French, with a summary in the other if available.

The opinions expressed in these papers are the sole responsibility of the author(s) and do not necessarily reflect those of the OECD or the governments of its member countries.

Comment on the series is welcome, and should be sent to gov.contact@oecd.org or the Public Governance and Territorial Development Directorate, 2, rue André Pascal, 75775 PARIS CEDEX 16, France.

OECD Regional Development Working Papers are published on www.oecd.org/gov/regional/workingpapers

Applications for permission to reproduce or translate all or part of this material should be made to: OECD Publishing, rights@oecd.org or by fax +33145249930.

(C) OECD 2011 


\begin{abstract}
This report on the Korean Strategy for Green Growth and its implementation in urban areas assesses the contributions of sub-national governments to Korea's National Strategy for Green Growth and identifies the main challenges for effective implementation at the local level. Korea's economy, heavily reliant on foreign exports, was hard hit by the recent global financial crisis. Since the 1970s, Korea has become one of the most energy-intensive economies in the OECD area, thanks to higher living standards, rapid urbanisation and an expanding industrial sector. As a result, the country's greenhouse gas emissions almost doubled between 1990 and 2005, registering the highest growth rate in the OECD area. It is in this context of rapid urbanisation and unprecedented resource consumption and environmental pressures that the report focuses on the role of urban areas within Korea's National Strategy for Green Growth. The effectiveness of Korea's green growth agenda, which has been driven by a central government vision and strategy, will largely hinge on the contribution of urban areas toward more sustainable, greener growth. Through the lens of a multilevel governance framework, an assessment of green growth policies in Korean cities helps to identify concrete strategies for delivering a coherent policy message and improving governance across all levels of government, with particular recommendations in terms of policy, funding, technical capacity and information sharing.
\end{abstract}

JEL classification: Q2, Q3, Q4, Q5, R1, R4, R5

Keywords: Climate; Global Warming; Sustainable Development; Government Policy; Planning;

Regional, Urban, Cities, Territorial, Regional Economics, Urban Sustainability, Green Growth 


\section{FOREWORD}

This working paper is one in a series of OECD Working Papers on Regional Development of the OECD Public Governance and Territorial Development Directorate.

This working paper has been produced by Lamia Kamal-Chaoui (Head of the Urban Development Unit, OECD), Fabio Grazi (Consultant, CIRED), Jongwan Joo (Policy Analyst, OECD) and Marissa Plouin (Consultant, OECD) under the supervision of Joaquim Oliveira Martins (Head of the Regional Development Policy Division, OECD). This paper will also be published in a chapter of the forthcoming the OECD National Urban Policy Review of Korea, conducted in collaboration with the Ministry of Land, Transport, and Maritime Affairs (MLTM) and due to be published in 2012.

The paper can be downloaded from the OECD website: www.oecd.org/gov/cities.

For more information about this paper and urban development activities, please contact:

Lamia Kamal-Chaoui (lamia.kamal-chaoui@ oecd.org) or Jongwan Joo (Jongwan.joo@ oecd.org) 


\section{TABLE OF CONTENTS}

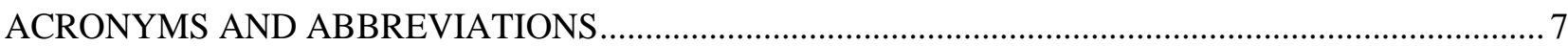

\section{THE IMPLEMENTATION OF THE KOREAN GREEN GROWTH STRATEGY}

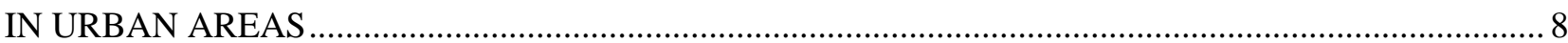

I. Cities as the drivers of economic growth and the locus of environmental concerns ............................. 9

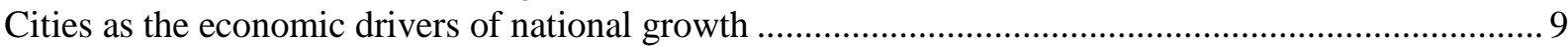

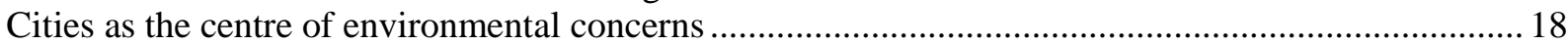

Observed changes in climate and their potential impacts on Korean cities ...........................................34

II. The Korean green growth strategy and the role of local governments ................................................ 36

Green growth: a new national growth paradigm to emerge from the financial crisis ............................ 36

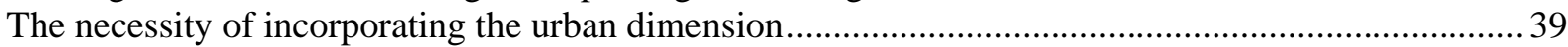

The legal and institutional framework guiding green growth implementation

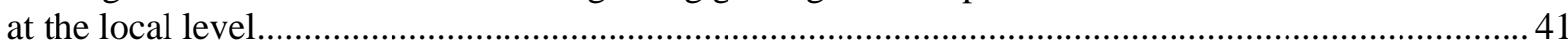

Contributions of local government to green growth in Korea: proposed actions

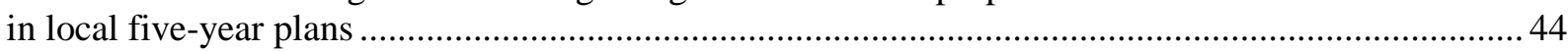

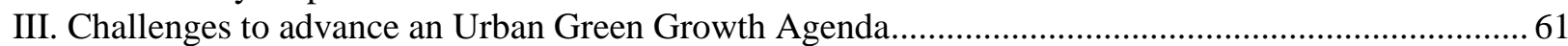

An international leader in green growth with a clear recognition of the urban dimension .....................61

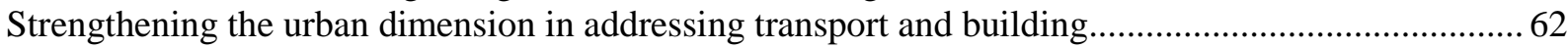

Implementation of the Green Growth Strategy: bridging the gaps in multi-level

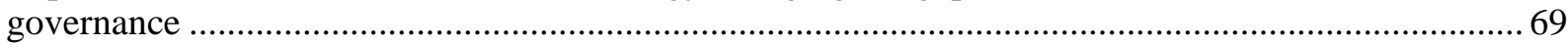

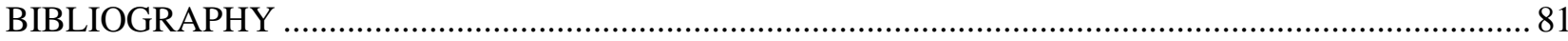

\section{Tables}

Table 1. Employment and demographic trends in large cities in Korea ........................................... 14

Table 2. Employment changes in medium-sized cities in Korea...................................................... 15

Table 3. Patent applications in seven metropolitan cities relative to the nation (2009) .................... 17

Table 4. R\&D expenditures in seven metropolitan cities relative to the nation (2009)...................... 18

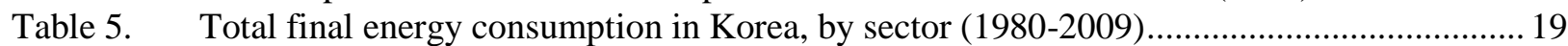

Table 6. Energy consumption in metropolitan cities/do regions (2009)........................................... 20

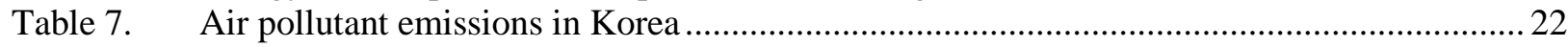

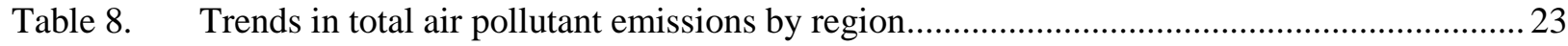

Table 9. Comparison of selected air pollutants in international cities ..............................................23

Table 10. Korean cities with the highest observed concentration of air pollutants (2008)..................24

Table 11. International comparison of average engine size of automobiles, Korea

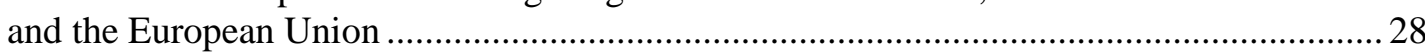

Table 12. Comparison of energy consumption by size of vehicle engine …….....................................2 29

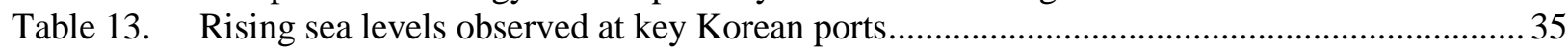

Table 14. Korea's Five-year Plan for Low-carbon, Green Growth (2009-13).................................... 37

Table 15. Budget allocation of Korea's Five-year Plan for Low-carbon, Green Growth ......................39

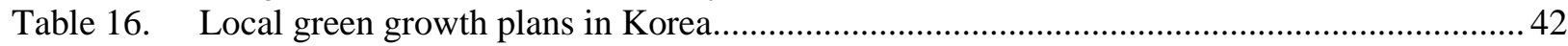

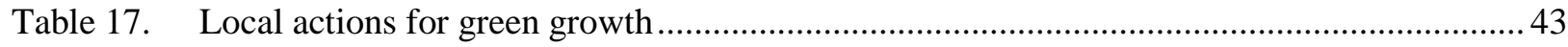

Table 18. Industries identified as new growth engines for the Korean economy ................................ 48

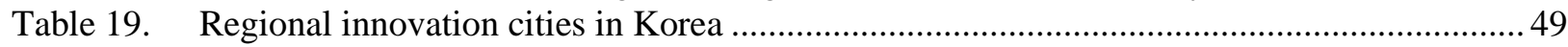

Table 20. Governance "gaps" for delivering green growth in Korean cities ....................................... 70

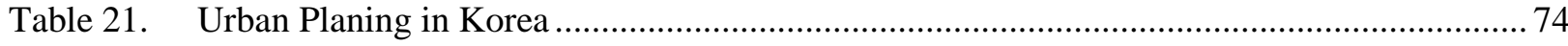




\section{Figures}

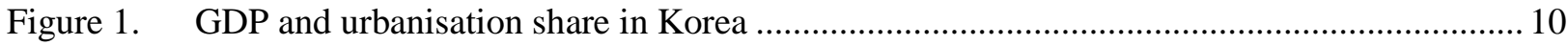

Figure 2. GDP growth rate and urban population growth rate in Korea .......................................... 10

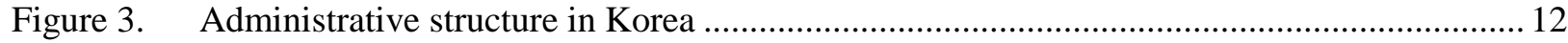

Figure 4. Regional contribution to employment growth .............................................................. 13

Figure 5. Share of population aged 25-64 with tertiary level of education in OECD

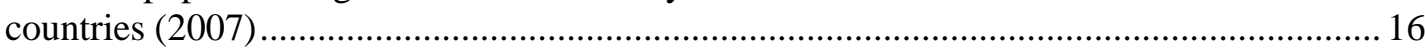

Figure 6. Tertiary education attainment share and population growth rate of

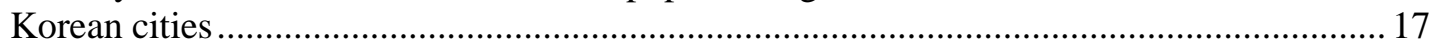

Figure 7. Korea has become one of the most energy-intesive economies in the

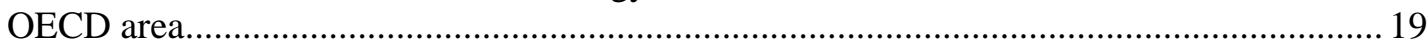

Figure 8. Total energy consumption (2008) and $\mathrm{CO}_{2}$ emissions (2006), by region ............................2 21

Figure 9. Per capita $\mathrm{CO}_{2}$ emissions in select Asian cities........................................................... 22

Figure 10. Trends in air pollution concentration in selected Korean metropolitan

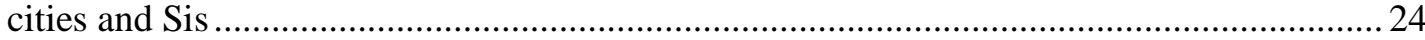

Figure 11. Concentration of daily nitrogen dioxide in select cities .................................................25

Figure 12. Concentration of daily sulphur dioxide in select cities ..................................................26

Figure 13. Concentration of daily suspended particulate matter in select cities ....................................26

Figure 14. Regional economic performance and vehicle ownership in Korean cities ..........................28

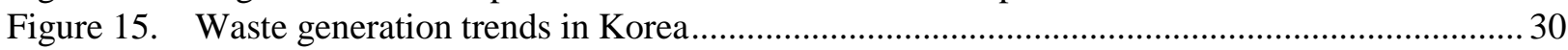

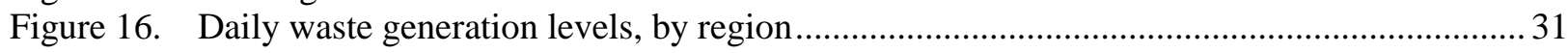

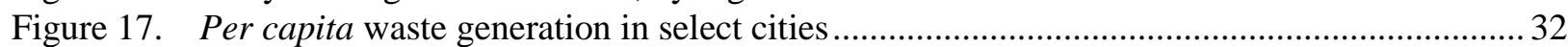

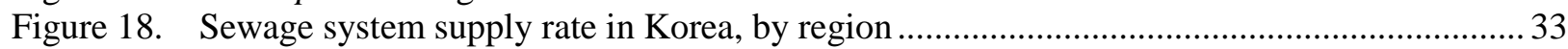

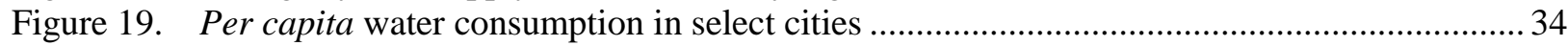

Figure 20. Rising average temperatures in Korean cities .................................................................. 36

Figure 21. Self-reliance ratio of finances in Korean metropolitan/do regions (2009) ........................... 76

Figure 22. Funding sources for local green growth plans (2009-13) ................................................. 77

\section{Boxes}

Box 1. Administrative organisation of local government in Korea.............................................. 11

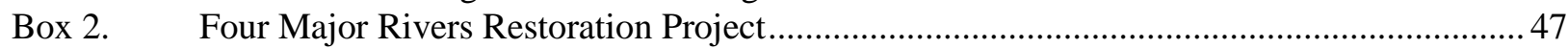

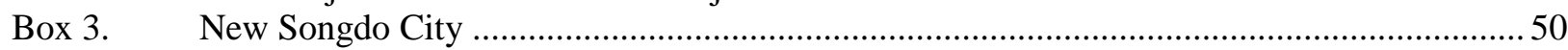

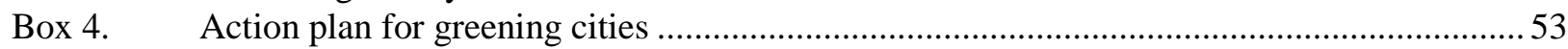

Box 5. Conflicts among stakeholders in the Gangneung-si green city demonstration

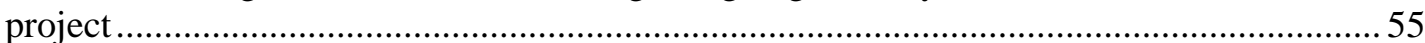

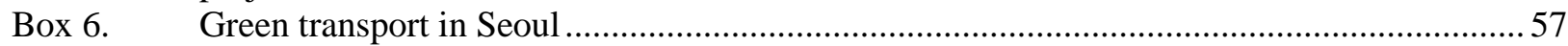

Box 7. OECD policy recommendations for greening household behaviour ....................................58

Box 8. An empirical analysis of the impact of urban form on transport-related carbon emissions 


\section{ACRONYMS AND ABBREVIATIONS}

$\begin{array}{ll}\text { BRT } & \text { Bus Rapid Transit Programs } \\ \text { CCC } & \text { Committee on Climate Change } \\ \text { CIP } & \text { Kingdom Climate Integration Programme } \\ \text { CNG } & \text { Concentrated Natural Gas } \\ \text { CPTY } & \text { Comprehensive Property Tax } \\ \text { CPUC } & \text { California Public Utilities Commission } \\ \text { FEZ } & \text { Free Economic Zone } \\ \text { FIRST } & \text { Financing Initiative for Renewable and Solar Technology } \\ \text { GDP } & \text { Gross domestic product } \\ \text { GGGI } & \text { Global Green Growth Institute } \\ \text { GIR } & \text { Greenhouse Gas Inventory and Research Centre } \\ \text { GTX } & \text { Great Train Express } \\ \text { IBD } & \text { Songdo International Business District } \\ \text { ICT } & \text { Information \& Communication Technology } \\ \text { IPCC } & \text { Intergovernmental Panel on Climate Change } \\ \text { KLIMP } & \text { Climate Investment Programme } \\ \text { KTX } & \text { Korea Train Express } \\ \text { LED } & \text { Light-Emitting Diode } \\ \text { LEED } & \text { Leadership in Energy and Environmental Design } \\ \text { MLTM } & \text { Transportation and Maritime Affairs } \\ \text { MMTC } & \text { Multi-Modal Transfer Center } \\ \text { NOx } & \text { Nitrogen Oxide } \\ \text { PCGG } & \text { The Presidential Committee on Green Growth } \\ \text { PPP } & \text { Public-private partnerships } \\ \text { R\&D } & \text { Research and Development } \\ \text { SME } & \text { Small and medium enterprises } \\ \text { SOx } & \text { Sulphur Oxide } \\ \text { TL4 } & \text { Territorial Level 4 } \\ \text { TOD } & \text { Transit Oriented Development } \\ & \end{array}$




\section{THE IMPLEMENTATION OF THE KOREAN GREEN GROWTH STRATEGY IN URBAN AREAS}

Korea is the first OECD country to have produced an explicit and comprehensive green growth strategy. In August 2008, on the occasion of the $60^{\text {th }}$ anniversary of the founding of the Republic of Korea, the President announced that the country would transition to a 'Low-carbon, Green Growth' model to guide long-term economic development over the next half-century. After several decades of economic growth, Korea's economy resiliency was challenged by the 2008 global financial crisis, which had unprecedented consequences. Following a period of rapidly increasing economic expansion that began in 2000 , with GDP increasing annually by nearly 5\%, the growth rate dropped to $2.2 \%$ in 2008 and even further in 2009 (Bank of Korea, 2009). Manufacturing was particularly hit: more than one-quarter (25.6\%) of output was lost as of January 2009. The economy then stabilised, growing at $2.2 \%$ and $-2.5 \%$ in 2008 and 2009 respectively. Some domestic recovery occurred in 2009, with Korea among the first OECD countries to show signs of the end of the financial crisis (Bank of Korea, 2009). However, the damage was profound for the real economy: more than 200000 jobs were lost only in the second semester of 2008.

The financial crisis revealed the limits of the traditional Korean growth model, characterised by domestic energy consumption heavily reliant on imports, and thus provided the government with the opportunity to re-evaluate its historical economic model and look toward new strategies for growth. In January 2009, the President unveiled the 'Green New Deal', a stimulus package of USD 38.5 billion, which identified a handful of large-scale infrastructure projects (namely, the Four Major Rivers Restoration and the expansion of the high-speed rail network) intended to stimulate the Korean economy through short-term job creation. In July 2009, the government announced the "National Strategy for Green Growth up to 2050", which includes mitigating climate change, creating new engines for economic growth and improving the quality of life. A Presidential Committee on Green Growth was established to coordinate the national green growth efforts. This committee published the "Five-year Green Growth Implementation Plan for 2009-2013" (hereafter referred to as the Five-year Plan) to guide the implementation of the national strategy. The Five-year plan absorbed the Green New Deal and benefitted from an investment of KRW 107.4 trillion (USD 83.6 billion), approximately $2 \%$ of the domestic GDP.

Conscious that no sustainability or green growth objectives can be achieved without the active involvement of the cities and regions, the Korean Green Growth Strategy includes specific actions targeting urban areas as well as binding provisions for sub-national governments to reflect green growth policy actions in their own five-year plans. This paper aims to assess the contributions of sub-national governments in the National Strategy for Green Growth Strategy and to identify the main challenges for an effective implementation at the local level.

- Part I will examine urbanisation, economic trends and environmental issues in Korea and the risks and challenges associated with climate change.

- Part II will discuss the role of sub-national governments within the context of Korea's National Strategy for Green Growth.

- $\quad$ Part III will propose a series of recommendations for strengthening the implementation of green growth policies at the urban scale, assessing policy instruments to green the urban transportation and building sectors and a set of governance challenges to advancing an urban green growth agenda. 


\section{Cities as the drivers of economic growth and the locus of environmental concerns}

Over half the world's population are living in cities today and as much as two-thirds are expected to become urban citizens by 2050. As key engines of economic growth, job creation and innovation, but also as major contributors to global warming and environmental problems, cities are at the heart of the transition to a green global economy. As the magnets for highly skilled people and advanced firms and the main centres of innovation, cities can provide the right scale for markets of eco-products and large-scale green infrastructure investment. Cities are also promising testing grounds for green technology development, such as electric cars and electric car rental schemes. How cities develop spatially affects both economic and environmental national objectives. The urban form matters: $\mathrm{CO}_{2}$ emissions per capita drop significantly as urban areas densify. Synergies and complementarities between environmental and economic policies, essential for achieving green growth, are stronger at the urban level.

In Korea, cities will have a key role to play in advancing green growth, particularly in Korea, where over $80 \%$ of the population lives in cities. This section begins with evidence of the role of Korean cities as both economic drivers of national growth, as well as the locus of growing environmental concerns, given the rising levels of energy and resource consumption, greenhouse gas emissions and pollution in urban areas. As major contributors to $\mathrm{CO}_{2}$ emissions in cities, the transportation and building sectors require particular attention in policies to promote green growth. The section concludes with a discussion of the observed changes in climate and their potential impacts on Korean cities, in terms of threats to Korea's urban population, infrastructure and economic well-being.

\section{Cities as the economic drivers of national growth}

As in many OECD countries, Korea's economic development since the 1960s has gone hand in hand with fast and unprecedented urbanisation (Figures 1 and 2). As industrialisation has expanded and further advanced, more labour forces and capital have been absorbed into urban areas. Indeed, since the modernisation of the Korean economy, the shares of urbanisation and industrialisation have been strikingly and consistently correlated. Following the UN definition of urban areas, the urbanisation share of Korea increased from $41 \%$ to $80 \%$ from 1970-2005 (Kwon, 2001) (see Box 1 for a description of the administrative structure of Korean cities). ${ }^{1}$ Korea shows a linear and positive relationship between economic growth and urbanisation. While the real GDP of Korea drastically increased almost 16 times between 1970 and 2009, its share of urbanisation also doubled during the same period, from $40.7 \%$ to 81.9\%. Between 1970 and 2010, the coefficient of the correlation between GDP size and urbanisation share was 0.887 .

1. In this paper, the term "cities" refers to both metropolitan cities and small and medium-sized cities, or Sis. 
Figure 1. GDP and urbanisation share in Korea

$1970-2010$

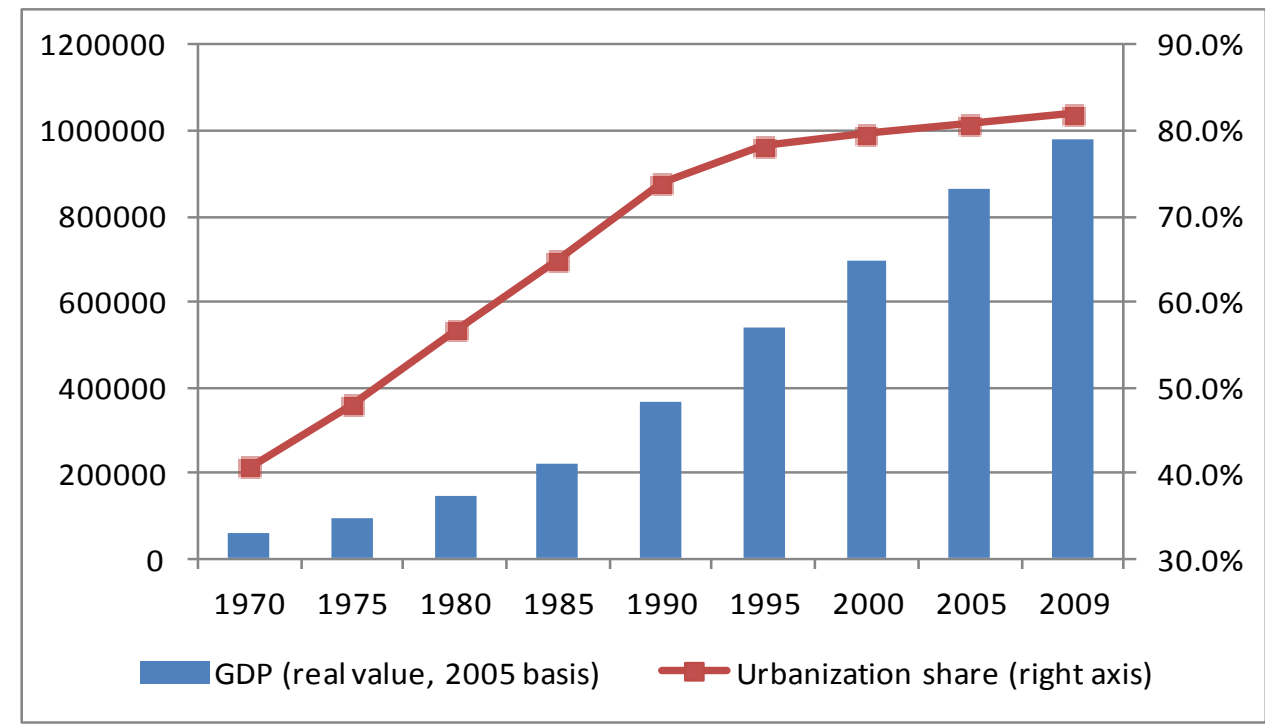

Notes: 1) Unit of left axis (GDP real value) is 1 billion KRW, 2) Urbanisation share is for 2010.

Source: UN-DESA for urbanisation share, KOSIS for GDP real value.

Figure 2. GDP growth rate and urban population growth rate in Korea

1970-2010 (five year intervals)

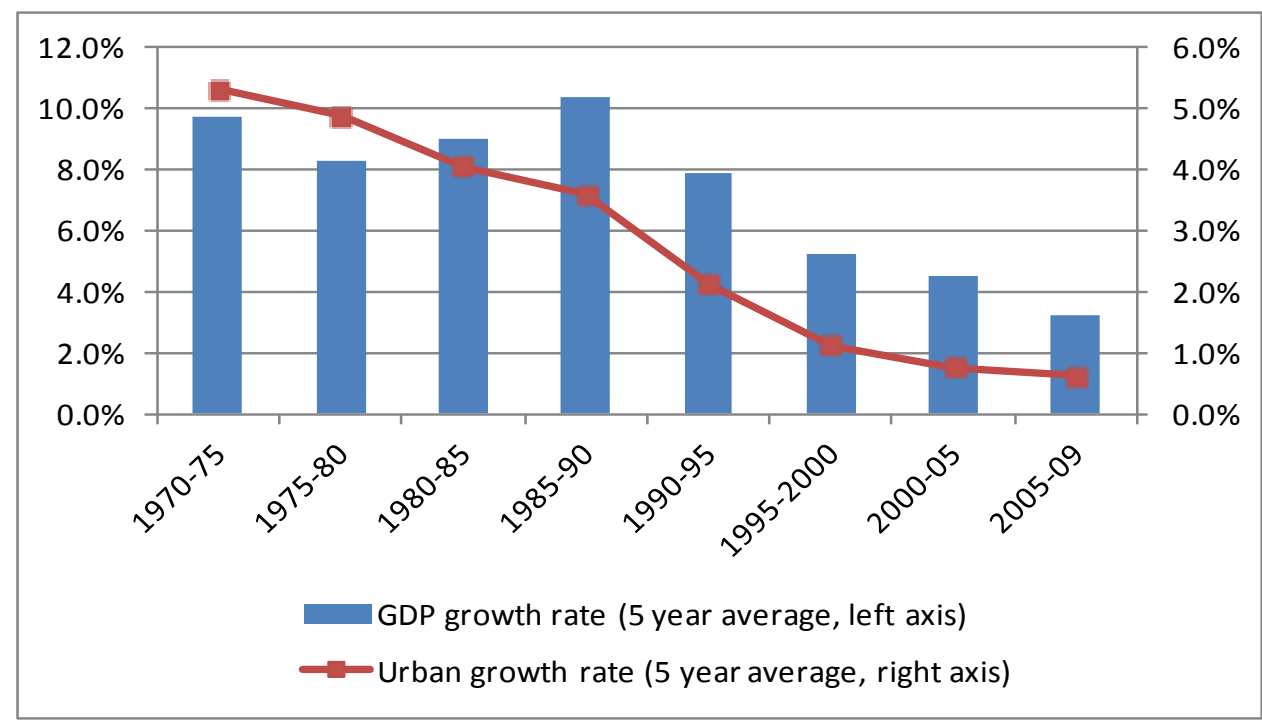

Note: For the urban growth rate, the most recent interval is 2005-2010, instead of 2005-2009.

Source: UN-DESA for urban growth rate, KOSIS for GDP growth rate. 


\section{Box 1. Administrative organisation of local government in Korea}

As a unitary state, Korea has a two tier system of local government (Figure 3).

(i) The upper (or regional) tier (Territorial Level 3 in OECD typology) includes Seoul Special City (with the status of a capital city), six metropolitan cities and nine provinces $(D o)$.

(ii) The lower (or basic local) tier (TL4 in OECD typology) is composed of $230^{1}$ bodies, including:

-- 75 cities (called $S i)$,

-- 86 counties (Gun, rural areas)

-- and 69 autonomous districts ( $\mathrm{Gu}$, urban areas which exist only in the metropolitan cities and Seoul).

The lower tier government is further divided into 3477 administrative sub-branches which are not legal entities and have no autonomous power: 215 Eup (defined as the urban division of a county or Gun), 1201 Myeon (the rural division of a county or Gun) and 2061 Dong (which belong to cities including Seoul City, metropolitan cities and lower-tier cities) (TL5).

Within this institutional framework, the Local Autonomous Act designates the following units as urban:

(i) Si, a lower administrative unit in TL 4 level with a population greater than 50000 , of which at least $60 \%$ resides in the urbanised areas.

(ii) Gu, an autonomous district in metropolitan cities and in Seoul.

Rural areas, known as counties or Guns, are further divided into two categories:

(i) Myeon, a basic subdivision of a Gun;

(ii) Eup, an urbanised area in a rural unit, with a population of more than 20000 people of which at least $40 \%$ live in the urbanised area of the unit.

In 1994, the Korean government introduced a new administrative unit, the "urban-rural integration city", which consolidates small or medium-sized cities with surrounding rural areas in order to generate economies of scale and to minimise urban-rural disparities. Despite its merits, the new administrative unit complicates the classification of urban and rural areas in Korea: as of 2009, 52 cities were designated as "urban-rural integration cities" with substantially different size and population (MOPAS, 2009). For instance, among those cities, Yongin-si, the most populated city in the Gyunggi Province, had 816000 inhabitants covering a surface area of $591 \mathrm{~km}^{2}$, while Samchuck-si, the least populated city in the Gangwon Province, had only 70000 inhabitants (less than one-tenth of Yongin) with over twice the surface area of Yongin. Urban-rural integration cities are a type of Si.

Notes: (1) The total figure includes two cities on Jeju Island which were designated as "Special Autonomous Provinces" in 2006. 


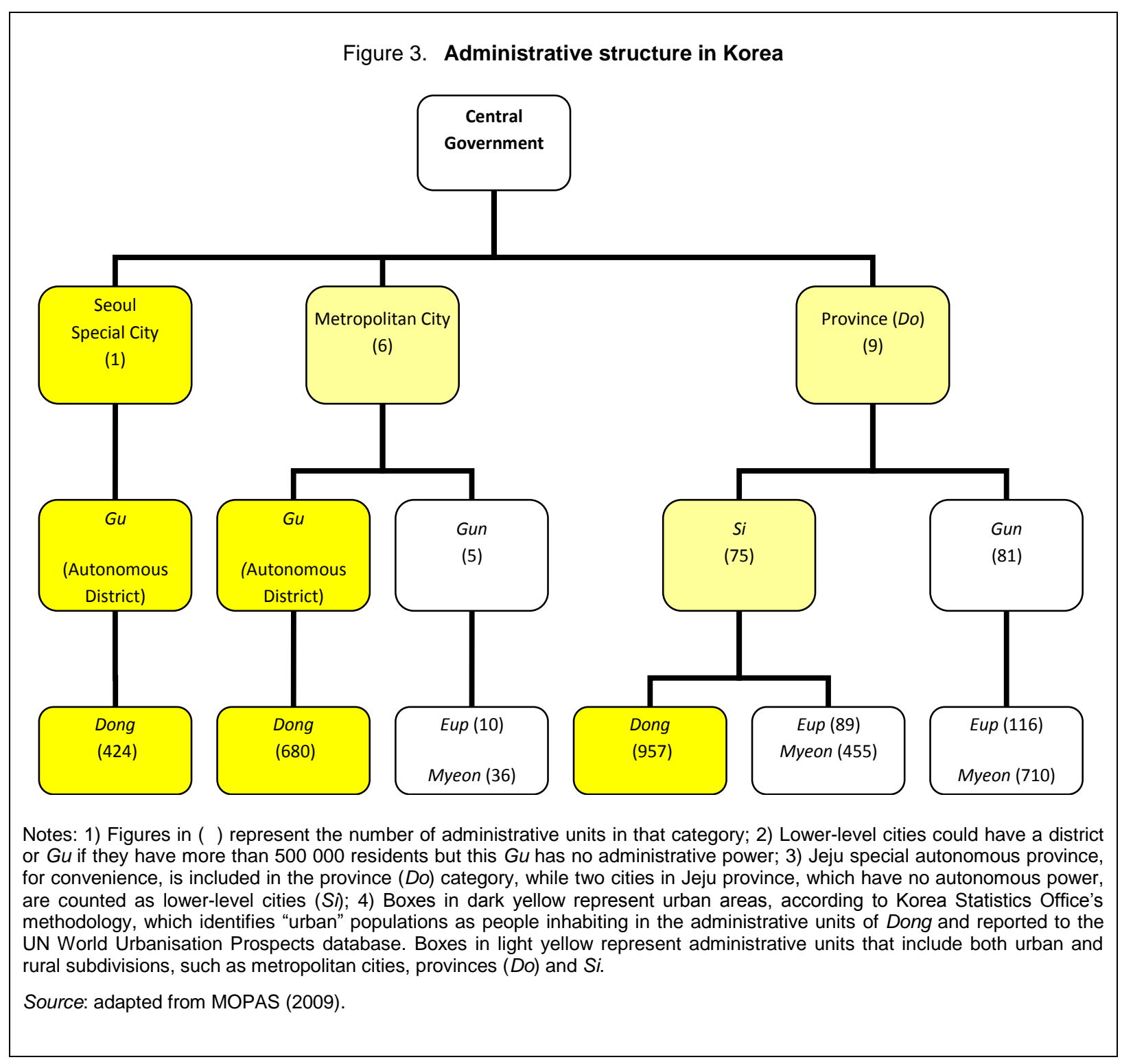

In Korea, seven metropolitan cities have accounted for the bulk of the national output: in 2009, Seoul, Busan, Daegu, Incheon, Gwangju, Daejon and Ulsan attracted $46.1 \%$ of national population and together produced $46.2 \%$ of national GDP. For its part, Seoul Metropolitan Area, composed of Seoul City, Incheon City and the Gyeonggi province contributed almost half of national GDP (48.7\%) and accounted for a similar share of the national population (49\%), with Seoul City representing $24.1 \%$ of national GDP and $20.5 \%$ of national population in the same year. As the second largest city in Korea, Busan accounted for $5.2 \%$ of the country's GDP in 2009 and for $7.1 \%$ of the country's population. Ulsan was responsible for exceptionally higher economic outputs given its national population share: in 2009, Ulsan contributed $4.7 \%$ to national GDP while its share of population remained $2.2 \%$. On the other hand, the provinces of Gwangwon, Chungbuk, Jeonbuk and Jeju, which hold no metropolitan cities and are comprised by substantially large rural areas, have continuously accounted for a limited share of national GDP and national population, and regularly produce a smaller share of the country's GDP than their share of the total population. 
Employment has also tended to concentrate in large cities in Korea, although some medium-sized cities have recently been able to spur job growth. Korea has one of the highest shares of national employment growth from the 10\% largest regions among OECD countries (Figure 4). Recent trends reflect different patterns, depending on technical change, sectoral shifts and the historical manufacturing legacy in each city. For instance, larger urban areas (including Seoul), which experienced sustained and high employment growth rates until 2000, have seen slower job creation rates in the past decade. Although all seven metropolitan cities in Korea recorded positive annual average employment growth rates between 2000 and 2007, these growth rates are significantly lower than previous decades (Table 1).

\section{Figure 4. Regional contribution to employment growth}

Percent of national employment increase contributed by the top $10 \%$ of TL3 regions, ranked by regional increase

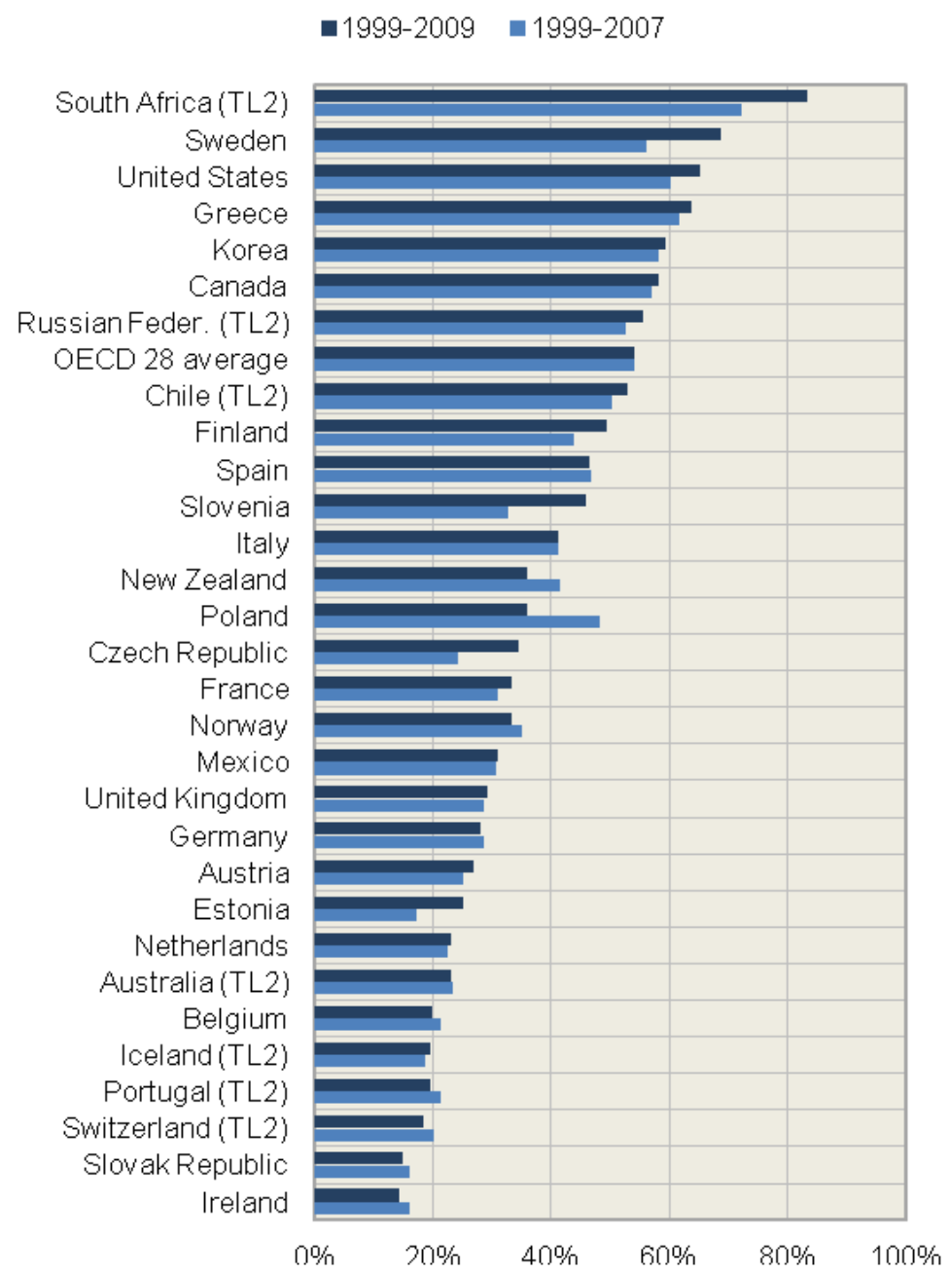

Source: OECD (2011a, forthcoming), Regions at a Glance, OECD, Paris. 
Table 1. Employment and demographic trends in large cities in Korea

Annual growth rates (\%)

\begin{tabular}{l|l|r|r|r|r}
\hline & & $1975-80$ & $1980-90$ & $1990-2000$ & $2000-05(07)^{1}$ \\
\hline Nationwide & Employment & 11.6 & 12.5 & 3.0 & 2.4 \\
& Manufacturing jobs & 13.4 & 13.8 & -5.7 & 0.8 \\
& Population & 1.5 & 1.5 & 0.6 & 0.5 \\
\hline \multirow{2}{*}{ Seoul } & Employment & 2.5 & 5.3 & 8.1 & 1.2 \\
& Manufacturing jobs & 5.9 & 3.2 & -1.9 & -3.4 \\
& Population & 2.2 & 3.0 & -0.7 & -0.2 \\
\hline Busan & Employment & -2.8 & 2.0 & 1.2 & -1.8 \\
& Manufacturing jobs & 3.3 & 1.9 & -4.9 & -0.8 \\
& Population & 5.2 & 1.9 & -0.4 & 1.4 \\
& Employment & - & -0.9 & 9.7 & -0.9 \\
& Manufacturing jobs & - & 1.0 & 0.1 & -0.1 \\
\hline Daegu & Population & - & 2.8 & 1.2 & 2.0 \\
& Employment & 14.9 & 1.5 & 8.5 & -0.4 \\
& Manufacturing jobs & 17.2 & 1.3 & 0.6 & 0.4 \\
\hline Gncheon & Population & 8.7 & 4.6 & 2.9 & 2.6 \\
& Employment & 6.4 & 3.9 & 13.3 & 2.9 \\
& Manufacturing jobs & 5.0 & 6.4 & 2.9 & 2.4 \\
& Population & 3.7 & 4.6 & 1.7 & 0.9 \\
\hline Daejeon & Employment & 8.9 & -4.8 & 13.3 & -1.3 \\
& Manufacturing jobs & -9.1 & 1.9 & 0.0 & 1.1 \\
\hline Ulsan & Population & 5.2 & 4.9 & 2.7 & 2.8 \\
& Employment & 12.5 & 3.6 & 8.6 & 0.7 \\
& Manufacturing jobs & 16.3 & 5.8 & 1.7 & 0.7 \\
\hline
\end{tabular}

(1) Employment data is for 2007; population data is for 2005.

Source: OECD own calculations based on KOSIS (2011).

Unlike metropolitan cities, medium-sized cities in Korea show a steady increase in employment between 1975 and 2007. Interestingly, some medium-sized cities have experienced employment growth rates above the national average in manufacturing. As larger cities begin to pay higher wages, labourintensive activities in manufacturing tend to relocate to smaller urban areas or abroad, leading to a sectoral shift in both larger and smaller cities spurred by capital deepening and technical change. For instance, Cheonan recorded 14.8\% annual employment growth in manufacturing between 1990 and 2000, whereas the national figure declined to $5.7 \%$. Cities that experienced rapid growth in manufacturing jobs in the 1970s and 1980s have, since the 1990s, been able to create new jobs in services, resulting in continued population influx. For instance, the industrialised cities of Bucheon, Cheonan and Changwon have grown faster than other medium-sized cities in terms of population since 1975 (Table 2). However, medium-sized cities located outside the Seoul Metropolitan Area with weak manufacturing activities often failed to generate new jobs in value-added services activities in the 1990s, leading to a prolonged decline in population. Typical administrative cities such as Jeonju, Chuncheon, Mokpo and Andong, which hold no strong manufacturing base (in 2007, these cities reported less than $10 \%$ of total jobs in the manufacturing sector), have generally suffered from population loss or stagnation. 
Table 2. Employment changes in medium-sized cities in Korea

\begin{tabular}{|c|c|c|c|c|c|c|}
\hline \multicolumn{7}{|c|}{ Percentage (\%) } \\
\hline & & & $1975-80$ & $1980-90$ & $1990-2000$ & $\begin{array}{c}2000- \\
2005(07)^{1}\end{array}$ \\
\hline \multirow{20}{*}{$\begin{array}{l}\text { Growing } \\
\text { cities }\end{array}$} & \multirow[t]{5}{*}{ Suwon } & Employment growth rate & 4.9 & 5.6 & 11.6 & 3.4 \\
\hline & & Manufacturing jobs growth rate & 13.3 & 4.1 & 0.8 & -3.0 \\
\hline & & Population growth rate & 6.7 & 7.6 & 3.9 & 2.0 \\
\hline & & Share of manufacturing jobs & 69.4 & 60.1 & 21.8 & 14.0 \\
\hline & & Employment rate (per 100 persons) & 15.0 & 12.4 & 25.3 & 28.9 \\
\hline & \multirow[t]{5}{*}{ Bucheon } & Employment growth rate & 21.4 & 4.0 & 8.8 & 1.7 \\
\hline & & Manufacturing jobs growth rate & 18.7 & 6.0 & 0.6 & -2.7 \\
\hline & & Population growth rate & 15.2 & 11.7 & 1.3 & 2.0 \\
\hline & & Share of manufacturing jobs & 71.4 & 85.8 & 39.3 & 28.9 \\
\hline & & Employment rate (per 100 persons) & 27.2 & 13.4 & 27.2 & 27.8 \\
\hline & \multirow{5}{*}{ Cheonan } & Employment growth rate & 21.9 & -4.0 & 20.2 & 5.6 \\
\hline & & Manufacturing jobs growth rate & 22.6 & -5.0 & 14.8 & 4.9 \\
\hline & & Population growth rate & 4.5 & 5.8 & 7.1 & 4.5 \\
\hline & & Share of manufacturing jobs & 64.3 & 58.1 & 36.8 & 35.0 \\
\hline & & Employment rate (per 100 persons) & 26.0 & 9.8 & 31.1 & 36.6 \\
\hline & \multirow[t]{5}{*}{ Changwon } & Employment growth rate & & 10.3 & 8.5 & 2.3 \\
\hline & & Manufacturing jobs growth rate & & 9.6 & 1.6 & 1.1 \\
\hline & & Population growth rate & & 7.1 & 2.7 & -0.6 \\
\hline & & Share of manufacturing jobs & 98.3 & 92.0 & 48.0 & 44.1 \\
\hline & & Employment rate (per 100 persons) & 16.6 & 22.3 & 38.3 & 46.5 \\
\hline \multirow{20}{*}{$\begin{array}{l}\text { Lagging } \\
\text { cities }\end{array}$} & \multirow[t]{5}{*}{ Jeonju } & Employment growth rate & -7.1 & 5.9 & 9.4 & 2.0 \\
\hline & & Manufacturing jobs growth rate & -4.2 & 6.5 & -4.5 & -4.6 \\
\hline & & Population growth rate & 3.3 & 3.5 & 1.8 & 0.2 \\
\hline & & Share of manufacturing jobs & 38.6 & 40.5 & 10.4 & 6.5 \\
\hline & & Employment rate (per 100 persons) & 9.3 & 11.7 & 24.3 & 27.5 \\
\hline & \multirow[t]{5}{*}{ Chuncheon } & Employment growth rate & 28.7 & -6.2 & 14.8 & 2.2 \\
\hline & & Manufacturing jobs growth rate & 32.9 & -0.2 & -1.6 & -2.2 \\
\hline & & Population growth rate & 8.5 & 0.3 & 1.5 & 0.7 \\
\hline & & Share of manufacturing jobs & 17.3 & 32.3 & 6.9 & 5.1 \\
\hline & & Employment rate (per 100 persons) & 14.9 & 7.6 & 26.0 & 29.4 \\
\hline & \multirow[t]{5}{*}{ Mokpo } & Employment growth rate & 17.0 & -10.8 & 12.1 & 0.5 \\
\hline & & Manufacturing jobs growth rate & 19.7 & -6.9 & -4.0 & -5.1 \\
\hline & & Population growth rate & 2.8 & 0.9 & 0.3 & -0.5 \\
\hline & & Share of manufacturing jobs & 24.9 & 38.5 & 8.2 & 5.5 \\
\hline & & Employment rate (per 100 persons) & 30.0 & 8.7 & 26.5 & 28.1 \\
\hline & \multirow[t]{5}{*}{ Andong } & Employment growth rate & 12.1 & -3.8 & 17.6 & 1.2 \\
\hline & & Manufacturing jobs growth rate & 4.6 & -2.9 & 6.6 & 2.0 \\
\hline & & Population growth rate & -2.3 & -1.8 & -0.8 & -1.4 \\
\hline & & Share of manufacturing jobs & 17.4 & 19.2 & 7.2 & 7.6 \\
\hline & & Employment rate (per 100 persons) & 5.1 & 4.1 & 22.7 & 26.4 \\
\hline
\end{tabular}

(1) Employment data is for 2007; population data is for 2005.

Source: OECD calculations based on KOSIS (2011).

Large cities have also been centres of skills and innovation. Korea's well-educated labour force and high tertiary education attainment have been key factors in Korea's economic success. The country's progress in tertiary education attainment has been unprecedented in the OECD - Korea ranks seven among OECD countries for the share of the population aged 15-64 with a tertiary education (Figure 5) - with the greatest advances in large cities, especially in Seoul and in cities located in the Seoul Metropolitan Area. Tertiary education attainment is part of a virtuous cycle that fosters agglomerations. Cities become good locations for investment when they increase the size of the local labour market, which among other factors, helps to create a talented and educated workforce. Talent is created locally and is brought in from other areas. The quantity and quality of workers attracts more workers, and the cycle continues despite of 
negative externalities. In the case of Korea, cities with annual population growth rates that have been slower than the national average tend to fall short of the national average in terms of tertiary education attainment levels (Figure 6). Between 1970 and 2005, 27 out of 68 Korean cities had a slower population growth rate than the national average, and within that group, only two cities (Gyeongsan-si in the Gyeongbuk province and Jeju-si in Jeju autonomous province, represented in the top-left corner of Figure 6) showed an above-average increase in tertiary education.

In terms of innovation, the seven largest metropolitan cities also concentrate the highest share of R\&D and patent applications: together, they accounted for $43.6 \%$ of total R\&D expenditures in 2009, led by Seoul (19.8\%) (Korea Institute of Science and Technology Evaluation \& Planning, 2010) (Table 3). Furthermore, $54 \%$ of the total patent applications were filed in metropolitan cities (Korean Intellectual Property Office, 2011), with Seoul contributing 33\% of the total (Table 4).

Figure 5. Share of population aged 25-64 with tertiary level of education in OECD countries (2007)

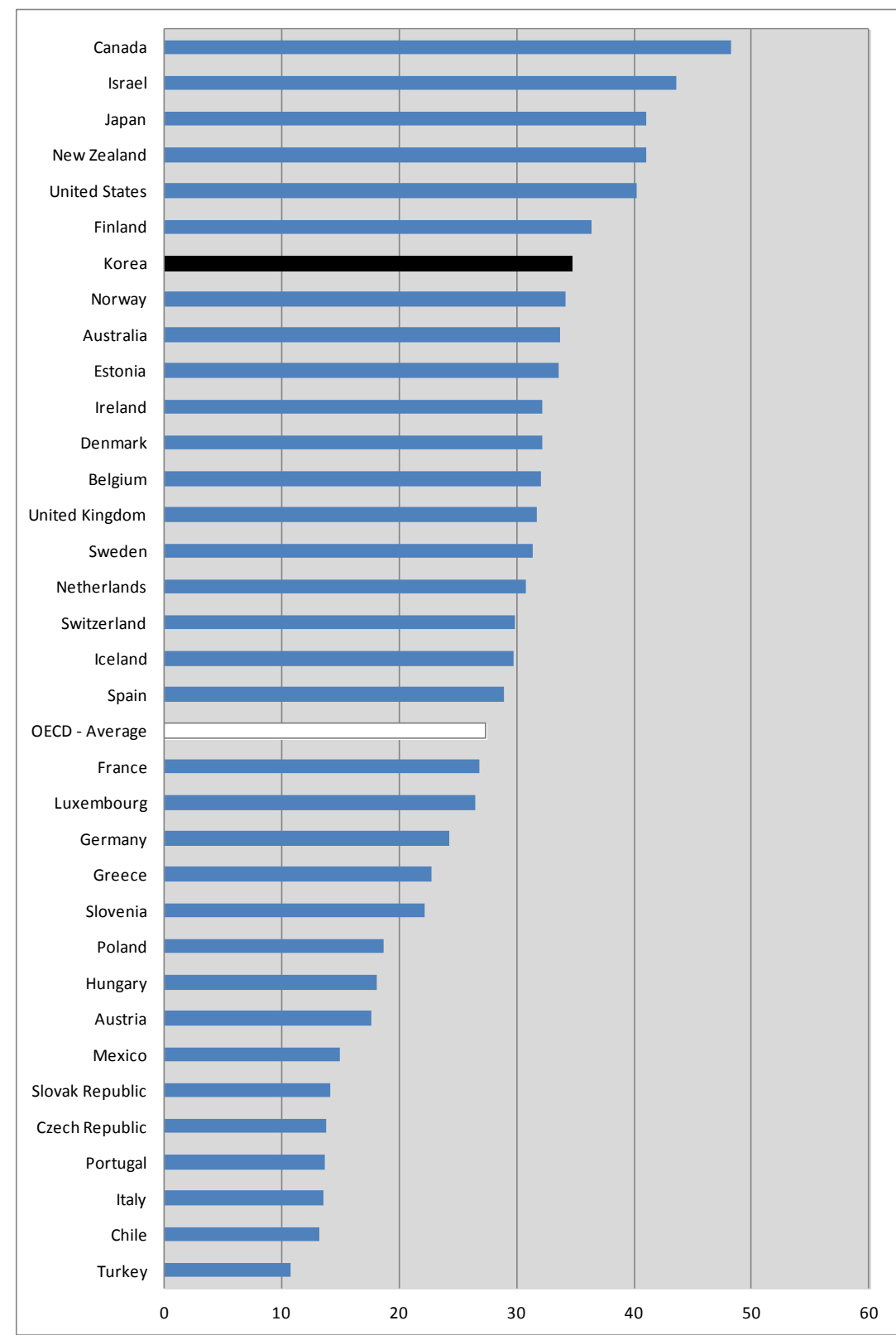

Source: OECD (2011a, forthcoming), Regions at a Glance, OECD, Paris. 
Figure 6. Tertiary education attainment share and population growth rate of Korean cities

Percentage point increase of tertiary education attainment share, annual average growth rate of population

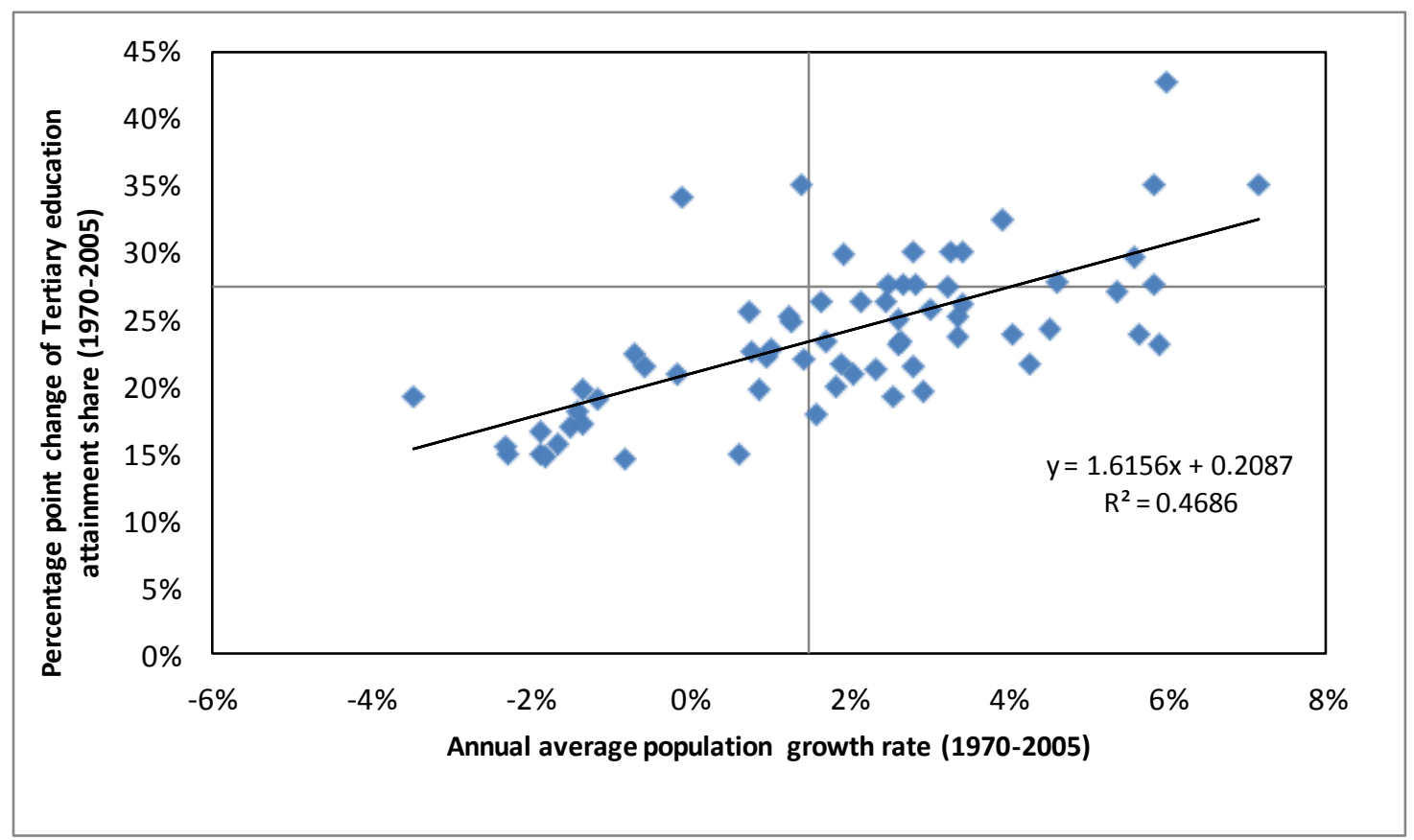

Notes: 1) Horizontal line represents nation-wide annual average population growth rate between 1970 and 2005, which is 1.49\%, 2) Vertical line indicates nation-wide percentage point change of tertiary education attainment share between 1970 and 2005, which is $27.5 \%, 3)$ Total number of cities in this figure is 68 .

Source: OECD own calculations based on data from the Korea Statistics Office (2011)

Table 3. Patent applications in seven metropolitan cities relative to the nation (2009)

\begin{tabular}{|l|r|r|}
\hline & Patent Applications & \% of national total \\
\hline Seoul & 42108 & $33 \%$ \\
\hline Busan & 3935 & $3 \%$ \\
\hline Daegu & 3585 & $3 \%$ \\
\hline Incheon & 5719 & $4 \%$ \\
\hline Gwangju & 2211 & $2 \%$ \\
\hline Daejeon & 9974 & $8 \%$ \\
\hline Ulsan & 1370 & $1 \%$ \\
\hline Total patent applications in seven metropolitan cities & 68902 & $54 \%$ \\
\hline Total patent applications nationwide & 127316 & $100 \%$ \\
\hline
\end{tabular}

Source: Korean Intellectual Property Office (2011). 
Table 4. R\&D expenditures in seven metropolitan cities relative to the nation (2009)

Unit: Million KRW

\begin{tabular}{|l|r|r|}
\hline & R\&D expenditures & $\begin{array}{c}\text { Share of } \\
\text { national total }\end{array}$ \\
\hline Seoul & 7304245 & 19.8 \\
\hline Incheon & 1440726 & 3.9 \\
\hline Busan & 811078 & 2.2 \\
\hline Ulsan & 394537 & 1.1 \\
\hline Daegu & 530827 & 1.4 \\
\hline Daejeon & 4356664 & 11.8 \\
\hline Gwangju & 1274963 & 3.5 \\
\hline Total R\&D expenditures in seven metropolitan cities & 16113040 & 43.6 \\
\hline Total R\&D expenditures nationwide & 36937423 & 100 \\
\hline
\end{tabular}

Source: Korea Institute of Science and Technology Evaluation \& Planning (2010).

\section{Cities as the centre of environmental concerns}

Korea's economic model and rapid growth since 1971, underpinned by a highly urbanised spatial form, have put growing pressure on the environment and led to increased resource consumption. On the one hand, the increased air pollution resulting from traffic congestion, energy consumption, greenhouse gas emissions and waste generation has been partly attributed to the negative externalities of urbanisation. On the other hand, agglomeration economies and economic of scale in urban areas could provide valuable solutions to address these concerns (for instance, in recycling waste).

\section{A rise in energy consumption, greenhouse gas emissions and pollution}

In the past several decades, higher living standards, urbanisation trends and an expanding industrial sector have contributed to Korea becoming one of the most energy-intensive economies in the OECD area (Figure 7). In 2008, Korea was the tenth largest energy consumer among OECD countries (IEA, 2010a). The country's energy intensity ${ }^{2}$ was a quarter above the OECD average in 2008 and the fourth highest in the OECD area (Jones, R. and B. Yoo, 2010). Its total energy self-sufficiency ${ }^{3}$ in 2008 was just 19.7\%, reflecting Korea's heavy reliance on foreign imports of oil and gas to meet national energy demand (97\% of energy consumption and 32.5\% of national imports) (IEA, 2010b). Korea's total energy consumption rose by $367 \%$ between 1980 and 2009, driven by significant increases in the transport and industrial sectors (Table 5). Energy consumption of the industrial sector increased by 506\% between 1980 and 2009, and continued to account for the largest share of total energy consumption, increasing its share from $44.9 \%$ of the total in 1980 to $58.3 \%$ in 2009 . The largest increase in energy consumption came from transport section. It grew more than a ten-fold between 1980 and 2009, which can mostly be attributed to the elevated energy consumption of roadway transport that comprised $79.1 \%$ of transport energy consumption in 2007. By contrast, energy consumption of the household/commercial sector decreased its share from a peak of $40.6 \%$ in 1980 to a low of $19.8 \%$ in 2007.

2. Energy intensity is calculated as TPES divided by GDP. Energy intensity is affected by many non-energy factors such as climate, geography, travel distance, home size and manufacturing structure.

3. Energy self-sufficiency is calculated as the production of energy divided by the total primary energy supply (TPES). 
Figure 7. Korea has become one of the most energy-intensive economies in the OECD area Tonnes of energy per unit of GDP in thousand 2000 USD using PPP exchange rates

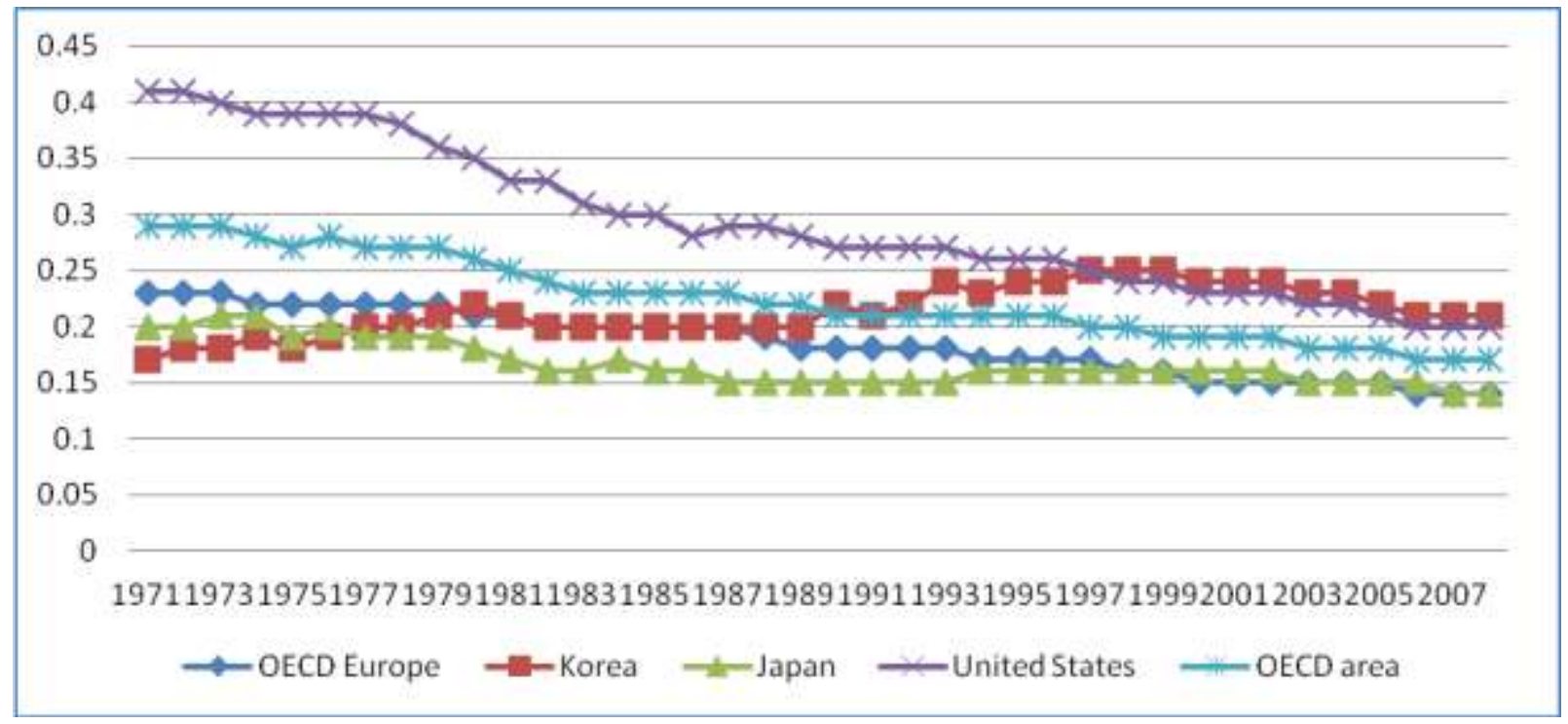

Source: IEA/OECD (2009a).

Table 5. Total final energy consumption in Korea, by sector (1980-2009)

Thousand tonnes (TOE)

\begin{tabular}{llllll|l} 
& $\mathbf{1 9 8 0}$ & $\mathbf{1 9 9 0}$ & $\mathbf{2 0 0 0}$ & $\mathbf{2 0 0 5}$ & $\mathbf{2 0 0 9}$ & \% change \\
\hline Transport & 3721 & 14173 & 30945 & 35559 & 35930 & $866 \%$ \\
(\% of total) & $9.60 \%$ & $18.90 \%$ & $20.70 \%$ & $20.60 \%$ & $19.70 \%$ & \\
\hline Industrial & 17506 & 36150 & 83912 & 94366 & 106118 & $506 \%$ \\
(\% of total) & $44.90 \%$ & $48.10 \%$ & $56.00 \%$ & $54.60 \%$ & $58.30 \%$ & \\
\hline Residential/commercial & 15836 & 21971 & 32370 & 36861 & 35722 & $126 \%$ \\
(\% of total) & $40.70 \%$ & $29.20 \%$ & $21.60 \%$ & $21.30 \%$ & $19.60 \%$ & \\
\hline Public sector & 1889 & 2813 & 2625 & 6068 & 4295 & $127 \%$ \\
(\% of total) & $4.90 \%$ & $3.80 \%$ & $1.80 \%$ & $3.50 \%$ & $2.40 \%$ & \\
\hline Total & $\mathbf{3 8 9 5 2}$ & $\mathbf{7 5 1 0 7}$ & $\mathbf{1 4 9 8 5 2}$ & $\mathbf{1 7 2} \mathbf{8 5 4}$ & $\mathbf{1 8 2 0 6 5}$ & $\mathbf{3 6 7 \%}$
\end{tabular}

Source: Korea Energy Economics Institute (2011).

Driven by an increase in energy use, Korea's greenhouse gas emissions almost doubled between 1990 and 2005, the highest growth rate in the OECD area. Korea's greenhouse gas emissions accounted for $1.3 \%$ of the world total in 2005, making it the fifteenth-largest emitter in the world and ninth in the OECD area (Jones, R. and B. Yoo, 2010). Over $89 \%$ of the rise in Korea's greenhouse gas emissions between 1990 and 2005 occurred between 1990 and 2000. As a result of Korea's rapid economic expansion and per capita income growth, per capita emissions rose by $71.6 \%$ between 1990 and 2005, far outstripping the OECD average of $2.1 \%$. On the other hand, Korea experienced a decrease of $12.7 \%$ in greenhouse gas emissions per unit of energy, reflecting greater use of natural gas and nuclear power (Jones, R. and B. Yoo, 2010). 
The breakdown of GHG emissions and energy consumption by region shows the importance of the contribution of the industrial sector in some cities, especially medium-sized cities. With the exception of the metropolitan area of Ulsan, provinces hosting medium-sized cities, including the provinces of Joellanam-do, Gyeonggi-do, Gyeongsangbuk-do and Chungcheongnam-do, recorded the highest levels of energy consumption. These regions (except the province of Gyeonggi-do) also record the highest levels of energy consumption on a per capita basis (Table 6). These medium-sized cities are the largest cities of these regions and host energy-intensive industries such as electricity generation facilities, petroleum refineries, oil and gas industries, steel mills and chemical industries. For instance, Pohang-si is the largest city in the province of Gyeongsangbuk-do (508 000 inhabitants) and has an important steel mill, while Yeosu-si is the largest city in Jeollanam-do (295 000) and has an important chemical industrial complex. These same regions also tend to concentrate a large share of national $\mathrm{CO}_{2}$ emissions (Figure 8). Emissions levels in Chungcheongnam-do are exceptionally high compared to other regions, due to the relatively rural character of the region and the presence of energy-intensive industries such as the Danggin thermoelectric power plants, Hyundai and other steel mill companies. Ulsan's large share of energy consumption from the industrial sector (85.2\%) can be attributed to its industrial past and present-day heavy industrial sector. Designated as an Industry Special District in 1962, Ulsan is today home to a number of major heavy industry firms, such as Hyundai and the SK Chemical Company.

Table 6. Energy consumption in metropolitan cities and provinces (do) (2009)

\begin{tabular}{|l|r|r|r|}
\hline & $\begin{array}{l}\text { Per capita energy } \\
\text { consumption (TOE) }\end{array}$ & $\begin{array}{l}\text { Total energy } \\
\text { consumption by } \\
\text { volume (1 000 TOE) }\end{array}$ & $\begin{array}{l}\text { Share of total energy } \\
\text { consumption from the } \\
\text { industrial sector (\%) }\end{array}$ \\
\hline Total & 3.76 & 182,576 & 58.3 \\
\hline Seoul & 1.54 & 15,482 & 8.9 \\
\hline Busan & 1.95 & 6,829 & 23.8 \\
\hline Daegu & 1.71 & 4,211 & 26.6 \\
\hline Incheon & 3.63 & 9,542 & 34.9 \\
\hline Gwangju & 1.49 & 2,149 & 17.0 \\
\hline Daejeon & 1.69 & 2,527 & 14.4 \\
\hline Ulsan & 19.26 & 20,892 & 85.2 \\
\hline Gyeonggi-do & 2.11 & 23,763 & 29.9 \\
\hline Gangwon-do & 4.69 & 6,860 & 61.9 \\
\hline Chungcheongbuk-do & 4 & 5,928 & 56.0 \\
\hline Chungcheongnam-do & 10.07 & 19,581 & 81.5 \\
\hline Jeollabuk-do & 2.66 & 4,648 & 41.8 \\
\hline Jeollanam-do & 19.09 & 34,053 & 92.1 \\
\hline Gyeongansgbuk-do & 6.76 & 17,716 & 75.0 \\
\hline Gyeongsangnam-do & 2.4 & 7,512 & 40.3 \\
\hline Jeju & 1.61 & 877 & 21.7 \\
\hline
\end{tabular}

Source: Ministry of Knowledge \& Economy (2009). 
Figure 8. Total energy consumption (2008) and $\mathrm{CO} 2$ emissions (2006), by region

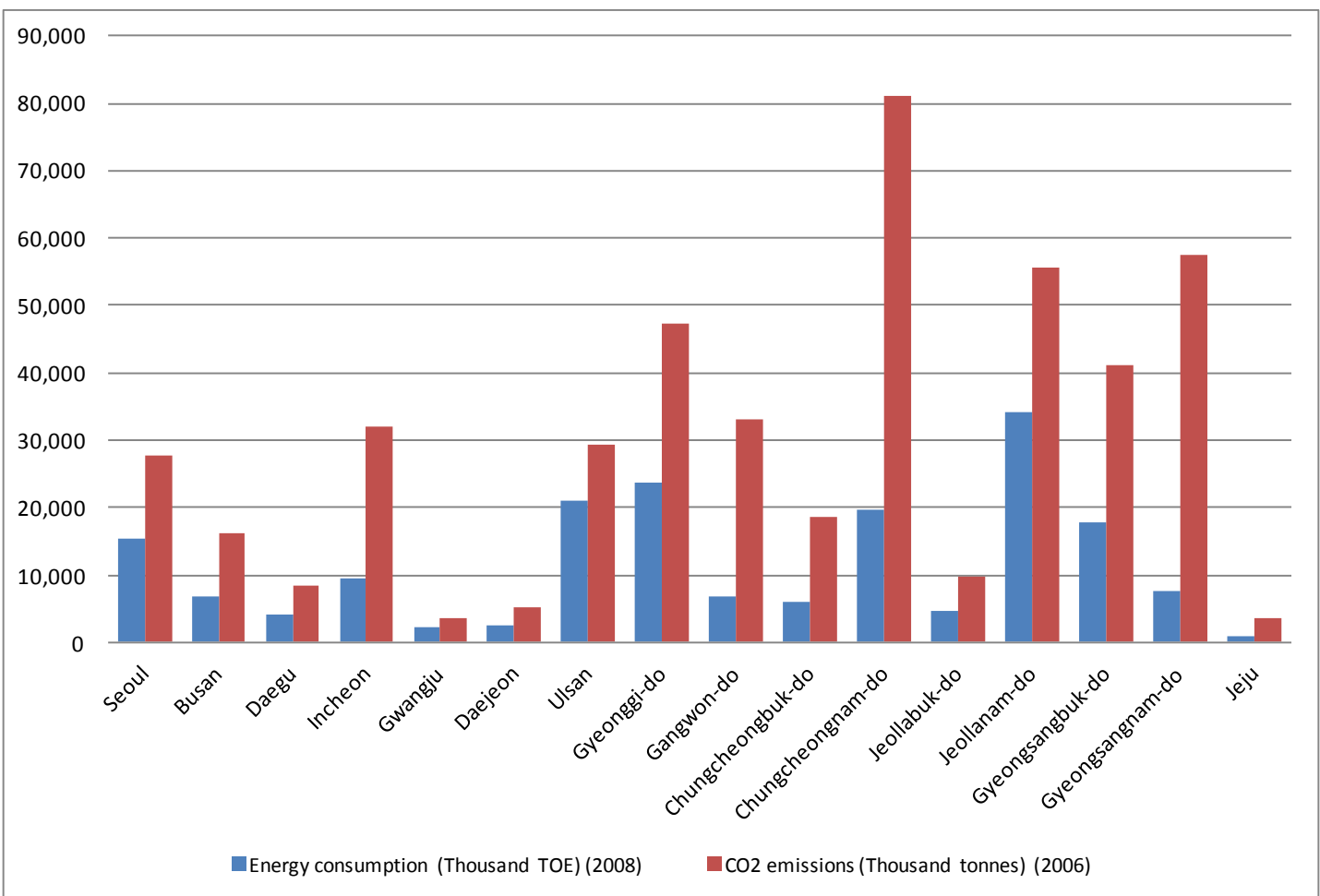

At the national level, Korea's per capita $\mathrm{CO}_{2}$ emissions fall around the OECD average of approximately 10 tonnes of $\mathrm{CO}_{2}$ per capita, given Korea's level of urbanisation, in line with those of Germany, Denmark and Austria. Among those countries with similar urbanisation levels, such as the United States, New Zealand, Spain, Mexico and Turkey, Korea comes in at a distant second behind the United States (19 tonnes of $\mathrm{CO}_{2}$ per capita).

When comparing Seoul with other large cities in the world, Seoul registers relatively low levels of GHG emissions. For instance, in a World Bank inventory of representative GHG baselines for a range of cities, Seoul records 4.1 tonnes of $\mathrm{CO}_{2}$-equivalent per capita, ${ }^{4}$ comparable to Tokyo (4.89 $\mathrm{tCO}_{2} \mathrm{e} /$ capita) and well below levels in Calgary (17.7 $\mathrm{tCO}_{2} \mathrm{e} /$ capita), Stuttgart (16.0 $\mathrm{tCO}_{2} \mathrm{e} /$ capita), Frankfurt (13.7 $\mathrm{tCO}_{2} \mathrm{e} /$ capita), Brussels (7.5 $\mathrm{tCO}_{2} \mathrm{e} /$ capita) and Helsinki ( $7 \mathrm{tCO}_{2} \mathrm{e} /$ capita), among others (World Bank, 2011). The Asian Green City Index report, a research project conducted by the Economist Intelligence Unit and Siemens on 22 major Asian cities, estimates the city's $\mathrm{CO}_{2}$ emissions at 3.7 tonnes per person (based on data from Korea Energy Economics Institute, 2009), below the 22-city average in the study (Figure 9) (The Economist Intelligence Unit, 2011). Seoul generates fewer $\mathrm{CO}_{2}$ emissions than Shanghai (9.7 tonnes/person), Guangzhou (9.2 tonnes/person) and Beijing (8.2 tonnes/person); about the same levels as Chinese Taipei (4.2 tonnes/person) and Karachi (3.1 tonnes/person), but well above levels in Bengalaru (0.5 tonnes/person), Mumbai (1.0 tonnes/person) and Delhi (1.1 tonnes/person). This same report found that Seoul's energy consumption per GDP performs better than Shanghai, Guangzhou and Beijing, about the same as Singapore and Kolkuta, but below levels in Tokyo and Hong Kong. Seoul's strong performance in energy consumption and $\mathrm{CO}_{2}$ emissions can be credited to an economy dominated by the service sector, bolstered by strong municipal policies on energy and $\mathrm{CO}_{2}$.

4. Data is for 1998 levels and is based on Dhakal, S. (2004). Note that the figure for Seoul should be interpreted with caution, however, as the data for Korea was not among those that were not peer reviewed by the World Bank. 
Figure 9. Per capita $\mathrm{CO} 2$ emissions in select Asian cities

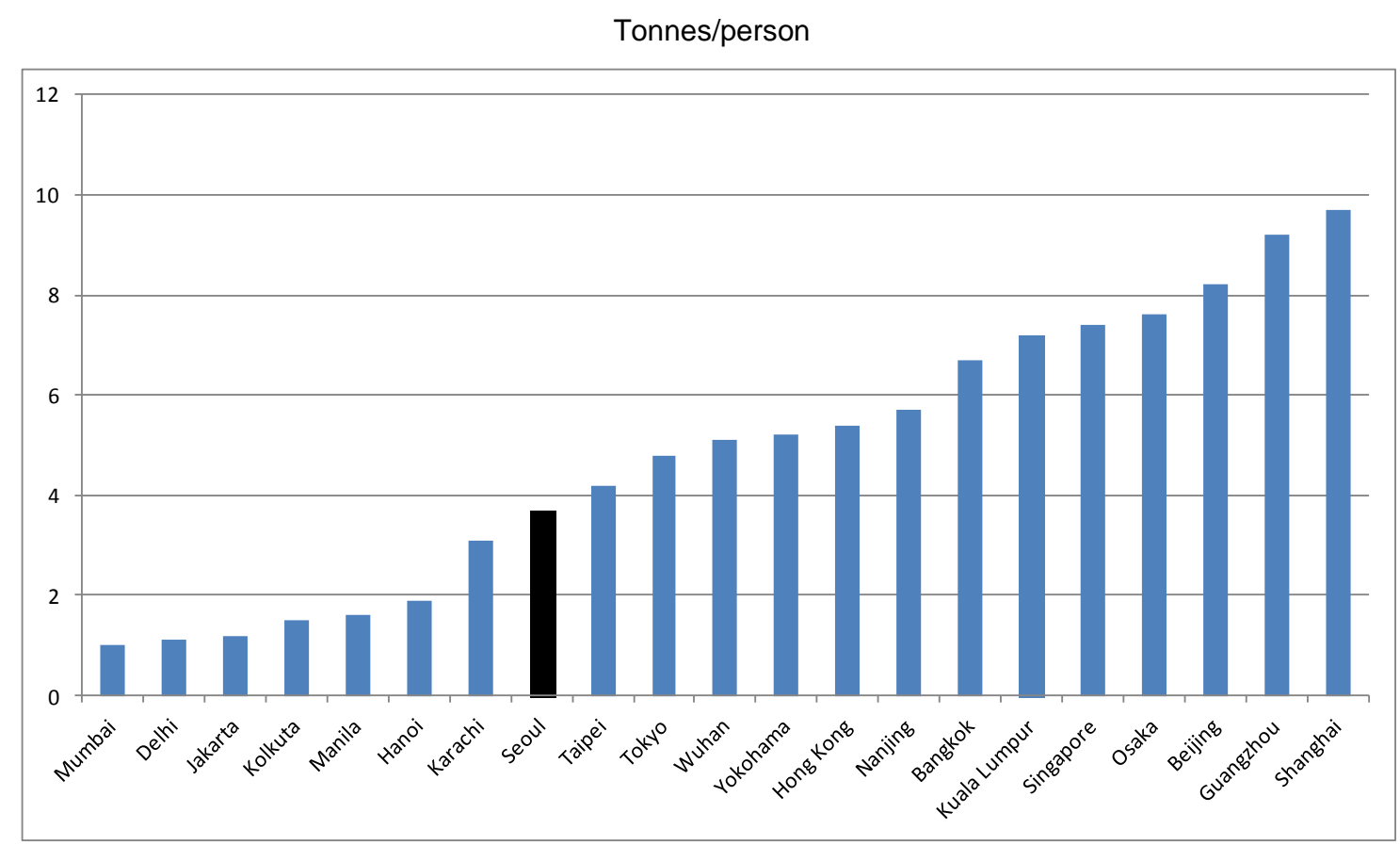

Source: Asian Green City Index.

The rise of direct energy consumption in Korean cities has also led to an increase of air pollution. Between 1999 and 2007, total air pollutants in Korea increased by 6.4\%, while emissions of Nitrogen Oxides (NOx), resulting from the combustion of fossil fuels, increased by 10.9\% (Table 7) (Korean Statistics Office, 2011). Although the Korean government has implemented very strict regulations on air pollution since the late 1990s, air quality in Korean cities, especially in Seoul, still remains poor compared to other OECD countries (OECD, 2006). Absolute levels of air pollutants in Korea are far worse than those of other OECD countries. Nevertheless, in terms of the emission intensity relative to a country's GDP size, Korea has recently made considerable progress. The Sulphur Oxide $\left(\mathrm{SO}_{\mathrm{x}}\right)$ intensity of the Korean economy $(0.6 \mathrm{~kg} / \mathrm{USD} 1000)$ lowered to half of the OECD average $(1.2 \mathrm{~kg} / \mathrm{USD} 1000)$ in 2003, whereas it was $27 \%$ higher than the OECD average in 1997. Korea also succeeded in holding $\mathrm{NO}_{\mathrm{x}}$ levels in line with the OECD average (1.4 kg/USD 1 000), reaching $1.3 \mathrm{~kg} / \mathrm{USD} 1000$ in 2003.

Table 7. Air pollutant emissions in Korea

Thousand tonnes

\begin{tabular}{l|lllllllll|l}
\hline & 1999 & 2000 & 2001 & 2002 & 2003 & 2004 & 2005 & 2006 & 2007 & $\begin{array}{l}\% \text { change } \\
(1999-2007)\end{array}$ \\
\hline CO & 885 & 900 & 845 & 822 & 805 & 816 & 788 & 829 & 808 & 91.3 \\
NOx & 1072 & 1222 & 1219 & 1242 & 1362 & 1377 & 1306 & 1274 & 1187 & 110.7 \\
SOx & 484 & 490 & 487 & 474 & 469 & 446 & 408 & 446 & 402 & 83.1 \\
TSP & 84 & 82 & 88 & 84 & 85 & 80 & 88 & 88 & 144 & 171.4 \\
PM 10 & 63 & 61 & 67 & 65 & 66 & 62 & 67 & 64 & 98 & 156.6 \\
VOC & 665 & 706 & 734 & 741 & 758 & 797 & 756 & 794 & 874 & 131.4 \\
\hline Total & 3253 & 3461 & 3440 & 3428 & 3545 & 3578 & 3413 & 3495 & 3513 & 108.0 \\
\hline
\end{tabular}

Note: CO, NOx, SOx, TSP, PM10 and VOC in this table respectively represent Carbon Monoxide, Nitrogen Oxides, Sulphur Oxide, Total Suspended Particles, Particulate Matters and Volatile Organic Compounds.

Source: Korea Statistics Office (2011). 
Seoul and the capital region display the highest level of total air pollutants. The capital area accounted for nearly one-third of all air pollutants in 1999 and again in 2007, reflecting its high concentration of people, infrastructure and transportation (notably private vehicles) (Table 8). Although Seoul's share of air pollutants relative to the national total is smaller than its share of national population, the concentration of air pollutants remains a concern. In terms of air pollutants per area $\left(\mathrm{km}^{2}\right)$, Seoul City was found to emit almost 18 times more than national average, indirectly reflecting its higher traffic congestion costs. Compared to several other OECD cities, the level of $\mathrm{NO}_{2}, \mathrm{SO}_{2}$ and $\mathrm{PM}_{10}$ are almost double those of Paris (Table 9). As a result, the social costs of air pollution are estimated at EUR 7.6 billion for Seoul MA and EUR 40 billion for the country as a whole (OECD, 2006).

Table 8. Trends in total air pollutant emissions by region

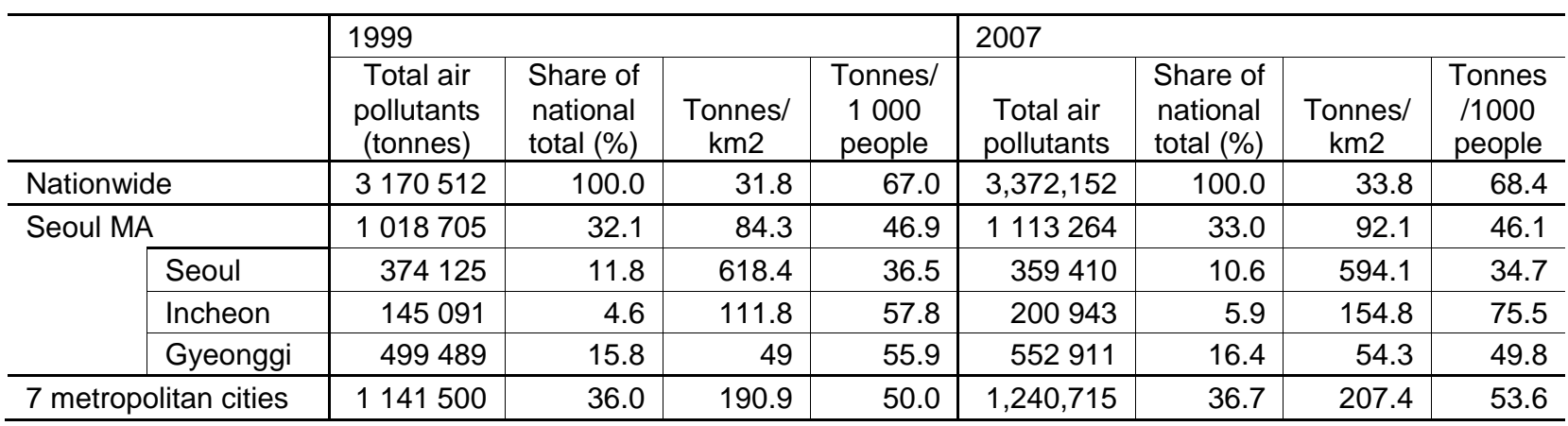

Source: National Institute of Environmental Research (2011).

Table 9. Comparison of selected air pollutants in international cities

\begin{tabular}{lrrr}
\hline & $\mathrm{NO}_{2}(\mathrm{PPM})$ & $\mathrm{SO}_{2}(\mathrm{PPM})$ & $\mathrm{PM}_{10}\left(\mu \mathrm{g} / \mathrm{m}^{3}\right)$ \\
\hline Seoul (2008) & 0.038 & 0.006 & 53 \\
Tokyo (2006) & 0.025 & 0.002 & 29 \\
London (2005) & 0.023 & 0.002 & 30 \\
Paris (2007) & 0.020 & 0.003 & 30 \\
New York (2006) & 0.034 & 0.010 & 26 \\
\hline
\end{tabular}

Source: Jun (2010).

Among Korean cities, environmental performance related to air pollution varies with the type of pollutants, with an increasing concentration of some air pollutants in medium-sized cities (Table 10). With the exception of the high concentrations of $\mathrm{SO}_{2}$ in Ulsan and $\mathrm{NO}_{2}$ in Seoul, the highest observed concentrations of $\mathrm{SO}_{2}, \mathrm{NO}_{2}, \mathrm{O}_{3}, \mathrm{CO}$ and $\mathrm{PM}_{10}$ are to be found in medium-sized cities (Table 10 and Figure 10). Except in the case of $\mathrm{PM}_{10}$, a number of medium-sized cities (Sis) recorded higher overall air pollutant concentrations than metropolitan cities. Gimcheon-si (located in the province of Gyeongsangnam-do) and Gangeung-si (located in the province of Gangwon-do), in particular, registered a more rapid increase in the concentration of air pollutants than other cities. Clear trends across various air pollutants are harder to discern, however. Between 1998 and 2008, most metropolitan cities and 31 medium-sized cities (Sis) registered decreasing $\mathrm{SO}_{2}$ and $\mathrm{CO}$ concentrations, while the concentration of $\mathrm{O}_{3}$, a main contributor to serious respiratory diseases, increased across nearly all metropolitan cities and medium-sized cities. Increased industrialisation in medium-sized cities explains in part the increase of pollution concentration, suggesting that the Korean government could pay more attention to medium-sized cities when addressing pollution issues. 
Table 10. Korean cities with the highest observed concentration of air pollutants (2008)

\begin{tabular}{|ll|ll|ll|ll|ll|}
\hline $\mathrm{SO}_{2}{ }^{1}$ & & $\mathrm{NO}_{2}{ }^{1}$ & & $\mathrm{O}_{3}{ }^{1}$ & & $\mathrm{CO}^{1}$ & & $\mathrm{PM}_{10}{ }^{2}$ \\
\hline Yeosu-si & 0.012 & Gwangmyeong-si & 0.041 & Jeju & 0.038 & Jecheon-si & 1 & Wonju-si & 65 \\
\hline Jecheon-si & 0.011 & Bucheon-si & 0.039 & Mokpo-si & 0.034 & Wonju-si & 0.9 & Gumi-si & 65 \\
\hline Chungju-si & 0.009 & Seoul & 0.038 & Jinhae-si & 0.033 & Gimcheon-si & 0.9 & Anyang-si & 63 \\
\hline Gimcheon-si & 0.009 & Suwon-si & 0.035 & Gangneung-si & 0.032 & Gumi-si & 0.9 & Chungju-si & 63 \\
\hline Ulsan & 0.008 & Seongnam-si & 0.034 & Yeosu-si & 0.03 & Chungju-si & 0.8 & Cheongju-si & 62 \\
\hline
\end{tabular}

Notes: (1) Measured in parts per million; (2) measured in $\mu \mathrm{g} / \mathrm{m}^{3}$

Source: Ministry of Environment (2009).

Figure 10. Trends in air pollution concentration in selected Korean metropolitan cities and Sis
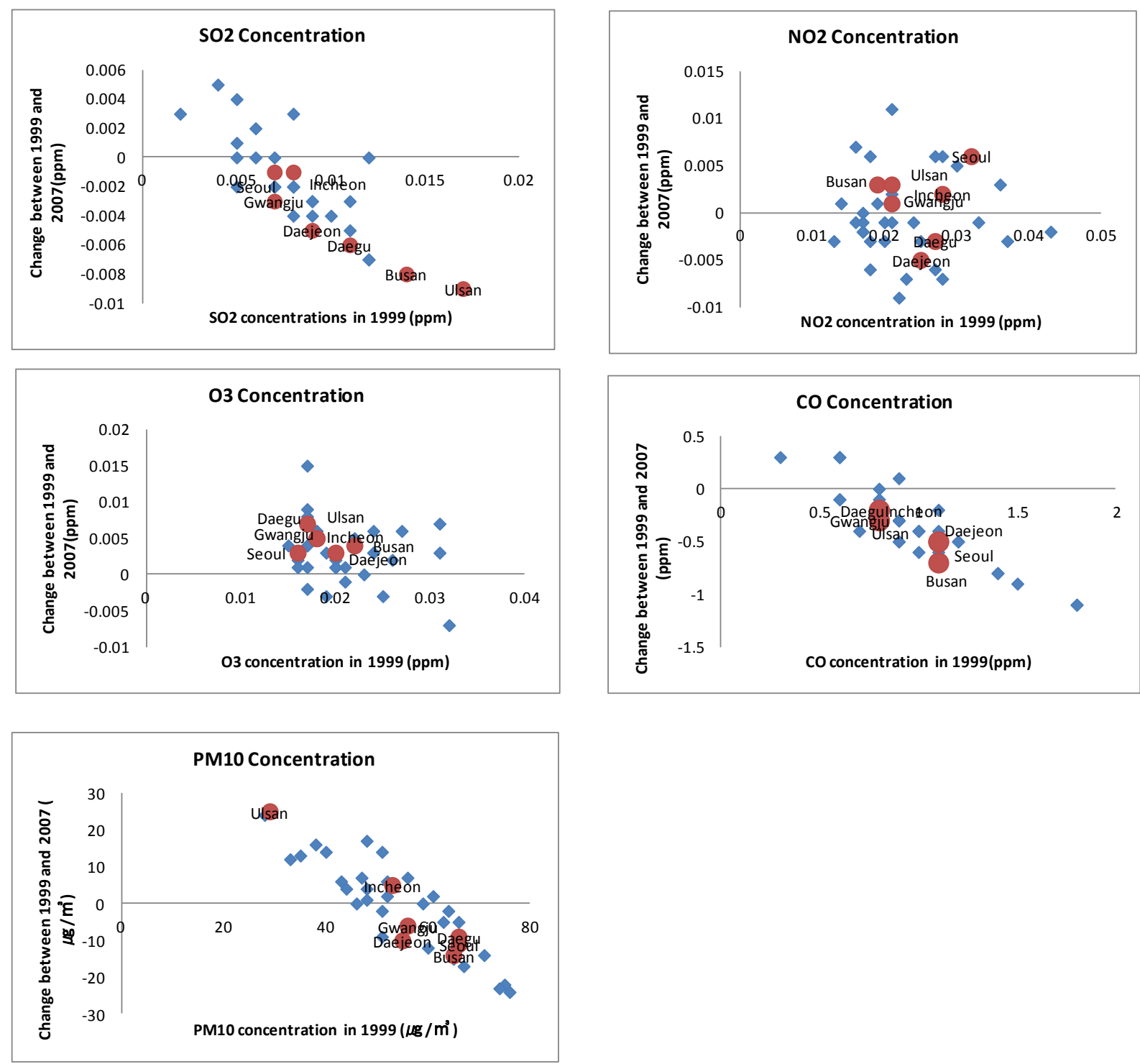

Note: Red dots represent Metropolitan cities; blue diamonds represent a selection of 31 Sis.

Source: Ministry of Environment (2009). 
Compared to other OECD countries, Korea's levels of nitrogen dioxide $\left(\mathrm{NO}_{2}\right)$ represent the primary concern in terms of air pollution. Among OECD countries, the total emissions of $\mathrm{NO}_{2}$ in Korea are higher than the OECD average (OECD, 2006), while Korea's total sulphur dioxide $\left(\mathrm{SO}_{2}\right)$ and $\mathrm{CO}_{2}$ emissions remain well below the OECD average. Compared with a selection of Asian and Latin American cities surveyed, Seoul displays a particularly high concentration of $\mathrm{NO}_{2}$, (71.4 micrograms per cubic metre), second only to Mumbai (Figure 11). This finding is echoed in the World Bank's World Development Indicators for air pollution, which reports $\mathrm{NO}_{2}$ levels in Busan $\left(51 \mu \mathrm{g} / \mathrm{m}^{3}\right)$, Seoul $\left(60 \mu \mathrm{g} / \mathrm{m}^{3}\right)$ and Daegu $(62$ $\mu \mathrm{g} / \mathrm{m}^{3}$ ) (World Bank, 2011). The high levels of $\mathrm{NO}_{2}$ are due to the city's dependence on private vehicles, which are responsible for nearly three-quarters of the city's air pollution. The use of natural gas in households has helped to limit the concentration of other air pollutants, including $\mathrm{SO}_{2}$ (Figure 13) and suspended particulate matter (Figure 13). Nevertheless, Seoul's average daily concentration of particulate matter (55 micrograms per cubic metre) is well above the World Health Organisation's safe guideline of 20 micrograms per cubic metre.

Figure 11. Concentration of daily nitrogen dioxide $\left(\mathrm{NO}_{2}\right)$ in select cities

$\left(\mu \mathrm{g} / \mathrm{m}^{3}\right)$

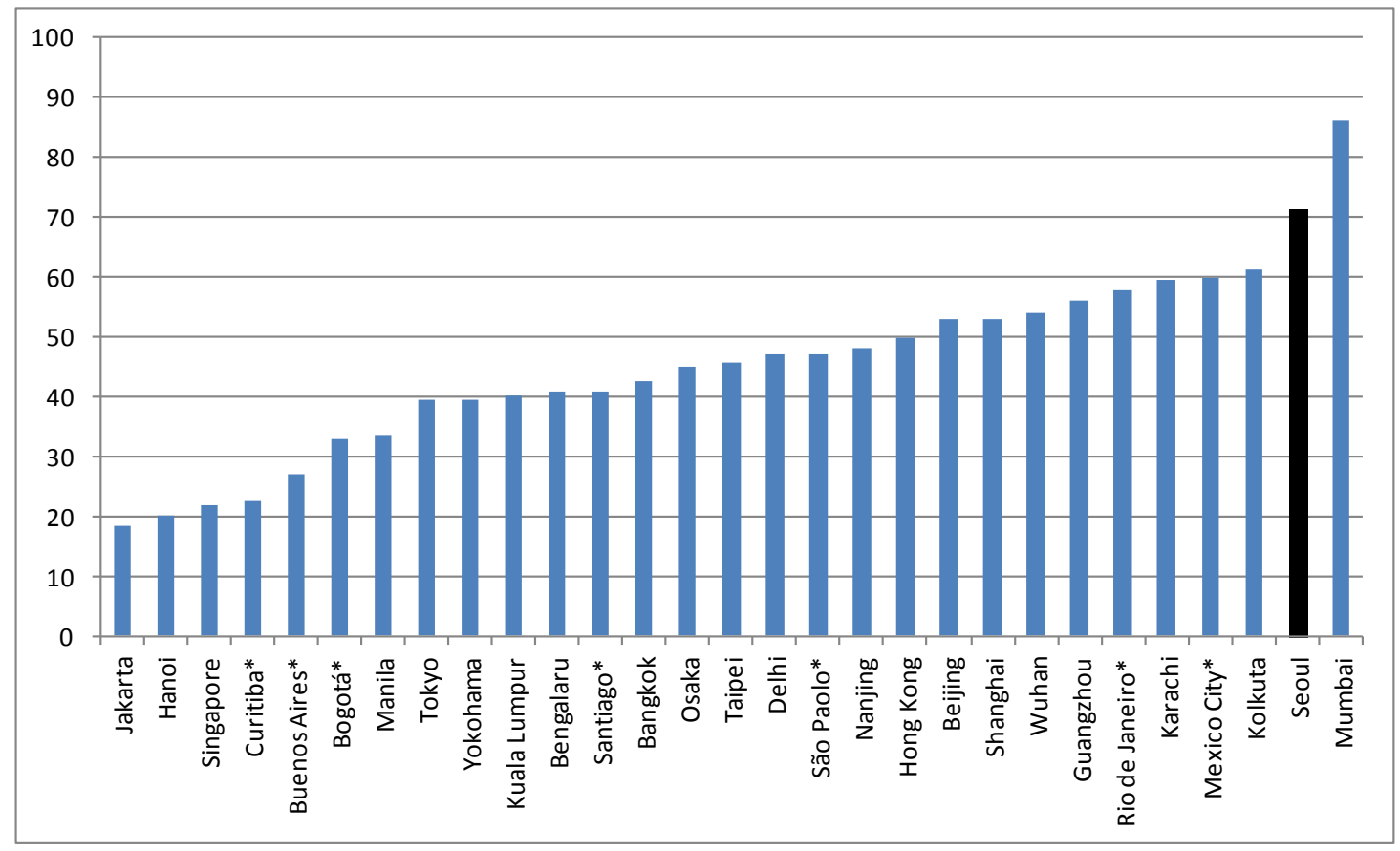

Notes: Data from a selection of Latin American cities are presented here.

Source: Asian Green City Index (2011), Latin American Green City Index (2010). 
Figure 12. Concentration of daily sulphur dioxide $\left(\mathrm{SO}_{2}\right)$ in select cities

$$
\left(\mu \mathrm{g} / \mathrm{m}^{3}\right)
$$

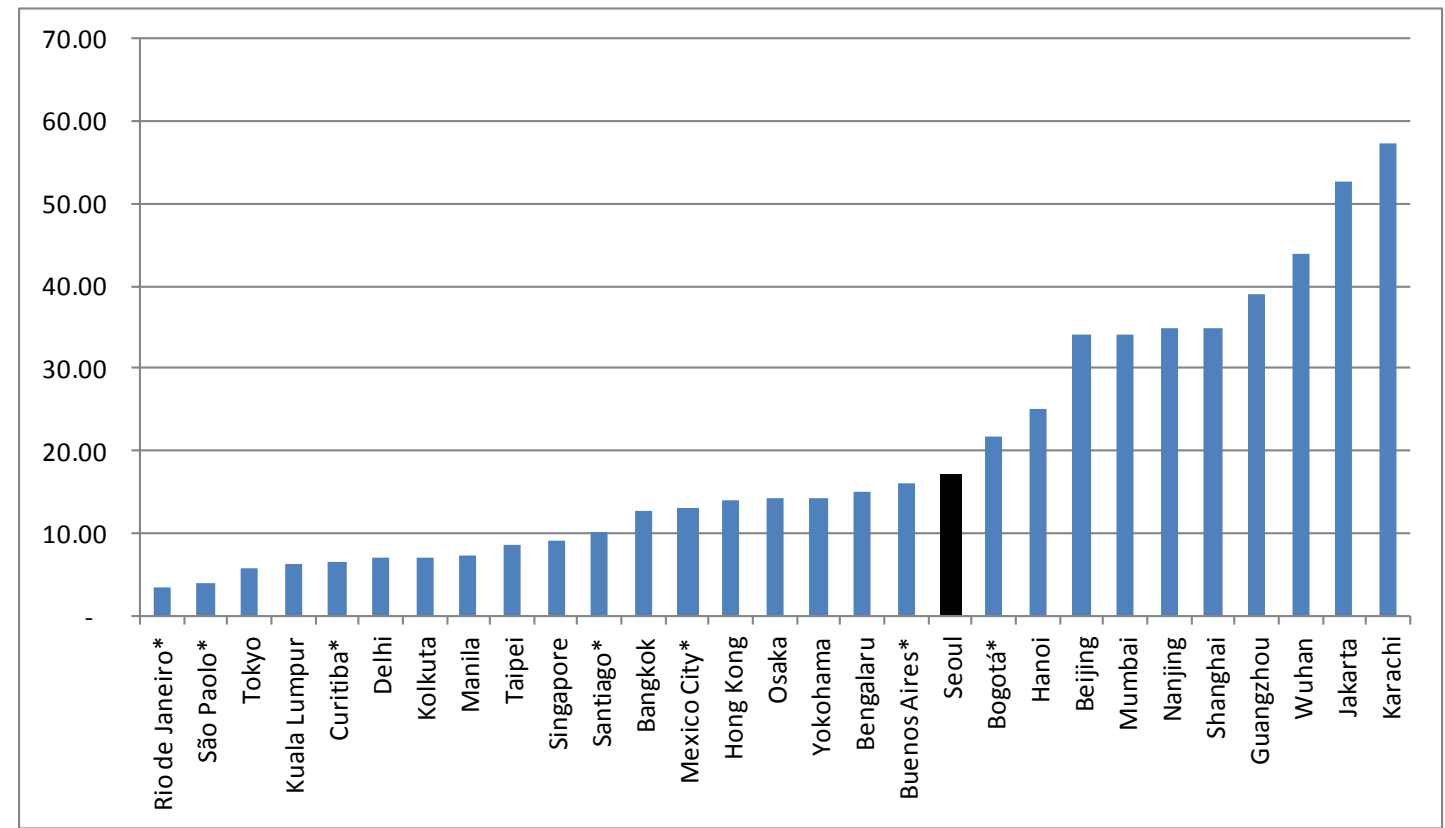

Notes: Data from a selection of Latin American cities are presented here.

Source: Asian Green City Index (2011), Latin American Green City Index (2010).

Figure 13. Concentration of daily suspended particulate matter in select cities

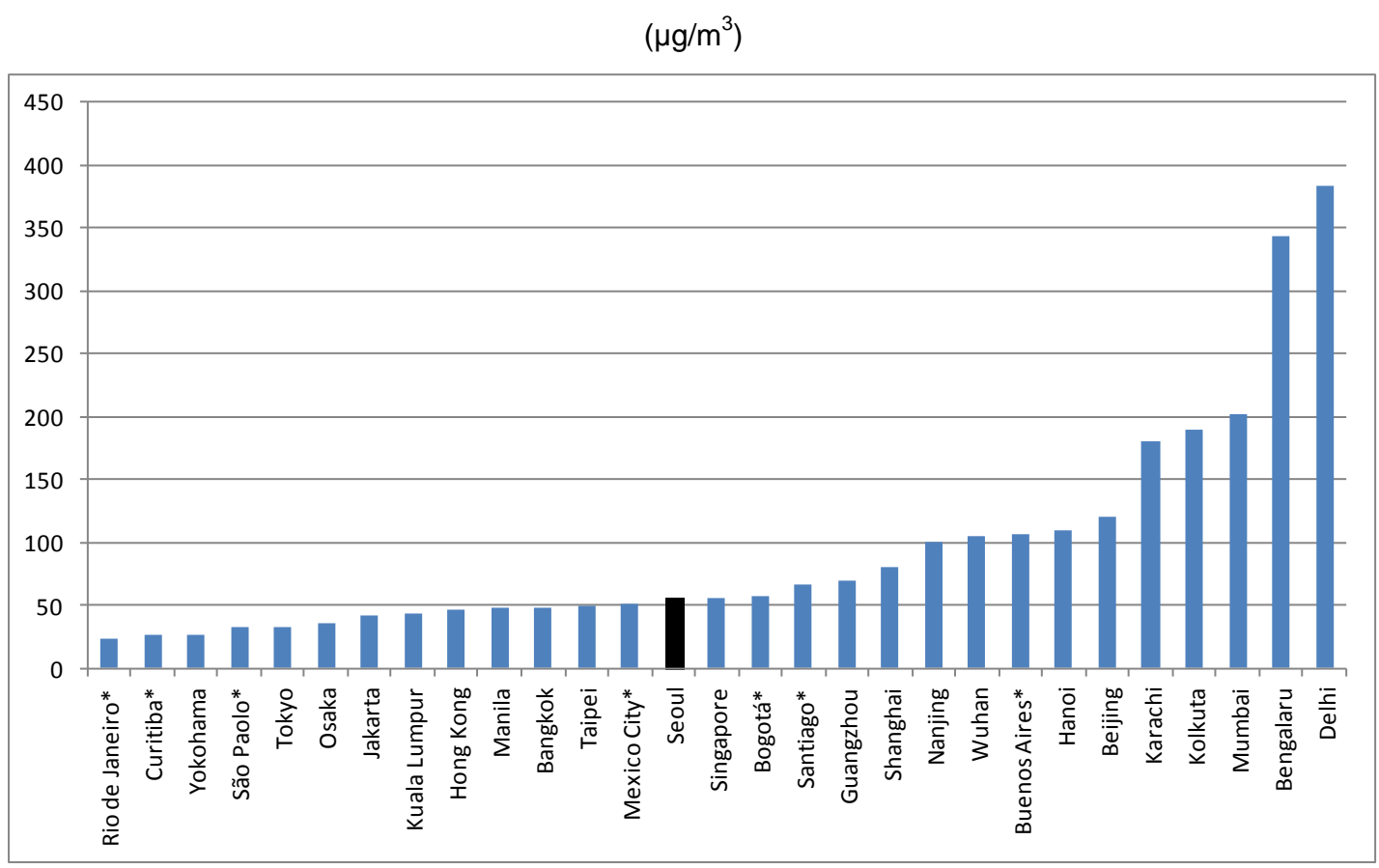

Notes: Data from a selection of Latin American cities are presented here.

Source: Asian Green City Index (2011), Latin American Green City Index (2010). 
Air pollution in Korea cities, as in many other OECD cities, has been largely associated with massive energy consumption. However, with rigid regulations on fuel qualities for industrial consumption, current air pollution levels can be mostly attributed to the transport sector (Kim, 2003). Air quality will continue to deteriorate as long as number of road vehicles and VKT are on the rise. In this regard, it is recommended for both central and local governments in Korea to persistently seek to implement policies to diminish road traffic volume, such as controlling traffic demand through market mechanisms, inducing a modal shift toward public transport with improvements to accessibility and enhancing capacities of individual vehicles to optimise energy consumption. These policy instruments will be discussed further in the third section of this paper.

\section{Transport and building: two important sectors to be addressed}

Aside from the industrial sector, which has contributed significantly to $\mathrm{CO}_{2}$ emissions and the concentration of various pollutants in medium-sized cities, two important sectors, namely (i) transport and (ii) building have increased their contribution to total $\mathrm{CO}_{2}$ emissions in both metropolitan and mediumsized cities.

(i) With the increase of car use and traffic congestion in many Korean cities, the rise of energy consumption in the transport sector has been the most dramatic. This sector increased its share of total energy consumption from $13.5 \%$ in 1980 to $19.7 \%$ in 2009 - an increase of $633 \%$ - due to higher rates of vehicle ownership (Korea Energy Economics Institute, 2011). Relying primarily on fossil fuels as a primary energy source, the transportation sector accounted for $20 \%$ of energy-related $\mathrm{CO}_{2}$ emissions in 2007 (MLTM, 2009). Historically, GDP growth and the expansion of the transport sector have been strongly correlated, while road transport has grown at an even faster rate (World Bank, 2010). Road transport is by far the dominant mode in Korea, representing $91 \%$ of passenger travel and $75 \%$ of freight transport (Eom and Shipper, 2010). From 1986 and 2008, an almost linear relationship has been observed between the growth in car use and per capita growth of GDP in Korea (Eom and Shipper, 2010). With the domestic GDP more than doubling between 1990 and 2010, a considerable rise in car and light-truck personal use was observed, consistent with motorisation trends in many rapidly developing Asian economies. Currently, $\mathrm{CO}_{2}$ emissions from road transport increased by $156.6 \%$ between 1990 and 2007, due in part to the rapid rise in car registration.

Road transport accounts for $96 \%$ of total passenger carbon emissions and $64 \%$ of overall carbon emissions from the domestic transportation sector, of which private vehicles accounted for $68 \%$ of $\mathrm{CO}_{2}$ emissions and buses for $28 \%$ in 2007 . These patterns are consistent with those of most developed countries (IEA, 2008) and reflect the trend that passenger transportation is increasingly more dependent on private vehicle use (KEEI, 2007). In Korea, car ownership has risen substantially in the past 30 years, with the number of vehicle registration applications increasing by 3285\%, a trend that is currently on track to continue (MLTM, 2011a forthcoming). Although the rate has slowed in recent years, vehicle registrations still increased by $49 \%$ between 2000 and 2010 . Vehicle ownership seems to be closely associated with the economic performance of cities (Figure 14). The Capital Region (Seoul, Incheon and Gyeonggi-do) recorded $45.1 \%$ of the national total of vehicle registrations in 2010, similar to its share of the total national population. Some less urbanised provinces, like Gyeongsangnam-do and Chungcheongbuk-do, have started to surpass the metropolitan cities, recording the highest increasing rates of car registration over the last ten years (respectively 71.5\% and 70.6\%) (MLTM, 2011a forthcoming). While the number of vehicles per capita generally tends to be lower in denser areas, this does not seem to be the case in the Capital Region. In 2010, the number of vehicle registration per square kilometre in Seoul is 4 928, 27 times higher than that of the national rate. This high concentration of cars in a small territory generates important pollution costs. 
Figure 14. Regional economic performance and vehicle ownership in Korean cities

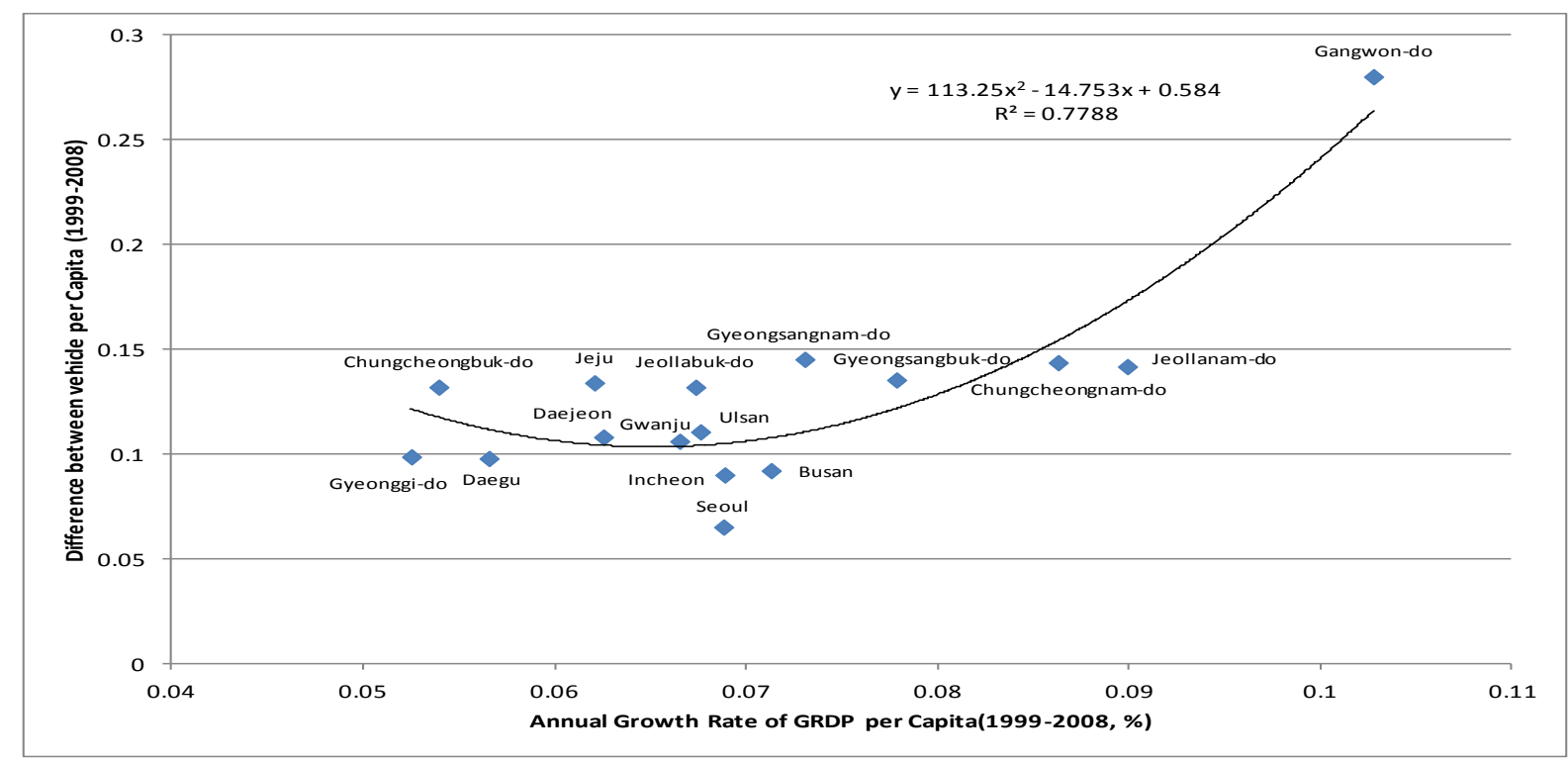

Source: OECD own calculations based on data from KOSIS (2011) and MLTM (2011).

It is worth noting the strong preference for bigger automobiles in Korea, which in turn has a considerable impact on air pollution. A main driver of air pollution in Korean cities has been road transport, which represented $32.9 \%$ of total air pollutants, higher than the share in the U.S., where urban sprawl has become one of the prevailing traits in most cities (OECD, 2009). The size of cars also has an impact on air pollution levels (Table 11). In 1992, the average engine size of automobiles in Korea $(1620 \mathrm{cc})$ was slightly lower than that of EU average $(1602 \mathrm{cc})$. Within a 15 -year period, however, the average engine size in Korea became $21.1 \%$ larger than EU average. According to the Korea Transport Institute (2008), the number of cars with large engines (2 $000 \mathrm{cc}$ or more) out of all newly registered cars in Korea represented $23.3 \%$ in 1998 and reached $56.6 \%$ in 2007. In general, automobile engine size is positively related to emission levels. Larger cars consume more energy, thereby emitting more air pollutants (Table 12). Larger cars (over $2000 \mathrm{cc}$ ) register $150 \%$ more Vehicles Kilometres Travelled (VKT), consume almost 3 times as much gasoline and generate twice as many $\mathrm{CO}_{2}$ emissions compared to small cars (less than $1000 \mathrm{cc}$ ).

Table 11. International comparison of average engine size of automobiles, Korea and the European Union cubic centimetres (cc)

\begin{tabular}{|c|c|c|c|c|c|}
\hline & & 1992 & 2002 & 2007 & $\begin{array}{l}\% \text { change } \\
(1992-2007)\end{array}$ \\
\hline Korea & & 1620 & 2100 & 2113 & $130.4 \%$ \\
\hline \multirow[t]{4}{*}{ EU average } & & 1602 & 1713 & 1744 & $108.9 \%$ \\
\hline & UK & 1617 & 1705 & 1777 & $109.9 \%$ \\
\hline & France & 1599 & 1757 & 1680 & $105.1 \%$ \\
\hline & Germany & 1776 & 1844 & 1863 & $104.9 \%$ \\
\hline
\end{tabular}

Source: Korea Transport Institute (2008). 
Table 12. Comparison of energy consumption by size of vehicle engine

\begin{tabular}{llllll}
\hline & VKT/year & $\begin{array}{l}\text { gasoline consumption } \\
\text { (liter/car) }\end{array}$ & $\begin{array}{l}\text { CO2 emission } \\
(\mathrm{g} / \mathrm{km})\end{array}$ & $\begin{array}{l}\text { yearly CO2 } \\
(\mathrm{kg} / \mathrm{car})\end{array}$ & Index * $^{*}$ \\
\hline Small $(<1000 \mathrm{cc})$ & 12307 & 932 & 177 & 2187 & 1.0 \\
Compact $(1000-1500 \mathrm{cc})$ & 13625 & 1179 & 204 & 2792 & 1.3 \\
Mid $(1500-2000 \mathrm{cc})$ & 14901 & 1621 & 252 & 3765 & 1.7 \\
Large $(>2000 \mathrm{cc})$ & 18190 & 2869 & 324 & 5902 & 2.7 \\
\hline
\end{tabular}

Source: Korea Transport Institute (2008).

(ii) Besides being one of the key growth factors in urban areas, the building sector is also one of the major energy-intensive sectors of the Korean economy. Energy consumption from the building sector in total consumption is particularly high in Seoul, where it accounts for $60 \%$ of the total (The Economist Intelligence Unit, 2011). Energy consumption levels of both the residential/commercial sector and the public sector increased between 1980 and 2009, though at much slower rates $(126 \%$ and $127 \%$, respectively) than the growth of the transportation and industrial sectors. Taken together, residential and commercial buildings account for $24 \%$ of domestic energy consumption (EKC, 2009) and has been increasing by $3.8 \%$ annually since 1980 (KICT, 2009). During this period (1980-2009), the share of the residential/commercial sector in total final energy consumption decreased from $40.7 \%$ in 1980 to $19.6 \%$ in 2009. The share of energy consumption from the public sector (public buildings, for example) also decreased during this period, from $4.9 \%$ in 1980 to $2.4 \%$ in 2009. In terms of emissions, the building sector is responsible for the $25 \%$ of energy-related greenhouse gas emissions in Korea (MLTM, 2009).

Fast urbanisation in Korea, along with wide fluctuations in housing prices, has led the government to implement a strong housing supply policy. According to the Long-term Housing Master Plan (2003-12), required by the Housing Act, the Korean government aims to provide five million housing units by 2012 (approximately 500000 per annum) to increase the nationwide housing supply ratio to $116.7 \%$ by 2012 . The government is currently on target to achieve this goal: between 2003 and 2008, on average, 485000 housing units (mainly apartments) were built annually, with half of those housing units built in Seoul Metropolitan Area. New construction techniques have been developed to allow for denser and more compact urban form, combined with an increased degree of flexibility in managing urban space, as is the case in Seoul and will be discussed further in section 2). Nevertheless, there is still significant room for greening buildings in Korea. A 2009 MLTM report found that new construction in Korea consumed more than twice as much energy $\left(200 \mathrm{kwh} / \mathrm{m}^{2}\right)$ as those in Germany $\left(90 \mathrm{kwh} / \mathrm{m}^{2}\right)(\mathrm{MLTM}, 2009)$.

\section{Waste and Water}

Between 2000 and 2009, total waste generation increased by $58 \%$ in Korea, which was divided between industrial waste (86\% of the total) and domestic waste (14\%) in 2009 (Ministry of Environment (MOE), 2010). The introduction of strict regulations on disposable goods and a volume-based disposal fee system for households in 1995 helped to limit domestic waste patterns to relatively stable levels between 2000 and 2009: domestic waste increased by just 10\% during this period (Figure 15). Industrial waste, however, increased by nearly $70 \%$ between 2000 and 2009 due to the expansion of energy-intensive industries throughout Korea (MOE, 2010). 
Figure 15. Waste generation trends in Korea

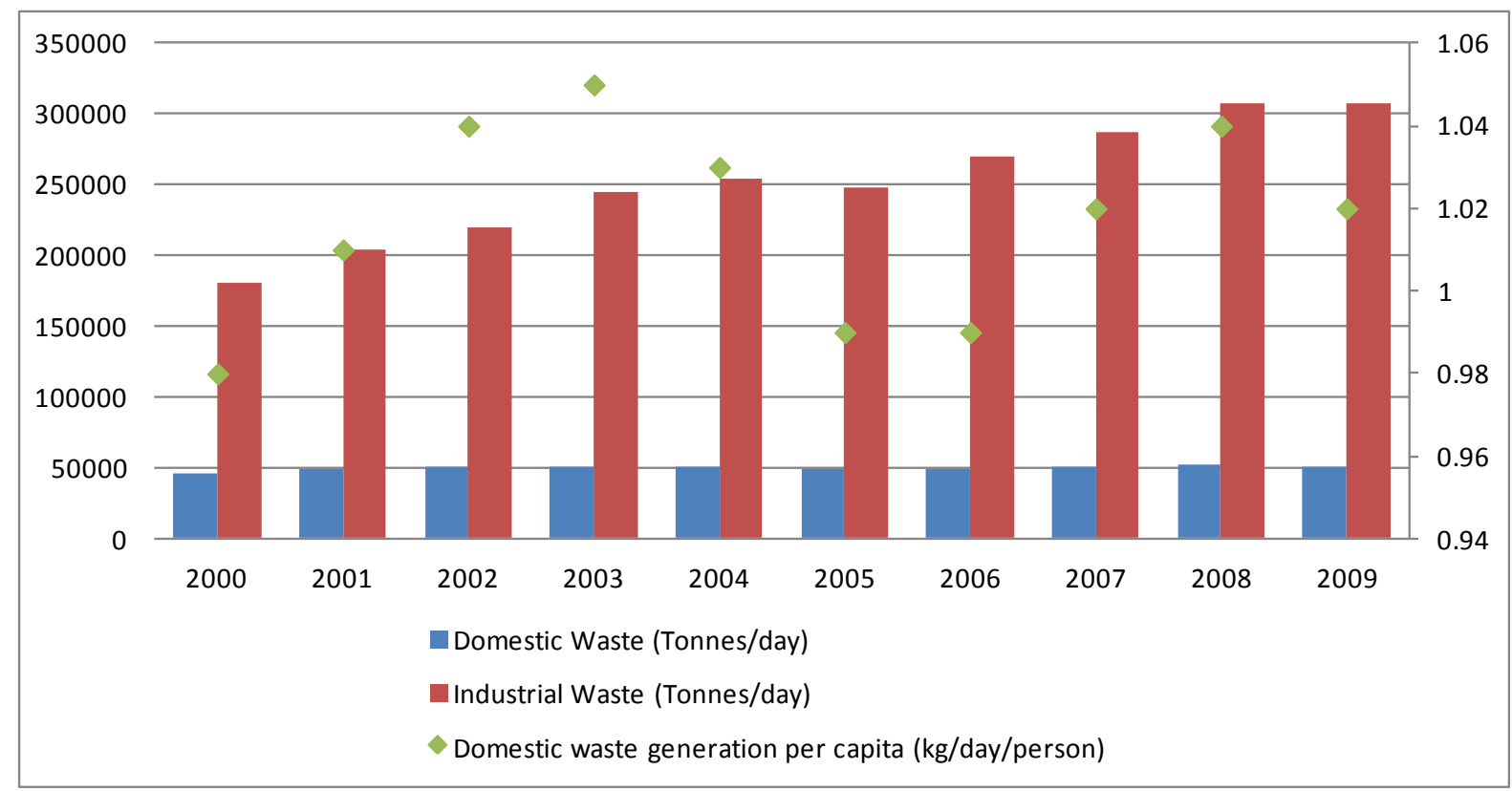

Source: Ministry of Environment (2010).

Different trends in total waste generation can be observed across cities and regions, reflecting characteristics of local economies:

(i) The Capital Region (Seoul, Incheon and Gyeonggi-do) generated 131832 tonnes per day, $36.8 \%$ of the national total in 2009. While the province of Gyeonggi-do registers the highest overall levels of daily waste generation due to high levels of industrial waste, Seoul, the most populated and economically active metropolitan city with the highest levels of GDP per capita, is responsible for the highest levels of domestic waste generation in tonnes per day, followed by Incheon, Pohang-si and Gwangyang-si (Figure 16). In per capita terms, total waste generation in Seoul has been lower than national average, but domestic waste per capita (i.e. excluding industrial and construction waste) is higher than the national average. Comparing Seoul with the 22 Asian cities shows that although the capital city records adequate waste collection and disposal for the totality of its waste, it also registers the highest levels of per capita waste generation among the cities surveyed (995.6 kg/person/year) (The Economist Intelligence Unit, 2011) (Figure 17). 
Figure 16. Daily municipal and industrial waste generation levels in Korean metropolitan cities and provinces (2009)

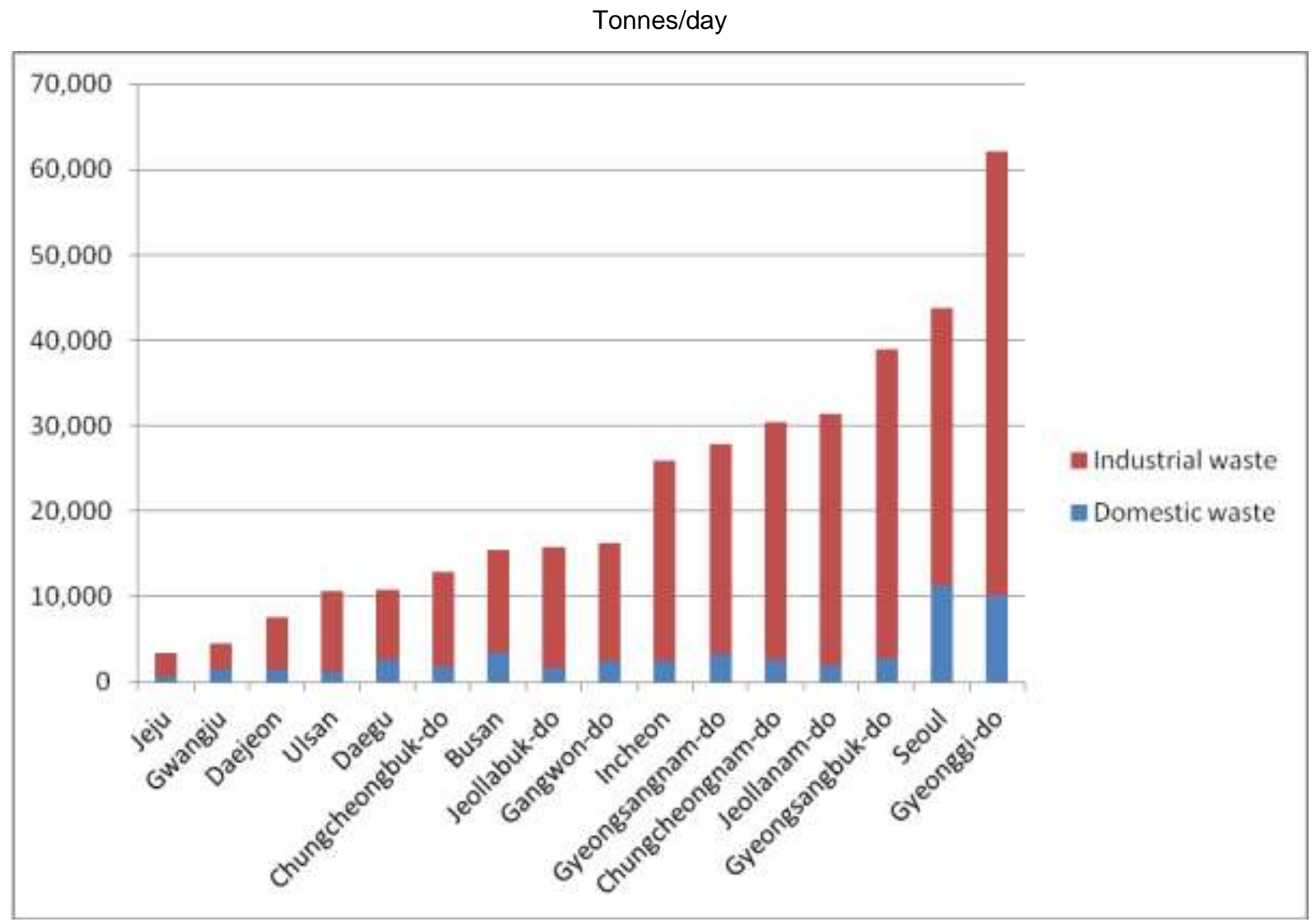

Source: Ministry of Environment (2010), 2009 Waste Generation and Disposal in Korea, MOE, Gyeonggi-do.

(ii) High levels of waste are observed in cities from heavily industrialised regions. High volume of waste generation of Pohang-si (located in the province of Gyeongsangbuk-do) and Gwangyang-si (located in the province of Jeollanam-do) can be explained by a high proportion of industrial waste, reflecting their heavy industrial complex areas.

(iii) Redevelopment and housing construction programmes may be responsible for the large share of waste generated in some medium-sized cities, such as Goyang-si and Seongnam-si located in Gyeonggi-do in the Capital Region.

(iv) Some smaller cities are responsible for high levels of waste per capita. This was the case for 39 out of 77 small cities (Sis), which displayed higher domestic waste generations per capita than the national average $(1.02 \mathrm{~kg} /$ day $)$. Five out of the ten small cities with the highest per capita waste generation rates are located in the province of Gangwon-do. Their high rank may be partially due to the large tourist population and related activities, which generate higher levels of domestic waste. ${ }^{5}$

5. Gangwon-do's large annual tourist population, which reached 46.3 million in 2008 - nearly double the population of Korea -generates large volumes of domestic waste (KOSIS based on Gangwon-do's statistics). In 2009, summer vacationers to the beaches of the Eastern Coast of Gangwon-do were estimated to generate $1.5 \mathrm{~kg}$ of waste per capita between July and August, nearly fifty percent higher than the daily national average (Seoul Newspaper, 15 September 2009). In order to reduce waste generation by tourists, 
Figure 17. Per capita waste generation in select cities

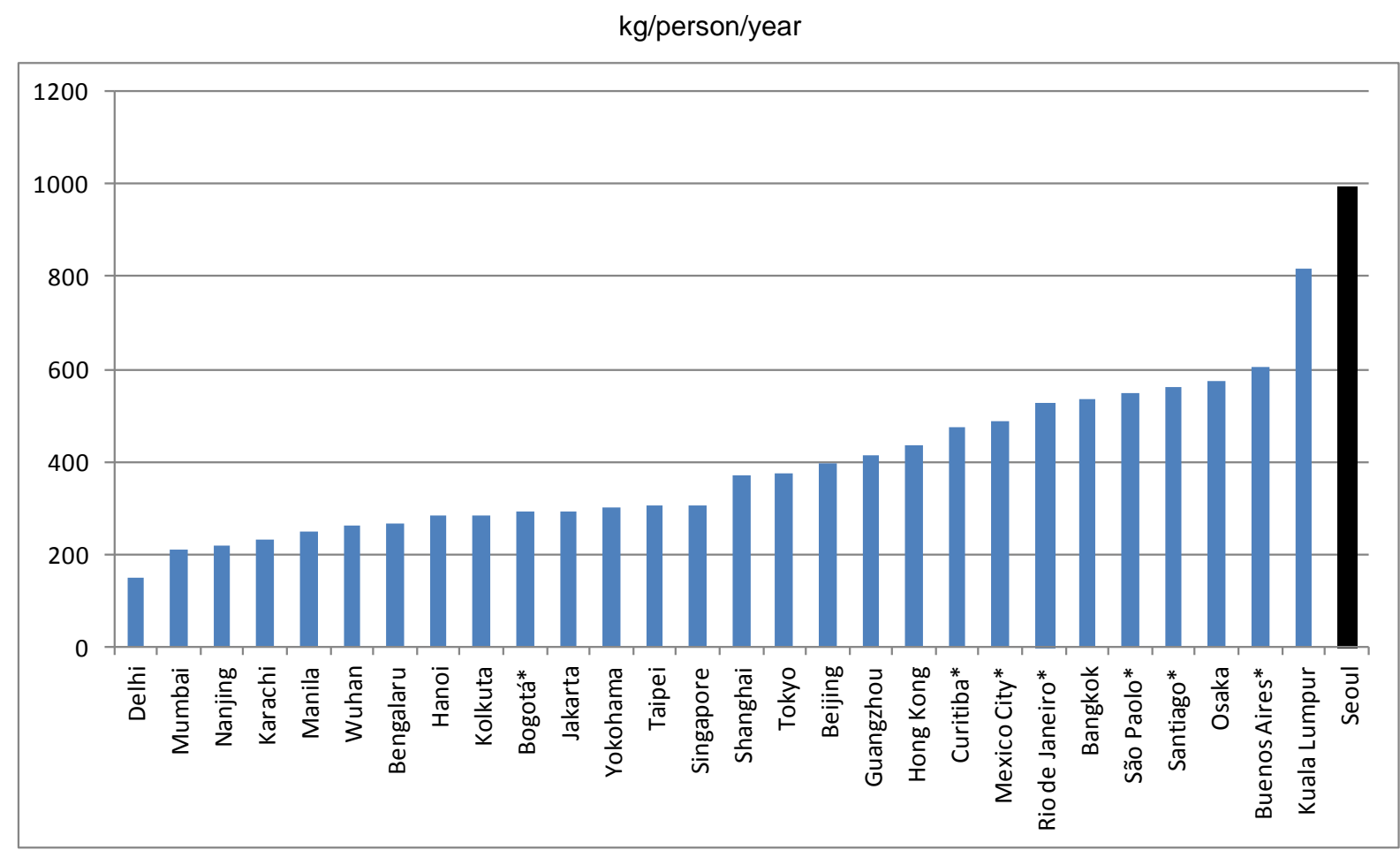

Note: Data from a selection of Latin American cities are presented here.

Source: The Economist Intelligence Unit (2011): Asian Green City Index: The Economist Intelligent Unit (2010), Latin American Green City Index

Most of the Korean population has access to sanitation: in 2010, the national average of sewage system supply rate was just over $89 \%$ (MOE, 2010) (Figure 18). The largest metropolitan cities register the highest supply rates: Seoul (100\%), Busan (99\%), Daegu (98\%) and Gwangju (98\%). The lowest levels of wastewater treatment can be found in the more rural provinces of Chungcheongnam-do (64\%), Jeollanamdo (68\%) and Gyeongsangbuk-do (72\%). Sanitation levels in Asian cities are highly correlated with income levels: all residents have access to sanitation services in Seoul, as in Osaka and Singapore. Findings in Latin American cities indicate that a sharp division exists between the provision of sanitation services and wastewater treatment. Seoul has actively implemented sanitation policies, including regular monitoring of treatment facilities and public awareness campaigns. Seoul has a higher share of sanitation access than the average rate in Latin American cities surveyed (93\%), as well as a higher rate of treated wastewater (an average of 52\% for Latin American cities surveyed) (The Economist Intelligence Unit, 2010).

Gangwon-do has introduced a number of policy initiatives, including education campaigns and reinforced monitoring efforts (Gangwon-do, 2010). 
Figure 18. Sewage system supply rate in Korea, by region

2010

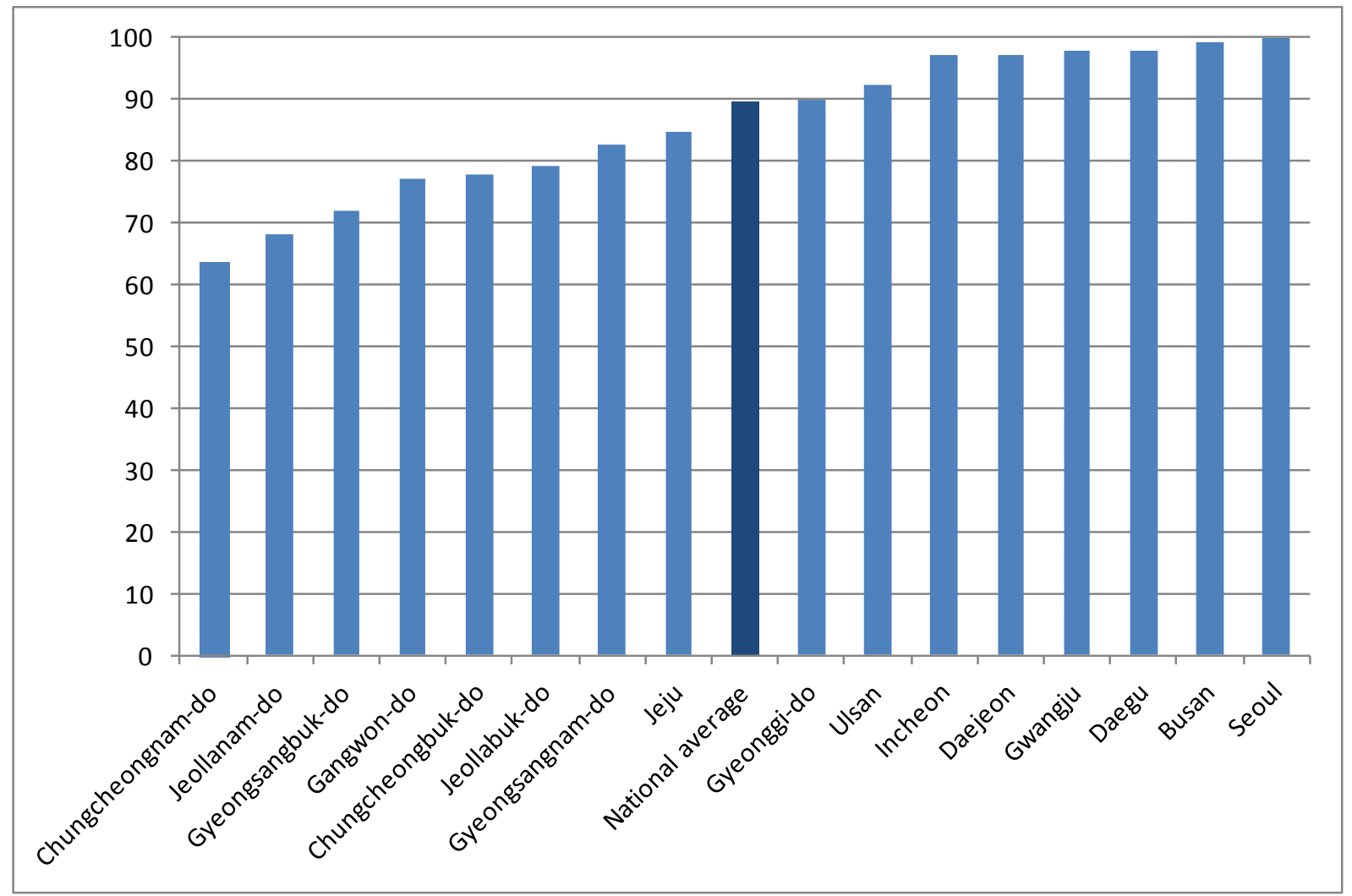

Source: Ministry of Environment, 2010 (2010 Environmental Statistics Yearbook, MOE, Gyeonggi-do).

Waste recycling has improved, albeit unevenly, in Korean cities. Nearly $82 \%$ of total waste was recycled in 2009 , followed by landfill (11\%), incineration (5\%) and sea disposal (2\%). Recycling increased by $91 \%$ between 2000 and 2009 due to policies imposing strict separate garbage collection regulations and increased public education. The largest levels of waste recycling can be observed in relatively small-sized cities, such as Gwacheon-si (98\%, located in the province of Gyeonggi-do), Gwangyang-si (97\%, Jeollanam-do), Pocheon-si (94\%, Gyenggi-do) and Taebaek-si (94\%, Gangwon-do). On the contrary, cities with the highest levels of waste going to landfills tend to be the most industrialised cities, such as Boryeong-si (38\%, located in Chungcheongnam-do), Jeonju-si (33\%, in Jeollabuk-do), Yeosu-si (34\%, in Jeollanam-do), Siheung-si (28\%, in Gyeonggi-do) and Incheon (29\%) (MOE, 2010). The waste recycling ratio in metropolitan cities, with the exception of Incheon, were near the national average: Seoul (86\%), Busan (84\%), Daegu (78\%), Daejeon (78\%) and Ulsan (78\%). Even though theses largest cities' improvements are remarkable, central and local governments should continue to make efforts to increase the share of recycled waste, given their overall large share of waste generation (33\% of the national total).

Water supply also varies across Korean cities, with the highest levels of access to clean water found in metropolitan cities and the lowest levels in more rural provinces. All or nearly all residents have access to clean water in Seoul (100\%), Busan (99.9\%), Daegu (99.8\%), Incheon (97.9\%), Gwangju (98.5\%), Daejeon (99.5\%) and Ulsan (96.5\%). Most provinces, with the exception of Jeju, record lower rates of access to clean water. In 2009, Chuncheongnam-do recorded the lowest ratio of $71.4 \%$, followed by Jeollanam-do 73.5\%. Only Gyeonggi-do reached over 95\% (MOE, 2010). 
Seoul has implemented water efficiency codes and strategies to improve and monitor water quality and pollution standards, in addition to promoting public awareness about water conservation, but water shortages have been identified as an environmental vulnerability in the face of climate change (The Economist Intelligence Unit, 2011). Among a selection of Asian and Latin American cites, Seoul's water consumption rate falls at just above the average for Asian cities surveyed, with 311 litres per person per day, in line with Singapore and Tokyo (Figure 20). Only 7\% of water is lost due to leaky pipes in Seoul, in line with Osaka (6.9\%) and Shanghai (10.2\%). Seoul's consumption rate is slightly higher than the average rate among the European cities (288 litres/person/day) and Latin American cities surveyed (264 litres/person/day) (The Economist Intelligence Unit, 2009; The Economist Intelligence Unit, 2010).

Figure 19. Per capita water consumption in select cities

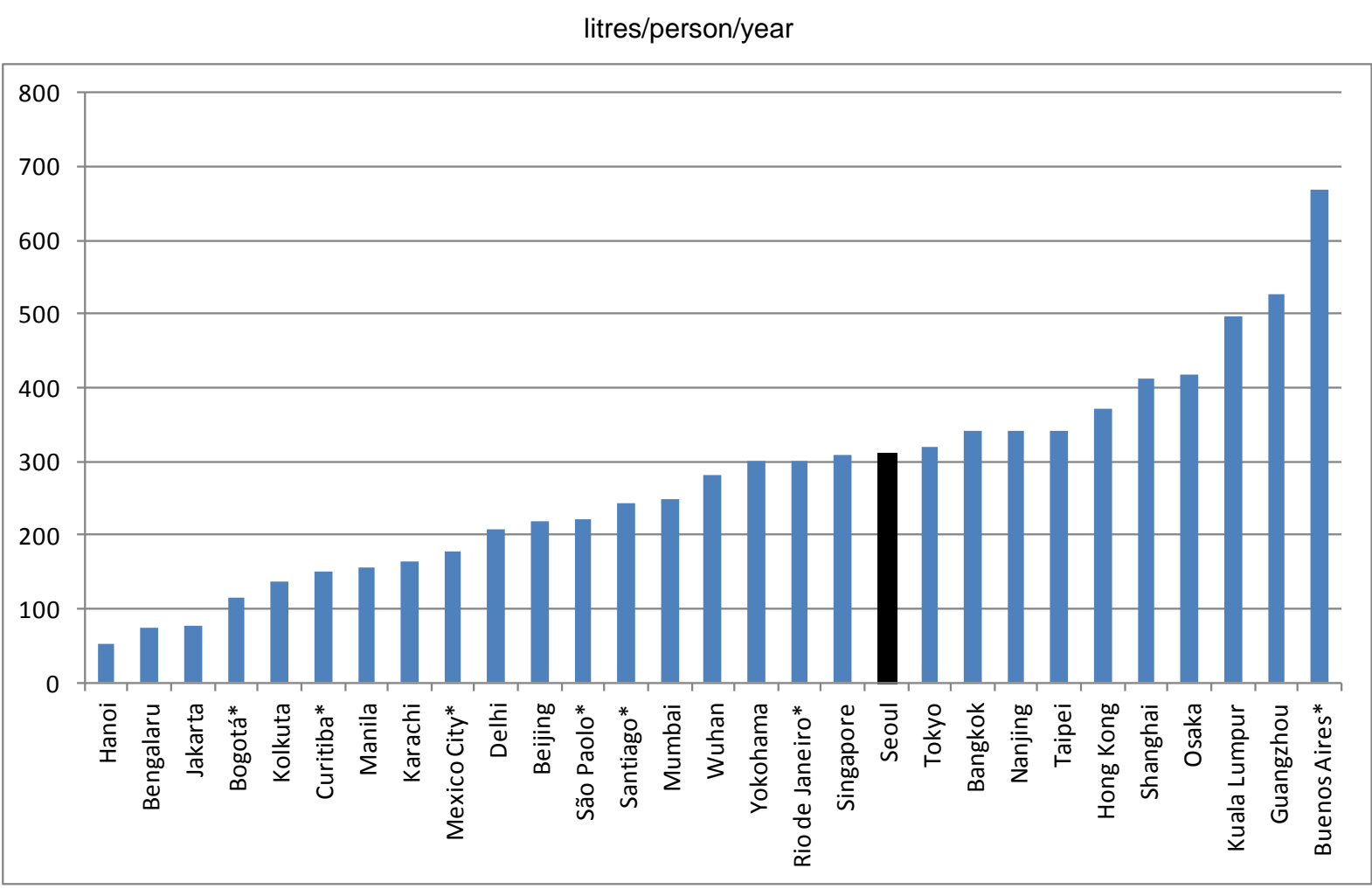

Note: Data from a selection of Latin American cities are presented here.

Source: Asian Green City Index, Latin American Green City Index.

\section{Observed changes in climate and their potential impacts on Korean cities}

Climate change impacts pose a significant threat to Korea's urban population, infrastructure and economic well-being. Cities concentrate people, infrastructure and economic activity, and as a result are particularly threatened by climate change. Cities in coastal or riverine locations, in resource-dependent regions and in locations at risk from extreme weather events, especially those undergoing rapid urbanisation or whose economies are closely linked with climate-sensitive, are especially vulnerable (IPCC, 2001 and 2007). In Korea, a country surrounded on three sides by the sea, a large share of cities rely on the sea for the fishing industry, the development of coastal areas for tourism and housing and port operations. Three key trends that threaten urban areas in Korea: (i) rising sea levels and sea temperatures; (ii) increasing precipitation; and (ii) rising surface temperature. 
(i) Rising sea levels and sea temperatures. Sea levels in Korea have risen on average by $4.02 \mathrm{~mm}$ per year between 1993 and 2008, 30\% higher than the global average of $3.16 \mathrm{~mm}$ per year (Cho. K., et al, 2009). The most significant increases have been observed in the South Sea $(4.66 \mathrm{~mm})$, the East Sea $(3.86 \mathrm{~mm})$ and the West Sea $(4.18 \mathrm{~mm})$. Rising sea levels have also been observed at key ports (Table 13), with the highest increases in sea levels recorded at the ports of Seoguipo $(0.6 \mathrm{~mm})$ and Jeju $(0.5 \mathrm{~mm})$ between 1960 and 2006. Sea temperatures have also increased. Between 1968 and 2002, the temperature of the South Sea increased by $0.93^{\circ} \mathrm{C}$, the West Sea by $0.81^{\circ} \mathrm{C}$ and the East Sea by $0.79^{\circ} \mathrm{C}(\mathrm{MOE}$ and NIER, 2010). These trends increase the potential for coastal erosion and severe flooding, thereby putting populations and infrastructure at risk and inevitably obliging coastal residents to migrate inland. The fishing industry and the local livelihoods associated with the industry are also threatened. Rising temperatures put a number of marine species at risk. For example, the catch of Wall-Eye Pollack has decreased dramatically, while the catch of the squid, generally caught in warmer seas, has been on the rise. Sea levels and temperatures are expected to continue to rise in Korea (MOE and NIER, 2010), further exacerbating risks to inhabitants, infrastructure and industry.

Table 13. Rising sea levels observed at key Korean ports

Increase (mm) between 1960 and 2006

\begin{tabular}{|l|l|l|l|l|l|l|l|l|l|}
\hline & Sokcho & Mookho & Ulleungdo & Busan & Yeosu & Jeju & Seoguipo & Mokpo & Gunsan \\
\hline $\begin{array}{l}\text { Increase in } \\
\text { sea level }\end{array}$ & 0.2 & 0.06 & 0.2 & 0.2 & 0.2 & 0.5 & 0.6 & 0.08 & 0.1 \\
\hline
\end{tabular}

Source: Korean Environmental Institute, 2009, Economic Analysis on Climate Change of Korea, KEI, Seoul, Korea.

(ii) Increasing precipitation. Consistent with global trends, between 1996 and 2005, average precipitation increased in Korea by $10 \%$ (KMA, 2008). During this period, the number of days with over $80 \mathrm{~mm}$ of precipitation increased from 20 to 28 days (KMA, 2008). The maximum precipitation per hour, one of the main causes of floods, increased from $94.6 \mathrm{~mm}$ per hour in the 1990s to $97.4 \mathrm{~mm}$ per hour in the following decade (KEI, 2009). Increased precipitation can hamper local and national development because authorities are obliged to spend scarce technical, human and financial resources on recovery efforts. Between 1999 and 2008, the provinces of Gangwon-do, Gyeongsangnam-do and Gyeongsangbuk-do recorded the highest levels of flood damage, which affected over 113000 residents and totaled KRW 7.1 trillion in damages (MOE, 2009; National Emergency Management Agency, 2009).

(iii) Rising surface temperatures and heat waves. From 1971 to 2000, average annual temperatures increased by $1.44^{\circ} \mathrm{C}$ (MOE, 2010). Average surface temperatures in major cities, such as Incheon, Suwon, Daegu and Ulsan, increased more rapidly than those in less populated rural areas (Yongduck-Gun and Haenam-Gun) (Figure 20). Korean authorities have attributed this rise in temperatures in part to increasing urbanisation (MOE and NIER, 2010). Rising temperatures have resulted in changes to ecosystems. The Hongnung Arboretum in Seoul, for example, recorded shifts in the flowering period for over half of local plant species (Kim, S., J. Sung and Y. Kim, 2009). The IPCC has also determined that it is likely that climate change has led to more frequent and more intense heat waves, which threaten public health (heat exhaustion, heatstroke, or even death), and may disproportionately affect different age groups and regions. Senior citizens, for example, were among the most affected populations during the 1994 heat wave in Seoul (Choi et al., 2005). 
Figure 20. Rising average temperatures in Korean cities

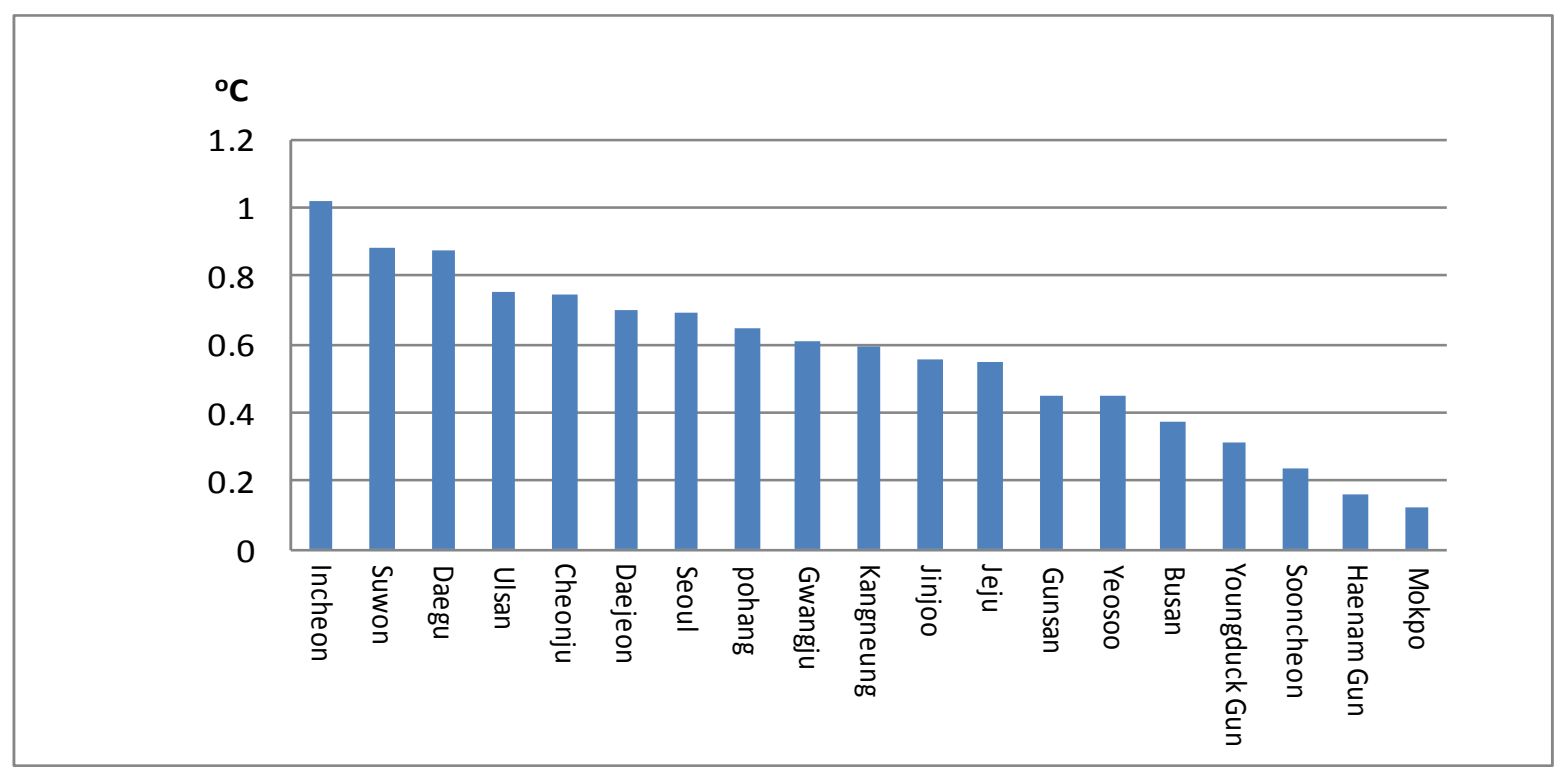

1. Difference in the average temperature from 1971 to 1999 and from 2000 to 2009.

Source: Own calculations based on data from Korea Meteorological Administration.

Sea levels, sea and surface temperatures, and both the frequency and intensity of extreme weather events (flooding, heat waves, cold fronts) are expected to continue to rise over time in Korea, as well as globally (MOE and NIER, 2010; IPCC, 2007). The Korean government has estimated that, assuming a $4^{\circ} \mathrm{C}$ increase in temperature, combined economic losses from agricultural, coastal development and human health costs due to climate change will result in a 5.6\% drop in GDP by 2100 relative to 2008 levels (MOE, 2008). Recent OECD work on assessing the vulnerability of port cities to climate extremes estimated that a combined 294000 inhabitants and assets totaling USD 33.3 billion are threatened by rising sea levels and extreme weather events in three Korean port cities - Busan, Incheon and Ulsan (OECD, 2007). These findings underscore the need for urban policies that address climate change mitigation and local adaptation. Adaptation policies, including urban infrastructure reinforcement, the efficient management of food resources and strategic land use planning that focuses new development away from floodplains, can help manage the economic, health and human risks associated with climate change.

\section{The Korean green growth strategy and the role of local governments}

\section{Green growth: a new national growth paradigm to emerge from the financial crisis}

The Korea's National Strategy for Green Growth to 2050, launched in 2009, specifies three objectives:

1. Promote a synergistic relationship between economic growth and environmental protection;

2. Improve quality of life and promote a green revolution in Korean lifestyles; and

3. Contribute to international efforts to fight climate change and other environmental threats. 
These objectives organise the country's long-term green growth vision around three strategic pillars:

1. Mitigating climate change and promoting energy independence;

2. Creating new engines for economic growth; and

3. Improving the quality of life and enhancing Korea's international standing.

To implement the National Strategy for Green Growth, the Five-year Plan identifies specific policies, quantifiable objectives and concrete projects to help achieve green growth (Table 14). For example, to mitigate climate change, the Five-year Plan proposes to reduce greenhouse gas emissions by developing a mandatory inventory of industrial emissions, a first step toward the creation of a domestic carbon market, and promoting the sustainable management and restoration of forests. To measure success, two quantitative objectives are cited: transform 400000 ha of wasteland into forest and introduce a downward trend in greenhouse gas emissions.

Table 14. Strategic objectives of Korea's Five-year Plan for Low-carbon, Green Growth (2009-2013)

\begin{tabular}{|c|c|c|c|}
\hline Strategic pillar & Strategic axis & Quantitative objective & Project \\
\hline \multirow[t]{3}{*}{$\begin{array}{l}\text { Mitigate climate } \\
\text { change and promote } \\
\text { energy } \\
\text { independence }\end{array}$} & $\begin{array}{l}\text { Effective mitigation of } \\
\text { GHG emissions }\end{array}$ & $\begin{array}{l}\text { - Transform } 400000 \text { ha of waste land } \\
\text { into forest } \\
\text { - Introduce a downward trend of } \\
\text { GHG emissions based on a } \\
\text { voluntary agreement }\end{array}$ & $\begin{array}{l}\text { - Mandatory inventory of } \\
\text { industrial GHG emissions as a } \\
\text { first step toward the creation of } \\
\text { a domestic carbon market) } \\
\text { - Restoration of damaged } \\
\text { forests, reforestation and } \\
\text { sustainable forest management } \\
\text { programmes }\end{array}$ \\
\hline & $\begin{array}{l}\text { Reduction of the use of } \\
\text { fossil fuels and the } \\
\text { enhancement of } \\
\text { energy independence }\end{array}$ & $\begin{array}{l}\text { - Increase energy efficiency from } \\
0.317 \text { tep/ USD } 1000 \text { in } 2009 \text { to } \\
0.233 \text { tep/ USD } 1000 \text { by } 2020 \\
\text { - Increase share of renewable energy } \\
\text { from } 2.7 \% \text { in } 2009 \text { to } 6.08 \% \text { by } \\
2020 \text { and } 20 \% \text { by } 2050 \\
\text { - Increase share of nuclear energy } \\
\text { from } 37 \% \text { in } 2009 \text { to } 32 \% \text { by } 2020 \\
\text { - Increase energy self-sufficiency rate } \\
\text { to } 65 \% \text { in } 2030\end{array}$ & $\begin{array}{l}\text { - Construction of } 12 \text { new nuclear } \\
\text { reactors } \\
\text { - Construction of a } 2 \mathrm{MW} \text { wind } \\
\text { complex } \\
\text { - Increase share of photovoltaic } \\
\text { (PV) solar panel installations } \\
\text { - Construction of tidal power } \\
\text { plants }\end{array}$ \\
\hline & $\begin{array}{l}\text { Strengthening the } \\
\text { capacity to adapt to } \\
\text { climate change }\end{array}$ & $\begin{array}{l}\text { - Increase share of environmentally } \\
\text { friendly food products from } 4.5 \% \text { in } \\
2009 \text { to } 18 \% \text { by } 2020 \\
\text { - Increase volume of protected forest } \\
\text { resources from } 862 \text { million cubic } \\
\text { metres in } 2009 \text { to } 1087 \text { million cubic } \\
\text { metres by } 2020\end{array}$ & $\begin{array}{l}\text { - Creation of a watchdog unit to } \\
\text { monitor climate change } \\
\text { impacts } \\
\text { - Strengthening of international } \\
\text { cooperation for food safety } \\
\text { - River retrofit and restoration of } \\
\text { the four principal rivers of the } \\
\text { country, including the } \\
\text { construction of dams and } \\
\text { infrastructure for water } \\
\text { treatment and distribution } \\
\text { - Extension of forest ecosystem } \\
\text { protection zones }\end{array}$ \\
\hline $\begin{array}{l}\text { Create new engines } \\
\text { for economic growth }\end{array}$ & $\begin{array}{l}\text { Development of green } \\
\text { technologies }\end{array}$ & $\begin{array}{l}\text { - Increase share of Korean green } \\
\text { technological firms in the global } \\
\text { market from } 2 \% \text { in } 2009 \text { to } 10 \% \text { by } \\
2020 \\
\text { - Increase number of foreign experts } \\
\text { in green technologies working in } \\
\text { Korea from } 25 \text { in } 2009 \text { to } 250 \text { by } \\
2020\end{array}$ & $\begin{array}{l}\text { - Increased investment in R\&D } \\
\text { through the support of the } \\
\text { National Council of Sciences } \\
\text { and Technologies } \\
\text { - Creation of an appropriate } \\
\text { financial system to finance } \\
\text { innovation } \\
\text { - Facilitation of technology } \\
\text { transfers through collaborative } \\
\text { agreements with leading } \\
\text { international research institutes }\end{array}$ \\
\hline
\end{tabular}




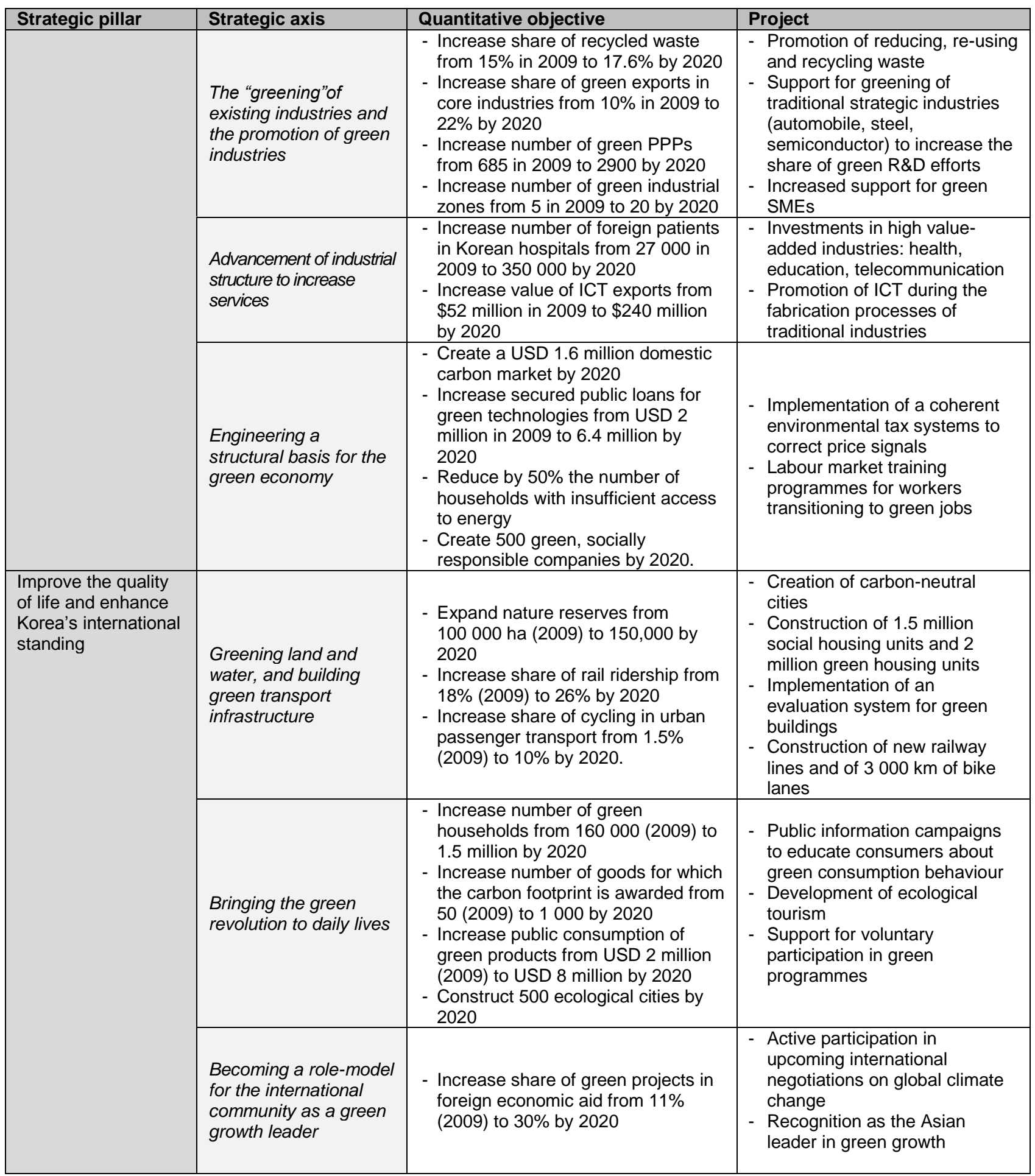

Source: The Presidential Committee on Green Growth (2009).

The Five-year Plan also assigns budget allocations from the national budget to each strategic pillar. Over half of the five-year spending is attributed to climate change adaptation and mitigation efforts and the development of clean sources of energy, while the creation of new economic engines and projects to improve living standards and enhance Korea's international status each receive about a quarter of the overall national budget (The Presidential Committee on Green Growth (PCGG), 2009). Approximately 
KRW 61 trillion - representing over half of the total budget for the Five-year plan - is allocated to two major infrastructure projects: the ongoing expansion of Korea's high-speed rail network, Korea Train Express (KTX), and the Four Major Rivers Restoration project, a large-scale sustainable water resources management initiative. In contrast, spending on R\&D accounts for just $12 \%$ of the Five-year Plan (Table 15).

Table 15. Budget allocation of Korea's Five-year Plan for Low-carbon, Green Growth

Trillion $\mathrm{KRW}^{1}$

\begin{tabular}{|c|c|c|c|c|c|c|}
\hline & Total & 2009 & 2010 & 2011 & 2012 & 2013 \\
\hline Total & 107.4 & 17.4 & 24.2 & 25.7 & 20.6 & 19.4 \\
\hline Central government budget & 98.9 & 17.4 & 20.5 & 21.9 & 19.6 & 19.4 \\
\hline Public enterprises' investment & 8.5 & - & 3.7 & 3.8 & 1.0 & - \\
\hline $\begin{array}{l}\text { Memorandum item: total green technology R\&D investment in all } \\
\text { categories }\end{array}$ & $(13.0)$ & (1.9) & (2.2) & (2.5) & (2.8) & (3.5) \\
\hline $\begin{array}{l}\text { 1. Climate change adaptation and mitigation \& enhancing } \\
\text { energy independence }\end{array}$ & 57.5 & 8.5 & 15.5 & 16.0 & 9.8 & 7.7 \\
\hline $\begin{array}{l}\text { Effective mitigation of greenhouse gas emissions } \\
\text { Reduction of the use of fossil fuels and the enhancement of }\end{array}$ & 5.4 & 1.0 & 0.9 & 1.0 & 1.1 & 1.3 \\
\hline energy independence & 15.4 & 2.8 & 3.8 & 2.9 & 3.0 & 2.8 \\
\hline $\begin{array}{l}\text { Strengthening the capacity to adapt to climate change } \\
\text { (Four Major Rivers Restoration Project) }\end{array}$ & $\begin{array}{l}36.7 \\
(15.4)\end{array}$ & $\begin{array}{l}4.7 \\
(0.8)\end{array}$ & $\begin{array}{l}10.9 \\
(6.4)\end{array}$ & $\begin{array}{l}12.0 \\
(7.1)\end{array}$ & $\begin{array}{l}5.6 \\
(1.1)\end{array}$ & $\begin{array}{ll}3.6 \\
(-)\end{array}$ \\
\hline 2. Create new engines for economic growth & 23.5 & 3.9 & 4.1 & 4.7 & 5.3 & 5.6 \\
\hline Development of green technologies & 7.6 & 1.5 & 1.4 & 1.5 & 1.5 & 1.6 \\
\hline $\begin{array}{l}\text { The "greening" of existing industries and promotion of green } \\
\text { industries }\end{array}$ & 45 & 07 & 09 & 09 & 10 & \\
\hline Advancement of industrial structure to increase services & $\begin{array}{l}4.5 \\
9.7\end{array}$ & 0.1 & 0.9 & 0.9 & 1.0 & 1.0 \\
\hline Engineering a structural basis for the green economy & 1.8 & 0.3 & 0.2 & 0.3 & $\begin{array}{l}2.4 \\
0.4\end{array}$ & $\begin{array}{l}2.5 \\
0.5\end{array}$ \\
\hline $\begin{array}{l}\text { 3. Improve the quality of life and enhance Korea's } \\
\text { international standing }\end{array}$ & 26.4 & 5.0 & 4.6 & 5.1 & 5.6 & 6.1 \\
\hline $\begin{array}{l}\text { Greening the land and water and building the green transport } \\
\text { infrastructure }\end{array}$ & 23.9 & 4.6 & 4.2 & 4.6 & 5.0 & 5.5 \\
\hline $\begin{array}{l}\text { Bringing the green revolution to daily lives } \\
\text { Becoming a role-model for the international community as a }\end{array}$ & 1.8 & 0.3 & 0.3 & 0.3 & 0.4 & 0.4 \\
\hline green growth leader & 0.7 & 0.1 & 0.1 & 0.1 & 0.1 & 0.1 \\
\hline
\end{tabular}

1. Actual budgets for 2009-10 and projections for 2011-13.

Source: OECD (2010), based on Ministry of Strategy and Finance and Presidential Committee on Green Growth (2009).

\section{The necessity of incorporating the urban dimension}

The Korean green growth agenda has been driven by a central government vision and strategy. The Presidential Committee on Green Growth, formed in 2009 to co-ordinate the agenda-setting, policy formation, monitoring and evaluation of green growth programmes at all levels of government, is composed of scientific experts and representatives from ministries, academia and the private sector. The role of sub-national governments has primarily been to comply with the instructions of the central government to implement local green growth projects with considerable, if not exclusive, financial support of the central government. Some exceptions do exist. Seoul, notably, has been a pioneer in green growth, with several decades of pro-active land use and transportation policies preceding the launch of the national government's National Strategy for Green Growth.

Korea's top-down approach to green growth is not unexpected. National policy has historically shaped local spatial and economic development in Korea. Policies and funding regimes pertaining to land use and density, economic development and transportation are formulated by a handful of ministries within the central government, with at times conflicting objectives. Local governments generally exercise control over the management of urban services, including local transportation networks, but tend to rely heavily on 
the financial support of the central government to operate these facilities. Nonalignment of related urban policies at the ministerial level, coupled with limited financial resources at the local level, can present considerable challenges to advance the green growth agenda at the local scale. Indeed, several of the current obstacles faced by local authorities in Korea (which will be discussed in further detail below) are not new, but instead reflect existing institutional challenges in Korea's traditional approach to land use, environmental and economic development planning.

Nevertheless, even a nationally-led, top-down institutional approach to green growth, as in the case of Korea, is compelled to incorporate an urban dimension due to the concentration of economic activity and production, infrastructure and energy consumption in cities. The effective management and organisation of urban areas is essential to greening environments at all scales. Green growth, in particular, hinges on compact urban form with robust transportation and public service linkages in order to support economic growth while reducing energy and natural resource consumption. Coastal and riverine areas, particularly vulnerable to climate change, can be made more resilient through targeted adaptation measures which aim to protect human and economic assets. Moreover, as mentioned previously, emissions reductions at the national level call for special attention of urban areas. With approximately $82 \%$ of its population living in urban areas, Korea had the fourth-highest energy intensity in the OECD area in 2008 and was the ninthlargest emitter of greenhouse gases in the OECD area (Jones, R. and B. Yoo, 2010). For Korea to achieve its national emissions reduction target of $30 \%$ by 2020 , sub-national governments must be an integral part of the strategy toward greener growth.

Further, policies elaborated at the national level must be implemented locally. This is especially true within a number of sectors integral to advancing greener growth that represent significant sources of local economic growth and, to a considerable extent, fall under the purview of sub-national governments, such as transportation, building and infrastructure. Hence, when national policies target low-carbon transportation, green buildings and cleaner, more efficient infrastructure networks, local jurisdictions play a role in translating the national vision into effective implementation strategies at the urban level. Korea's plans to construct transit centres in metropolitan cities and $3000 \mathrm{~km}$ of bike lanes, for example, will require co-ordination with local authorities to implement and manage the facilities. National policies pertaining to land use and transportation, such as updating building codes and expanding transportation networks, also inform residential and commercial land use patterns and commuting flows to urban areas.

Cities will inevitably serve as testing grounds for the implementation of national green growth policies at the urban level. For instance, the Korean government has historically sponsored demonstration projects in urban and rural areas as a way to localise national policy initiatives. With the launch of the National Strategy for Green Growth, a number of ministries organised competitions and trial projects to partner with local governments to develop green growth model projects, which include the Greening Cities project, the EcoRich City Competition, the Climate Change Adaptation Model City project, the Eco-city project and the Low-carbon, Green Village project. The National Strategy for Green Growth also provides an opportunity for cities to maximise competitiveness, which has been identified as a national urban policy priority, by initiating green growth projects that capitalise on local assets to stimulate local economic growth. Local authorities are well positioned to develop policy and programmatic solutions that best meet specific geographic, climatic, economic and cultural conditions; indeed, the central government explicitly calls upon local governments to tailor programmes to local conditions in the legislation and guidelines that have been drafted in support of green growth in the Framework Act on Low-carbon, Green Growth, described in further detail below. 


\section{The legal and institutional framework guiding green growth implementation at the local level}

The legal and institutional framework guiding the implementation of Korea's National Strategy for Green Growth at the local level consists of: (i) the Framework Act for Low-carbon, Green Growth enacted in 2010, and (ii) the Five-year Green Growth Implementation Plan.

\section{The Framework Act for Low-carbon, Green Growth}

The Framework Act for Low-carbon, Green Growth (hereafter referred to as the Framework Act) establishes the legal basis for implementing the government's National Strategy for Green Growth. The Framework Act articulates the roles of each level of government, the private sector and citizens. It is the primary centralised enabling framework for green growth action at the local level, authorising the central government to develop policy tools to assist local governments in implementing national green growth projects and policies. The contribution of urban planning and infrastructure management to support green growth is made explicit in the third article of the legislation, which grants the central government the authority to "rearrange infrastructure, including national land and cities, buildings and transportation, road, ports and harbours, and waterworks and sewerage systems, to make them suitable for low carbon, green growth while preserving the value of national resources and environment" (Article 3 of the Framework Act).

Local governments, in turn, are called upon to co-operate in full with the State's green growth strategy as follows:

- The Framework Act encourages cities to take local conditions and green growth impacts into account when formulating and executing plans and projects, to intensify green growth education and advocacy among residents and to encourage green growth among businesses, residents and nongovernmental organisations through the provision of information and financial support (Article 5).

- Only metropolitan city and provincial (Do) governments are required to establish and implement a local action plan for green growth in conformity with the national strategy; lower-level governments (at the Si, Gun and $\mathrm{Gu}$ levels) are encouraged, but not required, to develop action plans (Article 11).

- Local governments may establish a committee on green growth, under the control of the mayor/provincial (Do) governor, to review key green growth policies at the local level (Article 20).

- Each mayor/ provincial (Do) governor is also authorised to designate a Green Growth Officer from among public officials to promote green growth at the local level and liaise with the central government to ensure vertical coordination of green growth strategies (Article 21).

- Action plans developed by metropolitan cities and provinces (Do) must be submitted to the local committee on green growth (if one has been designated), the city council and, finally, the Presidential Committee on Green Growth for approval. All sixteen metropolitan cities and provinces $(D o)$ have prepared green growth action plans, which are closely organised around the ten policy directions enumerated in the National Strategy for Green Growth; a handful of lowerlevel cities ( $S i, G u$ and $G u n$ ) have established action plans (Table 16). 
Table 16. Local green growth plans in Korea

\begin{tabular}{|c|c|c|}
\hline $\begin{array}{l}\text { Metropolitan city } \\
\text { or province }(D o)\end{array}$ & Name of green growth plan & $\begin{array}{l}\text { Lower-level tiers of government (Si, Gun and } \mathrm{Gu} \text { ) that } \\
\text { have established green growth plans }\end{array}$ \\
\hline Seoul & Five-year Green Growth Plan & $\begin{array}{l}4 \text { out of } 25 \text { Gus (Jung-gu, Seongdong-gu, Dongjak-gu, } \\
\text { Seocho-gu) }\end{array}$ \\
\hline Busan & $\begin{array}{l}\text { Green Growth Strategy and } \\
\text { Five-year Implementation Plan }\end{array}$ & -- \\
\hline Daegu & $\begin{array}{l}\text { Green Growth Implementation } \\
\text { Plan }\end{array}$ & 2 Gus out of 7 Gus and 1 Gun (Nam-gu, Dalseo-gu, \\
\hline Incheon & $\begin{array}{l}\text { Green Growth Implementation } \\
\text { Plan }\end{array}$ & -- \\
\hline Gwangju & Five-year Green Growth Plan & 1 out of 5 Gus (Gwangsan-gu) \\
\hline Daejeon & $\begin{array}{l}\text { Green Growth Implementation } \\
\text { Plan }\end{array}$ & -- \\
\hline Ulsan & Five-year Green Growth Plan & -- \\
\hline Gyeonggi-do & $\begin{array}{l}\text { Comprehensive Green Growth } \\
\text { Implementation Plan }\end{array}$ & $\begin{array}{l}15 \text { out of } 27 \text { Sis and } 2 \text { out of } 4 \text { Guns (Suwon-si, } \\
\text { Uijeongbu-si, Ahyang-si, Pyeongtaek-si, Dongducheon- } \\
\text { si, Ansan-si, Namyangju-si, Osan-si, Siheung-si, } \\
\text { Gunpo-si, Hanam-si, Yongin-si, Gimpo-si, Hwaseong- } \\
\text { si, Yangju-si, Yeoju-gun, Yangpyeong-gun) }\end{array}$ \\
\hline Gangwon-do & Five-year Green Growth Plan & $\begin{array}{l}2 \text { out of } 7 \text { Sis and } 2 \text { out of } 11 \text { Guns: Wonju-si, Taebaek- } \\
\text { si, Yeongwol-gun, Cheorwon-gun }\end{array}$ \\
\hline $\begin{array}{l}\text { Chungchengbuk- } \\
\text { do }\end{array}$ & $\begin{array}{l}\text { Green Growth Implementation } \\
\text { Plan }\end{array}$ & 1 Gun out of 9 Guns and 3 Sis: Cheongwon-gun \\
\hline $\begin{array}{l}\text { Chungchengnam- } \\
\text { do }\end{array}$ & $\begin{array}{l}\text { Green Growth Strategy and } \\
\text { Implementation Plan }\end{array}$ & $\begin{array}{l}3 \text { out of } 7 \text { Sis and } 8 \text { out of } 9 \text { Guns: Cheonan-si, } \\
\text { Nonsans-si, Gyeryong-si, Geumsan-gun, Buyeo-gun, } \\
\text { Seocheon-gun, Cheongyang-gun, Hongseong-gun, } \\
\text { Yesan-gun, Dangin-gun, Taean-gun }\end{array}$ \\
\hline Jeollabuk-do & Five-year Green Growth Plan & 2 out of 6 Sis and 8 Guns: Kunsan-si, Namwon-si \\
\hline Jeollanam-do & Five-year Green Growth Plan & $\begin{array}{l}2 \text { out of } 5 \text { Sis and } 5 \text { out of } 17 \text { Guns: Yeosu-si, } \\
\text { Gwangyang-si, Damyang-gun, Gokseong-gun, } \\
\text { Hwasun-gun, Jangseong-gun, Jindo-gun }\end{array}$ \\
\hline $\begin{array}{l}\text { Gyeongsangbuk- } \\
\text { do }\end{array}$ & $\begin{array}{l}\text { Low Carbon, Green Growth } \\
\text { Implementation Plan }\end{array}$ & $\begin{array}{l}4 \text { out of } 10 \text { Sis and } 3 \text { out of } 13 \text { Guns: Pohang-si, } \\
\text { Gimcheon-si, Ahdong-si, Gumi-si, Uiseong-gun, } \\
\text { Goryeong-gun, Bonghwa-gun }\end{array}$ \\
\hline $\begin{array}{l}\text { Gyeongsangnam- } \\
\text { do }\end{array}$ & $\begin{array}{l}\text { Green Growth Implementation } \\
\text { Plan }\end{array}$ & $\begin{array}{l}2 \text { out of } 10 \text { Sis and } 3 \text { out of } 10 \text { Guns: Tongyeong-si, } \\
\text { Gimhae-si, Changyeong-gun, Hadong-gun, } \\
\text { Sancheong-gun }\end{array}$ \\
\hline Jeju & $\begin{array}{l}\text { Low Carbon, Green Growth } \\
\text { Five-year Plan }\end{array}$ & -- \\
\hline
\end{tabular}

Source: Based on responses to the OECD questionnaire to Korean local governments.

Beyond the requirements set forth in the Framework Act, the National Strategy for Green Growth directly and indirectly impacts local urban policies and planning, even in cities for which the development of a local action plan is not mandated. Most local green growth projects are financially supported, at least in part, by the central government in the form of inter-governmental transfers and matching funds. Many of these financial resources are earmarked for specific uses; for instance, the financing of construction costs for a subway line in metropolitan cities is split between the central government $(60 \%)$ and local government (40\%), except in the case of Seoul, where the central government covers only $40 \%$ of construction costs according to the Rules for construction and support of subway lines. Seoul's budget is financed in roughly equal shares by the local government (50\%) and private sources (45\%), with only $5 \%$ coming from central government sources (based on responses to OECD questionnaire to local governments, 2011). This is in sharp contrast to most other metropolitan cities and provinces, where 
central government funding is expected to contribute between 25 and $82 \%$ of the budget. It is also notable that several of the provincial governments have projected very large budgets to implement their green growth plans, yet have not provided any indication of the sources of this funding (Gyeonggi-do, Jeollanamdo, Gwangju, Gyeongsangnam-do, for example). This issue will be discussed further in the next section.

\section{The Five-year Green Growth Implementation Plan}

The Five-year Green Growth Implementation Plan, though non-binding, is designed to build national consensus around green growth and incorporate green growth spending in the national budget by identifying policies, objectives and concrete projects that can be implemented in support of the national strategy.

As mandated by the Framework Act, most sub-national governments (i.e. upper tier of local governments including metropolitan city and provincial $(D o)$ governments) have drafted five-year plans to implement local policies and projects to help meet the national green growth goals (Table 16). Most local actions are focused on greenhouse gas emissions mitigation and include plans to increase energy efficiency through the introduction of smart grid systems, curb emissions through green building retrofits, expand public transportation networks, foster the development of emerging green technologies and the greening of existing industrial sectors and develop eco-tourism sites (Table 17).

Table 17. Local actions for green growth

Elements of the five-year implementation plans of metropolitan city and provincial $(D o)$ governments

\begin{tabular}{|c|c|}
\hline $\begin{array}{l}\text { Metropolitan city / } \\
\text { province (Do) }\end{array}$ & Key Actions \\
\hline Seoul & $\begin{array}{l}\text { Introduce a smart grid network } \\
\text { Improve the energy efficiency of public buildings } \\
\text { Select and support "ten green technologies" } \\
\text { Reinforce the climate change monitoring system }\end{array}$ \\
\hline Busan & $\begin{array}{l}\text { Develop a smart grid cluster at the new port } \\
\text { Reinforce climate-friendly ocean management } \\
\text { Green traditional industries (i.e. automobile industry) } \\
\text { Establish open space networks }\end{array}$ \\
\hline Daegu & $\begin{array}{l}\text { Select and support seven green technologies } \\
\text { Green existing industries } \\
\text { Increase energy efficiency in the building and transportation sectors } \\
\text { Enhance sustainable forest management }\end{array}$ \\
\hline Incheon & $\begin{array}{l}\text { Establish green foundations } \\
\text { Increase forest area within the city } \\
\text { Construct a tidal plant }\end{array}$ \\
\hline Gwangju & $\begin{array}{l}\text { Promote the recycling of waste } \\
\text { Reinforce standards for disaster prevention facilities } \\
\text { Green existing industries } \\
\text { Implement a pilot carbon emissions trading scheme among public administrative agencies }\end{array}$ \\
\hline Daejeon & $\begin{array}{l}\text { Develop the Environment-Energy complex town } \\
\text { Reinforce the disaster response system } \\
\text { Expand the subway system with the construction of a new line } \\
\text { Expand the supply of renewable energy }\end{array}$ \\
\hline Ulsan & $\begin{array}{l}\text { Develop CDM projects } \\
\text { Develop an eco-industrial complex } \\
\text { Support the greening of the automobile, ship, petrochemical, technology industries } \\
\text { Establish an open space network }\end{array}$ \\
\hline Gyeonggi -do & $\begin{array}{l}\text { Develop an eco-industrial district, including green energy, eco-friendly vehicles and R\&D } \\
\text { Construct three GTX(Great Train eXpress) lines around the Capital area } \\
\text { Introduce a programme to plant } 100 \text { million trees } \\
\text { Green the university campus }\end{array}$ \\
\hline
\end{tabular}




\begin{tabular}{|c|c|}
\hline $\begin{array}{l}\text { Metropolitan city / } \\
\text { province }(D o)\end{array}$ & Key Actions \\
\hline Gangwon-do & $\begin{array}{l}\text { Reduce } \mathrm{CO}_{2} \text { emissions from the cement factory } \\
\text { Construct photovoltaic power generation sites } \\
\text { Maintain Korea's eastern coast } \\
\text { Reduce the use of chemical fertilizer }\end{array}$ \\
\hline Chungcheongbuk-do & $\begin{array}{l}\text { Promote solar-powered houses, targeting 5,000 households by } 2012 \\
\text { Support restoration of the Han River and the Geumgang River } \\
\text { Support the development of the solar energy industry } \\
\text { Increase the use of biomass energy }\end{array}$ \\
\hline Chungcheongnam-do & $\begin{array}{l}\text { Reduce greenhouse gas emissions from four thermal power plants } \\
\text { Develop four green technology clusters } \\
\text { Support five leading industries, including green cars, solar fuel cells and LED } \\
\text { Reinforce health care to prevent the spread of infectious diseases }\end{array}$ \\
\hline Jeollabuk-do & $\begin{array}{l}\text { Develop a low-carbon, green village demonstration project } \\
\text { Build a green technology/R\&D complex and an eco- industrial complex } \\
\text { Establish an eco-tourism site } \\
\text { Reinforce local resiliency to potential disasters associated with the river }\end{array}$ \\
\hline Jeollanam-do & $\begin{array}{l}\text { Develop an eco-friendly transportation network } \\
\text { Reinforce the management of coastal areas to protect against rising sea levels } \\
\text { Build } 50 \text { eco-friendly agricultural complexes } \\
\text { Promote eco-tourism }\end{array}$ \\
\hline Gyeongsangbuk-do & $\begin{array}{l}\text { Restore the Nakdong River } \\
\text { Green the agriculture and fishing industries } \\
\text { Develop Ulleung-do as carbon-zero island } \\
\text { Construct a hydrogen highway along the eastern coast of Korea }\end{array}$ \\
\hline Gyeongsangnam-do & $\begin{array}{l}\text { Select and foster } 10 \text { green technologies, including smart ships, wind power and energy } \\
\text { storage facilities } \\
\text { Construct hydrogen fuel cell generation facilities } \\
\text { Develop } 20 \text { low-carbon green cities } \\
\text { Restore the Nakdong river }\end{array}$ \\
\hline Jeju & $\begin{array}{l}\text { Implement a smart grid pilot project targeting } 6,000 \text { households } \\
\text { Expand the renewable energy supply } \\
\text { Introduce a light rail system } \\
\text { Develop a carbon-free tourism site }\end{array}$ \\
\hline
\end{tabular}

Source: The Presidential Committee on Green Growth (2010).

\section{Contributions of local government to green growth in Korea: proposed actions in local five-year plans}

The three strategic pillars that form Korea's National Strategy for Green Growth structure the fiveyear plans of the central government and most local governments: (i) mitigating climate change and promoting energy independence, (ii) creating new engines for economic growth and (iii) improving the quality of life and enhancing Korea's international standing. This section examines the contributions of local governments to the three strategic pillars and associated policy directions of Korea's Five-year Green Growth Plan. Local efforts will be described and, where possible, assessed within the context of the national policy infrastructure for green growth.

\section{(i) Mitigating climate change and promoting energy independence}

Climate change mitigation strategies have been initiated by the Korean government since the 1990s, prior to its ratification of the Kyoto Protocol to the UN Framework Convention on Climate Change in 2002 as a non-Annex I country. These market and non-market mechanisms to combat climate change included voluntary and negotiated reduction targets with companies responsible for the majority of greenhouse gas emissions, increased environmental taxes, energy efficiency programmes, participation in the international carbon market and the creation of a voluntary domestic carbon market (Jones, R. and B. Yoo, 2010). 
With the launch of the National Green Growth Strategy in 2009, the government committed to cut greenhouse gas emissions by $30 \%$ relative to the projected level in 2020, based on the business-as-usual scenario (PCGG, 2009). As mandated by the Framework Act (Article 42), most metropolitan city and provincial $(D o)$ governments have set local targets, adopting the national target of $30 \%$ with respect to BAU. ${ }^{6}$ Although not legally binding, the reduction targets have helped to frame the policy agenda and implicate the involvement of sub-national authorities. Korea's National Five-year Plan identifies three policy directions for mitigating climate change and promoting energy independence: (a) reduce $\mathrm{CO}_{2}$ emissions, (b) enhance energy self-sufficiency by decreasing dependence on fossil fuels, and (c) support climate change adaptation measures. Many local governments have structured their actions around the national framework.

(a) Reducing $\mathrm{CO}_{2}$ emissions: establishing an emissions inventory and target management system

City action to reduce $\mathrm{CO}_{2}$ emissions has been guided by the national emissions reduction target of $30 \%$ by 2020 and the institutional framework put in place by the State, pledging to reduce domestic emissions through the introduction of emission reduction policies, emissions inventories and an international research centre on greenhouse gas emissions. In short, the national policy consists of the following elements:

- To manage sectoral emissions, the Greenhouse Gas and Energy Target Management System introduced mandatory greenhouse gas emissions reductions targets, ${ }^{7}$ requiring companies emitting over 125000 tonnes of $\mathrm{CO}_{2}$ equivalent annually, known as "controlled entities," to negotiate reduction targets and pay fines for non-compliance. These targets will be further reinforced in 2013. In September 2010, the Ministry of the Environment announced that 470 companies in the agriculture, energy, waste, and building and transport sectors had been designated as "controlled entities", together accounting for approximately $60 \%$ of overall greenhouse gas emissions in Korea.

- To facilitate the development of a centralised database and research centre for the collection and management of greenhouse gas emissions data, the government introduced the Greenhouse Gas Inventory and Research Centre (GIR) in June 2010. Prior to the establishment of the GIR, emissions data pertaining to greenhouse gases and air pollution had been collected and managed independently by a handful of ministries, leading to monitoring challenges. Similar to the Committee on Climate Change (CCC) in the United Kingdom, GIR has been tasked with advising the government and private sector on setting and meeting carbon budgets.

At the sub-national level, a handful of metropolitan city and provincial (Do) governments have begun to establish local greenhouse gas inventories in recent years. Among the metropolitan city and provincial (Do) governments, all but three (Incheon, Gwangju, Jeollabuk-do) have created, or are in the process of creating, emissions inventories. These local inventories have largely been established on an ad hoc basis, however, which presents comparability challenges. As in most OECD countries, many local governments lack the technical and financial capacity to develop reliable local emissions inventories, which present two challenges that are particularly salient at the local level: (1) unlike the national greenhouse gas inventory, it is difficult to identify emissions, operational boundaries and sectors due to unlimited movement of products, waste and vehicles across jurisdictions, and (2) indirect greenhouse gas emissions discharged by electricity or heat pose further complications. As will be discussed further in the next section, the GIR

6. In its 2007 Green Energy Declaration, Seoul however, established an emissions reduction target of $40 \%$ by 2030, compared to 1990 levels.

7. This programme replaced the voluntary emissions reduction pilot programme established in 2010 in which 38 industrial firms committed to reduce energy consumption by $3.7 \%$ by 2012. 
could potentially take the lead on harmonising sub-national emissions inventories, working closely with international partners to ensure a common framework.

Finally, metropolitan city and provincial (Do) governments have also committed to implementing specific mitigation projects that are designed to help reduce $\mathrm{CO}_{2}$ emissions and reflect local priorities and conditions (Table 1). These projects, which will be discussed in further detail later in this section, include green infrastructure construction, building retrofits and the development of eco-neighbourhoods, and the greening of traditional industries.

(b) Enhancing energy self-sufficiency: investing in renewable and clean energies

With national government planning to decrease Korea's reliance on fossil fuels and enhance the country's energy independence by investing just over $14 \%$ of the Five-year Plan budget in renewable and clean energies, local governments have also pledged support for renewable energy in general (Daejeon and Jeju), solar energy (Gangwon-do, Chungcheongbuk-do), wind (Gyeongsangnam-do), biomass and waste (Gwangju, Chungcheongbuk-do).

Several demonstration projects, such as the smart grid pilot project for Jeju Island and the renewable energy district in Pyeongtaek, are intended to test national strategies for enhancing energy self-sufficiency at the local level. The city of Paju, for instance, has partnered with local industry to supply recycled waste heat from a municipal garbage incineration plant. Since 2010, the city has invested KRW 10 billion in a waste heat recovery system at the city's incineration plant that heats the LG Display factory with 100000 tonnes of recycled waste heat annually. It is estimated that each year the company will reduce greenhouse gas emissions by 13000 tonnes and save KRW 1 billion in fuel expenses, meanwhile adding KRW 3 billion annually to city revenue (Paju-si, 2010).

(c) Enhancing the resiliency of cities: local adaptation measures and the Four Major Rivers Restoration project

The National Climate Change Adaptation Master Plan, established in 2010 to guide adaptation measures at all levels of government, called for metropolitan city and provincial (Do) governments to submit climate change adaptation action plans by the first half of 2011. Some metropolitan cities have already introduced adaptation policies in their local green growth action plans, which include reinforcing disaster response systems (Gwangju and Daejeon), strengthening coastal and ocean management procedures (Busan, Gangwo-do, Jeollanam-do) and developing stronger riverine adaptation measures (Chungcheongbuk-do, Jeollabuk-do, Gyeongsangbuk-do and Gyeongsangnam-do). Seoul, in its 2007 Master Plan for Green Growth, lays out a series of policies for addressing adaptation issues. The city plans to carry out an assessment of climate change risks to human life, habitat and infrastructure; modify planning and development standards to account for climate change impacts; increase the amount of open space; and restore local streams. The city also intends to develop disaster plans addressing contagious disease, extreme temperatures, water shortages, ecosystem disruption and other risks.

One of the government's flagship projects to cope with climate change and stimulate economic growth is the Four Major Rivers Restoration, a large-scale sustainable water resources management initiative that accounts for just over 14\% of total projected spending in the national Five-year Plan (Box 2). The restoration aims to limit the impacts of natural disasters and protect natural eco-systems and cultural and historic resources primarily through the construction of 16 moveable weirs ${ }^{8}$ for a more effective response against floods and droughts (Office of National River Restoration, 2011). Efforts will also be made to enhance the quality of the environment around the rivers to stimulate eco-tourism. Several provincial governments, including Gyeongsangbuk-do, Gyeongsangnam-do and Chungcheongbuk-do, have indicated plans to contribute to this restoration project.

\footnotetext{
${ }^{8}$ Weirs are dams that allow water to flow over the top in the event of flooding.
} 


\section{Box 2. Four Major Rivers Restoration Project}

To cope with climate change and stimulate short-term economic growth, the Korean government is promoting the Four Major Rivers Restoration as an exemplary project in sustainable water resources management. The four rivers implicated in the project together stretch for $929 \mathrm{~km}$ and span the national territory, with the Han River in the north, the Geum River in the west, the Yeongsan River in the south and the Nakdong River in the east.

The rivers face significant environmental challenges. Repeated flooding and droughts have caused human casualties, eco-system loss and habitat degradation, property damage and forced displacement of riverine residents. Extreme weather events that lead to flooding and droughts are only expected to worsen in frequency and intensity as climate change impacts In the case of the Yeongsan River, toxic contamination from domestic and industrial waste disposal has resulted in water quality levels unfit even for agriculture and industrial use. These environmental challenges have implied dramatic economic consequences: over the past decade, the frequent flooding of the Nakdong River incurred KRW 67 trillion (USD 54.9 billion) in property damage and forced as many as 50000 people from their homes (Office of National River Restoration, 2011).

The restoration project hinges on the construction of 16 movable weirs, dams that allow water to flow over the top in the event of flooding, two new dams and heightened banks of 96 existing agricultural reservoirs. These measures are expected to improve irrigation and flood control and increase the procurement of water resources by $18 \%$ by 2050 . The installation of wastewater treatment and monitoring facilities should help improve water quality. These measures, combined with the construction of $1782 \mathrm{~km}$ of bike lanes, an enhanced public transportation network and the development of leisure and tourism facilities, are expected to spur eco-tourism along the banks of the four major rivers. According to the Four Major River Restoration Project Master Plan, the project would create 340000 new jobs and increase economic production by KRW 40 trillion.

The Korean government has identified several policy tools to maximise local development potential through the river restoration initiative. The Master Plan mandates that local companies should compose at least $40 \%$ of all joint ventures (with the exception of turn-key projects, which require $20 \%$ participation of local companies). Currently, 187 of 338 companies (55\%) are implicated in the restoration initiative. Specific lots have been consigned to the local government; as of March 2011, local governments are co-ordinating nearly a quarter of the lots associated with the restoration.

The government intends to invest KRW 22.2 trillion to complete the Four Major Rivers Restoration project, with spending divided among the Ministry of Land, Transport and Maritime Affairs (KRW 15.4 trillion), the Ministry of Agriculture, Fisheries and Food (KRW 3 trillion) and the Ministry of Environment (KRW 3.9 trillion). Of the MLTM's share of total investment, the Korean Water Resources Corporation assumes KRW 8 trillion, to be reimbursed through development profits for the riverside area. To co-ordinate the details of the project among the relevant ministries, the Office of National River Restoration was established. The project is expected to be completed by 2011.

Source: Office of National River Restoration (2011)

As in most OECD countries, local authorities have not played a significant role in establishing the priorities or policy agenda that will be implemented to meet national green growth objectives, yet their cooperation will be crucial to implement policies and achieve reduction targets. Experience in OECD countries can provide examples of how national governments have taken local input into account in designing national policies with respect to climate change. In Sweden, for example, the KLIMP climate investment programme was designed to stimulate local environmental initiatives and assist cities in climate change programme implementation (OECD, 2010a). KLIMP grants, attributed through a competitive process to cities that develop climate strategies, can provide central-government funding to municipalities that covers between $25 \%$ and $85 \%$ of project costs, with the city to cover the balance. Between 2003 and 2008, approximately 126 local climate investment projects, representing an investment of EUR 214.9 million, resulted in an estimated 1.1 billion tonnes of $\mathrm{CO}_{2}$ reduction per year (OECD, 2010a). However, it will be important for local governments to work in concert with national authorities to implement co-ordinated policies that address climate change mitigation. As a study reviewing the United Kingdom Climate Integration Programme (CIP) reveals, national policies can result in both synergistic and 
antagonistic interplays between national and local action on climate change (Jordan and Unwin, 2008, cited in OECD, 2010a).

\section{(ii) Develop new engines for economic growth}

Four strategic axes are identified in the National Five-year Plan to spur future economic growth: (a) the development of green technology as "new growth engines," (b) the greening of traditional industries through more efficient use of resources, improved waste management and targeted support to emerging green SMEs, (c) investments in high value-added industries, such as health care, education and telecommunication, ${ }^{9}$ and (d) the establishment of policy infrastructure to support green growth. Many cities are contributing to addressing these strategic axes.

(a) Develop green technologies while (c) investing in high value-added industries: new growth engines for the future

Korea's eco-innovation strategy is underpinned by the existing national policy framework, notably the Ten-year Basic Plan for the Development and Dissemination of New and Renewable Technologies (released in 2003) and the Long-term Vision for Science and Technological Development to 2025 (launched in 1999), which provide the strategic objectives for the country's future technological and industrial development (OECD, 2008). The Ten-year Basic Plan selected three high-priority areas for investment: fuel cells, photovoltaic and wind power. With the launch of the National Strategy for Green Growth in 2009, the government identified a number of additional technologies and industries as new engines for green growth (Table 18). Many local governments have pledged to generate job growth through support for green technological development in their five-year plans (i.e. Seoul, Daegu, Ulsan, Chungcheongnam-do, Jeollabuk-do and Gyeongsangnam-do. Seoul, in particular, plans to maximise its existing technological advantage and highly educated workforce to develop a new R\&D cluster in the Magok district as a test bed for green technologies such as LED, electric cars and hydrogen fuel cells. Daegu is focusing on seven key green technologies, including solar cells, solar heat, fuel cells, intelligent transportation system, LED, electricity IT, and waste-to-energy conversion systems.

Table 18. Industries identified as new growth engines for the Korean economy

\begin{tabular}{lll}
\multicolumn{1}{c}{ Green technology } & \multicolumn{1}{c}{ State-of-the-art fusion industries } & \multicolumn{1}{c}{ High value-added industries } \\
\hline Renewable energy & IT fusion industry & Healthcare \\
Low-carbon energies & IT fusion system & Education services \\
Water management & Robot applications & Green finance \\
LED applications & New material and nano-fusion & Contents and software \\
Green transportation & Biomedicines & MICE and tourism \\
State-of-the-art green cities & High value-added food industry & \\
Source: Cho, Won-Dong (2009). &
\end{tabular}

The emergence of a financial and institutional framework in support of green innovation has occurred since 2001, with the creation of tools and institutions to facilitate eco-innovation. Financial instruments to stimulate new business ventures in green technologies include Eco-Technopia 21, an R\&D fund merging public and private resources to support the development of core environmental technologies and the Environmental Venture Fund. To provide technical support and facilitate knowledge exchange, the Environmental Technology Business Incubator (ETBI) and the Korean Green Industry Complex cluster were developed. Finally, the Korea Environmental Industry \& Technology Institute (KEITI) was launched

9. The PCGG included this strategic axis in National Green Growth Strategy and Five-Year Plan since state of the art convergence technology industries that utilise ICT technologies and high value-added industries (in which the energy intensity per unit is lower than traditional industries) will enable Korea to purse climate change mitigation and sustainable development simultaneously. 
in 2009 to co-ordinate a comprehensive support system for environmental ventures, including the development of environmental technology, certification of environmental technologies and products and support to promote Korea's environmental industry, including in foreign markets, green firms and green procurement.

Innovation has also been seen as a tool to achieve more balanced territorial development. The emergence of a regionalised innovation strategy began with the passage of the 2002 Industrial Cluster Activation Act and the launch of the 2004-08 Five-year Plan for Industrial Clusters. Eleven regional innovation cities were designated to support the government's plans to strategically relocate 175 public agencies (including ministries, research institutions and supporting agencies) from the Capital Region to other metropolitan cities and provinces in Seoul. The relocation project is expected to reduce the share of public agencies in the Seoul Metropolitan Area from approximately 85\% to 35\% (MLTM, 2011b). Regional innovation cities have been designed to capitalise on the local industrial strengths and the knowledge and skills of the relocated public workers and researchers and promote networking and collaboration among regional industries, universities, research institutes and local governments to stimulate local economies and enhance the innovation capacity of local areas. The new cities will also be endowed with cultural and educational amenities in order to attract high-quality workers. While each innovation city is organised around a core concept, only a handful of the themes explicitly focus on eco-innovation. In Ulsan, for example, Korea seeks to develop an industrial cluster for energy by relocating a number of energy-related public agencies to the historically manufacturing city of the automobile, shipbuilding and petrochemical industries. The joint innovation city of Gwangju and Jeonnam is intended as the site of another industrial cluster for energy (particularly renewable energy), IT, culture and arts, reinforced by the relocation of the Korea Electric Power Corporation (Table 19).

Table 19. Regional innovation cities in Korea

\begin{tabular}{|l|l|l|l|}
\hline \multicolumn{1}{|c|}{ Region(s) } & \multicolumn{1}{|c|}{ City/urban districts } & Population & \multicolumn{1}{c|}{ Concept } \\
\hline Gangwon & Wonju City & 30000 & Tourism, health and resource development \\
\hline Chungbuk & $\begin{array}{l}\text { Jincheon Gun and } \\
\text { Umsung Gun }\end{array}$ & 42000 & Centre for IT and biotech \\
\hline Jeonbuk & Jeonju City & 29000 & $\begin{array}{l}\text { Agriculture and national territory and urban } \\
\text { development research }\end{array}$ \\
\hline Gwangju, Jeoanam & Naju City & 50000 & $\begin{array}{l}\text { Industrial cluster of energy (particularly } \\
\text { renewable energy), IT, culture and arts }\end{array}$ \\
\hline Gyeonbuk & Gimcheon City & 26000 & Hub for logistics and agro-livestock \\
\hline Gyeongsangnam-do & Jinju City & 38000 & Inno-River City (enterprise support, eco-city) \\
\hline Jeju & Seogwipo City & 5000 & Training Polis (foreign trade, leisure, tourism) \\
\hline Busan & Yeongdo-gu, Nam-gu & 7200 & $\begin{array}{l}\text { Hub for maritime affairs and fisheries, film and } \\
\text { finance }\end{array}$ \\
\hline Daegu & Dong -gu & 23000 & Centre for international education and industry \\
\hline Ulsan & Jung-gu & 20000 & $\begin{array}{l}\text { Centre for energy, labour, welfare and } \\
\text { manufacturing }\end{array}$ \\
\hline
\end{tabular}

Source: MLTM (2011).

The development of regional environmental technology development centres represents a combined national and local approach to "greening" the existing regional innovation system. Korea's regional environmental technology development centres bring together representatives from universities, administrative agencies, research institutes, industries and non-governmental organisations to solve unique local environmental problems collectively. The responsibilities of each centre include analysis and study of 
local environmental pollution, development of environmental technology, environmental education and technical support to enterprises coping with environmental management problems, dissemination of new environmental technologies, and promotion and education regarding new environmental technologies to local people (OECD, 2011b).

Additional efforts to regionalise Korea's innovation strategy are reflected in several model city projects to foster green innovation. New Songdo City is a flagship urban development project by the Korean government to combine ecological and economic objectives (Box 3). In the coastal area of Gangneung in the Gangwon-do province, for example, the central government partnered with provincial and local authorities within the framework of the Model Green City programme to develop a zeroemissions city centred on green technology and green transportation and building. Jeju Island has been selected as the site of the country's smart grid demonstration project, and is one of the government's flagship initiatives. Launched in 2009, the demonstration project will test smart grid technologies and R\&D outcomes with the intent of developing a successful smart grid business model. The project aims to test a variety of advanced smart grid technologies (including smart technologies related to power networks, buildings, renewable energy and transportation) in one place to assess potential synergy effects. The USD 200 million project combines public spending of USD 50 million with private sector investment of USD 150 million from auto makers, telecommunications companies and home appliance manufacturers (Jeju, 2011).

\section{Box 3. New Songdo City}

New Songdo City represents a Built on a man-made island within the Incheon Free Economic Zone (FEZ), about $60 \mathrm{~km}$ from Seoul and in close proximity to Beijing, Shanghai and Tokyo, New Songdo City is a low-carbon city intended to attract businesses and foreign investment to generate a new commercial hub in Northeast Asia. Plans for the eco-city, launched in 2000, are to construct a city of science, knowledge and advanced technologies that will emit just one-third of the greenhouse gases that are observed in cities of a similar size. The new city will host 250000 inhabitants by 2020 and will comprise residential complexes, a university and the Songdo International Business District (IBD). Project developers hope to attract multinational corporations by providing high-quality hotels, schools, technology infrastructure, and convention centres. The project has an estimated cost of USD 35 billion. A partnership between the City of Incheon and two private partners, developer Gale International and construction manager POSCO E\&C, a Korean steelmaker, was made in 2001. The project attracted considerable private investment, from major financial institutions. Meanwhile, a number of architecture, engineering, design and technology firms are contributing to the development of the city, particularly in terms of green technology integration. It is expected that these considerable investments in New Songdo City will enhance the country's competitiveness

Ecological design features, underpinned by a strong technological coherence make New Songdo City a futuristic and an advanced technology city. Green building design is an important element of the programme, and includes elements such as green roofs, passive solar design, and a number of buildings in accordance with the LEED standard. LED public lighting will be used. Measures to reduce the urban heat island effect, improve wastewater management, collect rainwater will be implemented. Further, Korean designers plan to take advantage of their comparative advantage in broadband investment by combining ITC technologies and clean technologies in order to widely diffuse the city's computer-based technologies. Designers intend to create an artificial intelligence environment and to provide customers with access to new terminals and services via appropriate interfaces. It is expected that the considerable investments required for the project will enhance the country's competitiveness.

Source : Alussi, A. et al. (2011).

Overall, the regionalisation of green technological development and eco-innovation strategies is a fairly recent development in Korea and could be further strengthened. Innovation clusters and model city projects can help foster green technological advancement, which can in turn drive down the cost of the green products and processes. Largely funded by the central government over a fixed time period, 
however, these initiatives risk limited sustainability and replicability; in some cases, they may also lead to technological lock-in. As highlighted in OECD work on green growth, heavy investments in isolated projects can lead to a fragmented approach that spreads out scarce public resources and prevent the development of a broad-based green growth strategy (OECD, 2011c). Place-based strategies that take local strengths and challenges into account are more likely to be successful over the long term (OECD, 2011c). Funding for green growth programmes at the local/regional level remains a central issue in OECD countries. In the case of Korea, the discussion relates as well to the fact that securing additional funding for developing green growth programmes beyond central government-driven projects remains a considerable challenge, given the generally low levels of self-reliance of sub-national governments in Korea. ${ }^{10}$ Combining public and private financing, as in the case of Eco-Technopia 21, could be a strong way forward.

(b) Green existing industries: a focus on traditional strategic industries with reinforced support for SMEs

With the Five-year Plan aiming to green existing industries through waste reduction and recycling, greening traditional strategic industries, policies to increase energy efficiency and reduce resource consumption and increased support for SMEs, a number of local governments have plans to make traditional industries in the region more sustainable. Many local governments are targeting very specific sectors with a strong local presence: the automobile industry (Busan, Ulsan), shipping (Ulsan), petrochemical industries (Ulsan), agriculture (Jeollanam-do, Gyeongsangbuk-do), fishing (Gyeongsangbuk-do) and cement (Gangwon-do). Increased energy efficiency in buildings is a priority for Seoul, Daegu and Chungcheongbuk-do (recall Table 1). Although it would be premature to assess these greening initiatives, experiences elsewhere can provide relevant lessons. Lafarge, one of the world's largest cement companies, for example, succeeded in reducing GHG emissions by improvements to the energy efficiency of factories, the use of alternative fuels (e.g. biomass) to fire its cement kilns, and the use of less harmful additives.

Because SMEs generally lack the financial resources and technical capacity to develop their own greening programmes, they have been the target of special workforce training programmes and targeted innovation support. Samsung Electronics has partnered with the Korean University of Technology (KUT) to establish the Advanced Technology Education Centre in support of technical training for Samsungrelated SMEs. Intended to upgrade the skills of Samsung engineers, courses are provided in renewable energy, next-generation battery technology and LED application technology (Jeong, J., 2011). The Small and Medium Business Administration (SMBA) has launched a programme to enhance collaboration amongst industry, universities and research institutions by providing financial support for selected SMEs to develop skills and advanced technology. Jointly with local governments, the SMBA selects SMEs, awarding extra points to green businesses and provides $75 \%$ of the financing for spending on technological development. In 2010, the SMBA awarded KRW 56 billion for 1228 projects. (SMBA, 2011).

\section{(d) Policy infrastructure to promote job growth}

Since the launch of the National Strategy for Green Growth, Korea has actively pursued the development of comprehensive policy infrastructure to promote job growth, namely with targeted workforce training and skills development programmes to help prepare workers in the transition to the green economy. To green Korea's regional public training institutions, the government introduced curriculum on renewable energy and green technologies in the regional polytechnics college system. Incorporating green technology courses in the 36-school polytechnics college system has led to the creation of 13 new departments related to green growth and the green economy, and 590 students have received training (Ministry of Employment and Labour, 2011). Curriculum reflects regional demands and

10. This issue will be discussed further in the next section. 
links to local SMEs to develop the "core green workforce" for local businesses. In addition, the government has founded two specialised graduate schools, one focusing on climate change, supported by the Ministry of Environment, and the other on renewable energy, supported by the Ministry of Knowledge and Economy (Ministry of Employment and Labour, 2011).

To support collaboration among universities, industry and research institutions, the government initiated a joint research operation with Seoul National University and the Institute of Atomic Energy Research to research green technology (Korean Ministry of Employment and Labour, 2011). The government is also making modifications to the national vocational qualification system in favour of green jobs specification by greening existing qualifications to embrace green skills and technology and introducing new green qualifications, such as engineers specialising in LED application development, photovoltaic systems or electric cars (Ministry of Employment and Labour, 2011). These efforts are laudable but could be combined with the regional innovation cluster system to help regionalise green technology industries and build on local strengths.

\section{(iii) Improve the quality of life and enhance Korea's international standing}

The third strategic pillar of Korea's National Strategy for Green Growth seeks (a) to improve the quality of life through the development of eco-cities, green building projects and green infrastructure, (b) to encourage more sustainable consumption habits through public information campaigns, eco-tourism sites and voluntary participation in eco-lifestyle programmes, and (c) to enhance Korea's international standing as a leader in green growth through participation in international negotiations and contributions to global climate change research.

(a) Improving the quality of life: improving air quality in urban areas through eco-cities, green buildings and infrastructure

The government's urban planning guidelines and action plan for greening cities promote compact urban development through integrated land use and transportation planning in urban areas. These policy documents are complemented by model green city demonstration projects, designed to test new strategies and technologies for green urban development. The greening of the existing building stock and the expansion of public transit networks represent nevertheless the core urban sectors in which significant reductions in resource consumption and environmental degradation can be achieved: the building and transportation sectors are the most important energy end users and together accounted for nearly $40 \%$ of all $\mathrm{CO} 2$ emissions in 2009. Since 1980, these sectors have increased their contribution to total levels of $\mathrm{CO}_{2}$ emissions in both large and medium-sized cities.

Improving air quality in urban areas is a priority in Korea, which as mentioned in the previous section, registered the third largest increase in NOx emissions in the OECD area between 1990 and 2007, due to Korea's rapid economic growth and urbanisation processes and its expanding industrial sector. The capital region has been a particular focus of government action because as mentioned previously, it displays some of the worst levels of air pollution among OECD countries (Jones, R. and B. Yoo, 2010). With the objective of reducing air pollution in the capital region to the OECD average by 2014, the Korean government introduced an emission cap-and-trade programme in 2008 (Jones, R. and B. Yoo, 2010). The system, which covers NOx, SOx and Total Suspended Particles in the capital region, began with largescale emitters and was extended to mid-size emitters in January 2010 to cover a total of 136 factories in the capital region. The emission levels of the three pollutants are allocated to each source within the overall total limit. Emitters with excess pollution are able to purchase emission permits from those with surplus emission allowances. In case industrial emitters exceed their allocated amount, they have to pay a penalty charge and their permissible emission level is reduced for the following year (Jones, R. and B. Yoo, 2010). The trading system applies only to fixed sources of emissions (primarily from industry), however, when 
vehicles are a major pollution source in the capital region, accounting for around half of NOx emissions. Although the automobile fuel efficiency regulations introduced in 2006 have increased fuel efficiency, the standards remain well below those in EU countries and Japan (Jones, R. and B. Yoo, 2010). Nevertheless, efforts should be strengthened in medium-sized cities, where increased industrialisation has led to rising concentrations of air pollutants. Policies to discourage travel by private vehicle (improvements to public transit and non-motorised travel networks, increased energy efficiency in vehicles to optimise energy consumption, as well as market-based instruments like parking tariffs and congestion charging) will be further discussed in the next section.

A set of urban policy documents lay the foundation for more compact, greener urban development. The planning guidelines and action plan for greening cities were developed by the Ministry of Land, Transportation and Maritime Affairs (MLTM) to help guide the implementation of the National Strategy for Green Growth at the local level. The guidelines encourage local authorities to integrate environmentally sustainable spatial planning, building and transportation policies into local plans and call on local governments to determine current emission levels, establish reduction targets and evaluate local plans based on their potential to achieve energy efficiency. In particular, the action plan promotes compact city planning through transit-oriented developments to minimise urban sprawl and lower carbon emissions, the construction of intermodal transit centres in major railway stations and the management of dense urban centres through cutting-edge technology projects (such as the Ubiquitous City or Smart City initiatives) (Box 4). Although non-binding, these policy documents help to articulate concrete urban planning strategies for reducing emissions at the local level, and are intended to be easily incorporated into local planning goals.

\section{Box 4. Action plan for greening cities}

In November 2009, the Ministry of Land, Transportation and Maritime Affairs (MLTM) proposed an action plan for greening cities to help local authorities integrate environmentally sustainable spatial planning, building and transportation policies into local plans.

\section{Green urban planning}

- Implement compact city planning principles through transit-oriented development (TOD), the development of intermodal transit centres in major railway stations, and the efficient management of densely populated urban centres through cutting-edge technological initiatives, such as the Ubiquitous City or Smart City projects.

- Improve resource management systems by expanding automatic waste collection systems, developing comprehensive energy management systems to utilise energy from multiple sources and introducing a rainwater collection system.

- $\quad$ Securing ecological urban green spaces by revitalising the urban river system (streamlets, swamps and reservoirs), requiring the provision of open space near high-density developments, permitting commercial facilities to be established in public parks and restoring the deteriorated Greenbelt Zones.

\section{Green building}

- Strengthen energy efficiency provisions in building codes by imposing stricter insulation standards, introducing an annual energy consumption limit on new constructions and achieving "zero-energy" buildings in the residential and non-residential sector by 2025.

- $\quad$ Provide 1 million green homes by 2018 by supporting the Public Housing Corporation's annual target of 100,000 green homes between 2009 and 2018 and reducing energy consumption in the residential sector by $30 \%$. 
- Support green building $\boldsymbol{R} \& \boldsymbol{D}$ by developing leading green building technology, training design and construction engineers and providing low-interest loans to improve the energy efficiency of existing buildings.

\section{Green transportation}

- Prioritise low carbon infrastructure investments by increasing the share of national SOC spending to railway from $29.3 \%$ to $50 \%$ by 2020 and restricting road investments from $57.2 \%$ to $40 \%$ by 2020 .

- Control traffic demand through the expansion of congestion charges in major cities, more efficient road uses (via the Intelligent Transport System) and introducing a "Green Traffic Priority Region" to manage areas of heavy traffic volume.

- $\quad$ Expand pedestrian and bicycle infrastructure through the development of pedestrian priority districts and the construction of $3114 \mathrm{~km}$ of bicycle lanes by 2018 .

- $\quad$ Promote public transit use by expanding bus rapid transit (BRT) lanes, expanding the metropolitan-wide railway and completing the second bullet train line, connecting Seoul to Gwangju.

- Promote transit-oriented development and green transportation through the construction of a MultiModal Transfer Center (MMTC). As a first step, the Ministry of Land, Transport and Maritime Affairs established the Five Year Multi-Modal Transfer Centre Development Master Plan (2011-15) in 2010. According to the Master Plan, MLTM hopes that nearly 15 multi-modal transfer centres will be constructed by 2015. In particular, rail station areas will be developed as mixed-use and high-density areas that reduce journey time from home to work. Total expenditures for the project are anticipated at KRW four trillion, to be funded mainly by the private sector. Eight trial stations were designated in 2010: Dongdaegu, Iksan, Ulsan, Songjeong, Bujeon, Dongrae, Daegok and Nanchuncheon. This plan's key objectives are as follows:

- Concentrate transport facilities such as railway stations and bus terminals in each multi-modal transfer centre to reduce transferring time/distance by $50 \%$ and improve convenience for travelers;

- Connect the public transport services lines within the multi-modal transfer centres;

- Develop multi-modal transit centers as multi-functional areas by installing various neighbourhood living facilities such as commercial services, cultural facilities and offices; and

- $\quad$ Promote non-motorised transport (walking and cycling) around multi-modal transfer centres by reinforcing regulations including designating public transport exclusive zones or pedestrian exclusive zones.

- Ubiquitous City (U-City) is a Korean urban development model that seeks to overcome the fundamental limitations of development in traditional cities by integrating cutting-edge IT technology into urban space and creating a sustainable, human-oriented city. The main purpose of the $\mathrm{U}$-city model is to provide residents with real-time traffic data, e-medical support and disaster information by using advanced IT infrastructure. The U-city model is believed to offer urban service more efficiently and improve responsiveness to natural disaster. Beginning with Dongtan U-City (located in Hwaseong-si), completed in September, 2008, 36 local authorities (52 district areas) have actively introduced U-City urban development projects. More recently, the $\mathrm{U}$-City model has been enhanced to include a greater focus on ecological technology, in the U-eco city model.

Source: MLTM (2009).

Several pilot projects to promote green cities have been implemented as well by different national authorities, with very similar objectives: the EcoRich City Competition project (Presidential Committee on Green Growth), the Climate Change Adaptation Model City Project (Ministry of Environment), the Green 
City Project (Ministry of Environment), Eco City Project (Ministry of Environment), Low-carbon, Green Village Project (a joint project involving six ministries), and guidelines for low-carbon, green cities (Ministry for Land, Transportation and Maritime Affairs). These projects aim to encourage locally tailored climate change actions and can be a useful tool for testing innovative urban planning strategies and green technological development, such as smart grids. Nevertheless, conflicts have emerged amongst ministries in the management of these at times competing green growth demonstration projects (Box 5). Better coordination among ministries could help to unlock synergies between similar projects, on the one hand, and limit redundancies to better disseminate scarce public resources on the other hand.

\section{Box 5. Conflicts among stakeholders in the Gangneung-si green city demonstration project}

In 2009, Korean government declared its intention to build a "low carbon, green city" in Gangneung-si, located in Gangwon-do, on the eastern coast of South Korea. The project aimed to enhance the city's capabilities of carbon reduction and maximise its green growth potential. The Korean government expected this project to establish the model of Green City and disperse to other cities. However, this project was controversial from an early stage. Various stakeholders including Ministry of Land, Transport, and Maritime affairs, Ministry of Environment, and local government of Gangwon-do were at the heart of heated controversy. First, the concept of green city project was a controversial topic between MLTM and MOE, since MOE focused on environmental protection while MLTM stressed development process or maximization of Return on Investment, not surprisingly, based on both ministries' scope of the work. Second, Ministries had conflicts with Municipalities. In fact, Gangwon-do was trying to expand scope of the project while expecting as much as financial support from central governments. However, central governments intended to conduct the project in a phased process while considering maximizing ROI. Also central governments wanted local government to fund much of the finances locally. In order to resolve a conflict, several instruments such as discussion and seminar were employed, resulting in MOU for collaboration signed by MLTM, MOE, Gangwon-do and Gangneung city government. In January 2010, MLTM and MOE announced "The Basic Strategy for Building Gangneung Green City, which will be completed by 2016. Many controversies seem to be settled by this basic strategy, however, challenges such as consolidation of spatial and environmental policies and securing budget still remain.

Source: Wang, K.I. (2009).

Greening infrastructure is an essential pillar of the Korean Green Growth Strategy. As mentioned before, the building and transportation sectors in Korea are among the most important energy end users. Given the fast growth rate of the Korean economy, the relatively low price of fossil fuels and the uncertain and slow process of shifting to other energy sources, $\mathrm{CO}_{2}$ emissions are likely to increase substantially during the next future in these two sectors without the implementation of additional policy measures to slow this trend. As such, greening the building and transportation sectors will be essential to achieve green growth objectives at the urban scale - not just because these sectors are responsible for high levels of energy intensity and greenhouse gas emissions, but also because they have the potential to stimulate local job growth and, in most cases, fall within the purview of sub-national governments.

The building sector alone is one of the most energy-intensive sectors in the Korean economy: residential and commercial buildings combined account for $19.62 \%$ of domestic energy consumption in 2009, an increase of $155 \%$ since 1980 (Korea Statistics Office, 2011). To reduce emissions in the building sector, the government plans to (i) strengthen the regulatory environment of the building sector through updated building codes and reinforced energy-efficiency standards for public buildings and new construction, (ii) support green building by providing technical and financial support to the private sector and, in some cases, developing large-scale green building retrofit projects and (iii) increase the supply of green buildings with the construction of one million green homes in the Bogeumjari district and the retrofitting of nine thousand rental apartments. These projects are to be complemented by the construction of fourteen "Environment Energy Towns" and 800 low-carbon, green villages in eight distinct geographical zones of Korea. 
At the local level, Seoul has been recognised by the Clinton Foundation as an international leader in green building retrofit projects. The first phase targeted public building retrofits, while the second phase expanded the project to the private sector. Improving the energy efficiency of historical buildings is a special challenge in Seoul. City authorities are currently working with the national government to revise regulations for new building construction standards. In 2007, the city created the Green Architecture Standards, equivalent to the LEED standard, as an institutional device to reduce greenhouse gas emissions from the building sector. New public buildings in Seoul are required to meet the green standard, while incentives are given to private sector partners in the form of acquisition and registration tax cuts.

With the transportation sector accounting for over 19.7\% of total energy consumption in 2009 (Korea Statistics Office, 2011), Korea aims to cut transport-related emissions by enhancing energy efficiency and developing renewable energy resources. Plans to develop renewable fuel standards, for example, will help make bio-diesel and biogas available for private and public vehicles and increase the share of biodiesel to $3 \%$ of fuel demand in the transportation sector by 2012, and to $7 \%$ by 2020 (UNEP, 2009).

Coupled with densification policies, improvements to the transportation network can stimulate increased public transportation ridership, cycling and walking, which can in turn lead to reductions in greenhouse gas emissions. Improvements to the public transportation system are planned to increase the share of public transportation to 55\% of total transport activity by 2013 (Presidential Commission on Green Growth in Korea, 2009). The expansion of the high-speed train system is one of the flagship transportation projects of the Five-year Plan. The Five-year Plan also calls for the creation of over $3000 \mathrm{~km}$ of bike lanes in urban areas, which is expected to stimulate the share of bicycle use from $1.5 \%$ in 2009 to $5 \%$ in 2013. Approximately USD 8.5 billion will be invested in the greening of the transportation network, which is expected to create 16000 new jobs (Cho, 2009).

In their five-year plans, many metropolitan/Do governments intend to curb greenhouse gas emissions by developing local and regional transportation network improvements. Daegu, Daejeon, Gyeonggi-do, Jeollanam-do, Gyeongsangbuk-do and Jeju all include specific transportation measures in their local action plans. Gyeongsangbuk-do, for example, plans to build a hydrogen highway along the eastern coast of Korea. Several urban areas with major public infrastructure facilities and networks (ports, airports, subways) plan to green the infrastructure or to develop green projects around these facilities. Daejeon, for example, plans to expand the subway system with the construction of a new line; Busan plans to develop a smart grid cluster around the new port.

To complement the measures undertaken by the central government, the city of Seoul has been active in its efforts to reduce air pollution levels through a series of policies meant to stimulate low-carbon transportation: improvements to the public transportation system, investments in hybrid taxis and electric buses, subsidies for transport companies willing to switch to green vehicles and discounts to motorists who drive electric cars. For the past several decades, Seoul has been a leader in green transportation and continues to innovate (Box 6). The construction of the Great Train Express (GTX), the first high speed rail system in the Seoul metropolitan area, represents one of the major transportation projects in the capital region. GTX is expected to significantly affect future urban growth pattern in the region by changing the mobility between areas and reducing the reliance on road traffic. Research has demonstrated that a high speed transportation system results in urban expansion, as the transportation nodes become nuclei for urban growth, promoting polycentric spatial structure (Debrezion et al., 2007). Proximity to transit stations provides reduced travel time and cost and eventually can foster the agglomeration of urban activities. 


\section{Box 6. Green transport in Seoul}

In 2009, the transportation sector was responsible for $19.7 \%$ of greenhouse gas emissions in Korea (Korea Energy Economics Institute, 2010), 80\% of which result from road-based transport (Hwang and Park, 2010). With over 10 million residents within city limits and 22 million in the greater metropolitan area, Seoul is home to one of the largest global transportation networks. Roughly $65 \%$ of the population commutes through public transportation, namely bus and rail services; 2.2 million personal vehicles also travel within the city. Costs of congestion associated with personal vehicle usage at peak hours exceed USD 8 billion per year (Pucher et al, 2005).

For the past several decades, Seoul has relied on a mix of policies to respond to increasing congestion in an effort to green its transportation system. The city's approach integrates financial incentives, monitoring mechanisms and infrastructure investment programmes that are designed to improve urban attractiveness, economic productivity and environmental quality of life in the metropolitan area. The programme's primary intent is to reduce the amount of private car usage within the city limits. Improvements in public transportation accessibility and performance are simultaneously coupled with disincentives toward using personal vehicles. In addition, the city has taken steps to encourage walking and bicycle usage to further green transportation modes by providing car-free pedestrian walk ways and bicycle lanes.

Specific policy initiatives include:

- Greening of the public fleet: Since 2004, the government has increased its involvement in bus service planning and system upgrades. The Seoul Municipal Government has converted approximately $95 \%$ of its bus fleet fuel sources from traditional diesel engines to concentrated natural gas (CNG), a cleaner burning source. The bus rapid transit programs (BRT), which has expanded bus routes and designated dedicated bus lanes aim, aims to improve average bus speed by approximately $82 \%$ while reducing accident rates by $13 \%$. Improved bus design and accessibility should increase passenger capacity by nearly $40 \%$. In addition to bus service renovations, Seoul is in the process of constructing an additional $159 \mathrm{~km}$ of subway rails (expected to be completed by 2019), which will accommodate an anticipated increase in ridership from 35\% to over $50 \%$. However, total underground rail construction accounts for roughly $80 \%$ of city public debt, with half of this amount absorbed by the national government.

- Voluntary "no driving day": Through the Commute Trip Reduction programme, financial incentives are offered to drivers that volunteer to find an alternative method of commuting on given days. Within the first two years of the programme, 750000 vehicles had registered, approximately $34 \%$ of the total pool of private cars. Participants are eligible for a $5 \%$ reduction in their automobile tax, reduced congestion charges and parking fee discounts. The city deployed radio frequency identification stations, the e-Tag system, which provides communal parking in designated areas adjacent to public transport facilities in order to monitor compliance of registered participants. With one million cars participating, it is estimated that the programme could result in a nearly $10 \%$ reduction in air pollutants and greenhouse gas equivalents, while also decreasing congestion by roughly $10 \%$. Social costs are projected to be reduced by a total of USD 754 million in annual savings.

- Travel demand management: Since 1996, congestion charges levying fees at peak travel hours have helped curb private automobile use in Seoul, reduce downtown traffic by approximately $13 \%$ and improve average travel speed by over $80 \%$. The T-Money transportation card enables passengers to transfer between different modes of public transportation in the metropolitan region for free or at a discounted rate, further reducing barriers to adopting public transportation over personal vehicle.

- Urban design to accommodate electric vehicles: In collaboration with KAIST, Seoul is investigating the implementation of electric vehicles for private and public modes of transportation. Installing electric recharging strips on $10-20 \%$ of the cities roads could enable all road-based transportation to operate electrically continuously, without having to recharge at a station.

Source: Pucher, J. et al. (2005); Mok, Y-M (2010). 
An OECD modelling exercise examined the potential impacts of the GTX high-speed rail on the spatial structure of the Seoul metropolitan region under the condition of altered transportation accessibility (OECD, 2011d, forthcoming). The simulation demonstrated that GTX high-speed rail would create a more polycentric structure that limits urban sprawl. The construction of GTX would be likely to pull urban development into the vicinities of GTX stations, facilitating polycentric urban development by imposing both centrifugal growth at the regional scale and centripetal growth at the local scale around the proposed stations. GTX would redistribute development pressure from around Seoul city by extending the commuting distance and reducing travel time. Urban development at more distant locations could take place as a result, but, unlike urban sprawl, would be concentrated in local agglomerations around stations due to the better transportation accessibility. Further, by shaping new agglomeration centres at the local level, GTX stations would prevent possible scattered development in other areas of the metropolitan region. The overall impact of the GTX scenario would be the creation of new urban growth clusters farther from Seoul and a spatial structure that could support transit-oriented development. The result of this scenario also supports possible Transit Oriented Development (TOD), which is considered as an effective means to foster compact city development as well as economic development of local areas.

(b) Toward more sustainable consumption habits: public awareness campaigns, eco-tourism, eco-lifestyle programmes

Korea's National Strategy for Green Growth proposes to "bring the green revolution into daily life" by promoting green growth in regular school curricula and education for adults, developing a green lifestyle index for citizens with incentives (such as a carbon point system), creating carbon footprint labeling and certification systems for goods, implementing a voluntary low-carbon smart village movement and developing eco-tourism sites and practices. A recent OECD survey of ten countries found that environmental pressures resulting from household behaviour are significant, and their impacts are projected to increase in the future (OECD, 2011e). While great variation across surveyed countries was observed in the case of charging consumers for environmental services, Korea represented one of the countries in which nearly $80 \%$ of households were charged for water consumption on a per-unit basis. Recognition of energy-efficient appliances in Korea was among the highest of countries surveyed, at $96 \%$. Nevertheless, the difference between the level of recognition of appliance energy-efficiency labels and reported installation was also high in most countries surveyed, including Korea. However, in terms of public transport access, compared to respondents in other surveyed countries, urban and suburban households in Korea were less likely to live within 15 minutes from a public transport stop or station. Korea also recorded one of the lowest levels of government support to households installing energy efficient items (13\%). The findings prompted a number of cross-cutting policy lessons (Box 7).

\section{Box 7. OECD policy recommendations for greening household behaviour}

To reach a better understanding of the factors driving households' environment-related decisions in order to inform policy design and implementation, a study of household behaviour was conducted by the OECD in ten countries. Five areas of particular concern to decision makers, given their environmental significance, were examined: residential energy use, domestic water consumption, waste generation and recycling, organic food consumption, and personal transport choices. The findings prompted a number of cross-cutting policy lessons.

First, providing the right incentives is key. The role played by incentive-based instruments to spur behavioural change is clearly confirmed. Metering and billing encourage energy and water savings. Households charged for the water they use are also more likely to install water-efficient equipment at home and consume approximately $20 \%$ less water. In addition, waste charges increase recycling volumes and affect waste prevention behaviour. Finally, fuel costs are found to have a negative effect on car use, confirming the existing literature. Survey results suggest that changing relative prices (for electricity, water, fuel) is necessary if emissions are to be reduced and natural resources to be conserved. While measures that have a direct effect on prices such as charges or taxes appear to be necessary, they do not prove to always be sufficient, particularly for pressing environmental concerns. 
The impacts of economic incentives may be limited in the short term, but increase with time, particularly in the areas of transport, energy or water, as consumers adjust their holdings of durable equipment and invest in energyefficient or water-efficient appliances. In a similar way, the response to the introduction of fuel-related taxes is limited in the first instance to reducing the use of motor vehicles while, in the medium term, households can change vehicles, or even travel mode. In the longer term, the choice of location of residence may be adjusted to increase the proximity to public transportation. Attention should also be paid to distributional concerns. For instance, the survey provides new evidence that low-income households are the most adversely affected by increases in water charges.

Second, information and awareness play a significant role. These "softer" instruments, based on the provision of information to consumers and education can have an even more substantial complementary role to induce changes on the demand side than earlier thought. The environmental awareness of consumers has a clear influence on a number of household decisions. For example, environmental awareness is a main driver for water-saving behaviours and reduces the likelihood of owning a car. Concern for the environment also influences demand for energy-efficient appliances and renewable energy, as well as the intensity of waste recycling and decisions to consume organic food. This indicates that an important task for governments may be to multiply information campaigns in order to raise people's environmental awareness. This may spur behavioural change, but can also, help to increase the political acceptability of environmental policies, facilitating their implementation. Governments have a significant role to play to promote "greener" behaviour by increasing the general level of educational attainment, as well as through targeted public information campaigns.

Third, consumers tend to make greener and more informed decisions when eco-labels are clear and comprehensible. As such, measures that encourage ease of identification and understanding of eco-labels are likely to be more effective. Moreover, labels prove to be particularly effective if they relate to both the public and private benefits of the good or service. An example is the reduced energy bill resulting from energy-saving behaviour that also leads to a reduction in greenhouse gas emissions.

Fourth, the role of norms, particularly in households' motivation to recycle material or not, can also be significant. Policies have an effect on people's intrinsic and social norms, and policy makers need to take into account the effect of different policy measures on norms. For instance, some measures may result in reduced voluntary provision of the good in question. This also suggests that information policy and training programmes to help make informed decisions can play a role in stimulating personal motives by stressing the social aspects of environmentfriendly behaviours such as recycling and waste prevention.

Fifth, supply-side measures should also be implemented to green household behaviour as they can increase the range of substitution possibilities. Governments have a significant role to play. In a number of areas (transport, recycling, energy) the provision of adequate infrastructure and services can have an impact at least as important, if not more important than relative prices. Moreover, environmental policy measures tend to have a more significant effect on individual behaviour when implemented in combination with investments in related environmental services. Access to public transport affects car ownership and car use. Installing meters also encourages people to reduce energy and water consumption, through both behavioural change and investment in more efficient appliances. However, it is important to bear in mind the administrative costs associated with the provision of infrastructures. Also, some environment-friendly decisions tend to be only weakly driven by demand and thus may rely heavily upon complementary measures targeting the supply side (particularly in the case of renewable energy).

Finally, in many cases, using a mix of instruments is likely to increase the impact of environmental policies targeting behavioural change. When implementing policy packages, it is important to keep in mind that there may be a significant time-lag for households to adjust. Taking into account this lag in the responsiveness to price incentives is particularly important when addressing certain environmental concerns (such as water scarcity). Further, the time horizon involved in decision-making processes can vary significantly across policy areas, where short-term responses may be smaller as households adjust their stock of durables and invest in more efficient equipment, limiting the overall reduction in consumption levels early on. The impact of pricing can be more significant in the long term but welldesigned information-based measures can make a difference in the short term. Attention should also be paid to potential redundancy and conflicting effects when applying a package of measures to target a similar externality.

Source: OECD (2011e). 
Local and regional governments can go a long way to increasing local green consumption by financing arrangements that reduce the upfront cost hurdles and unit costs of distributed energy technologies. Marginal price incentives can shift preferences of more sensitive consumers. Direct observation and imitation by other consumers can then lead to wider market penetration. The City of Berkeley's Financing Initiative for Renewable and Solar Technology (FIRST) programme reduces cost hurdles by providing loans to homeowners to purchase and install solar photovoltaic systems at interest rates and payback periods similar to those for home mortgages. Borrowers repay the city through an additional, transferrable tax added to their annual property taxes. The California Public Utilities Commission (CPUC) developed a state-wide Solar Hot Water incentive program. The proposed incentive amount for residential SWH systems is expected to be about USD 1500 per system on average. Effective programmes to facilitate and reduce the cost of green investments often involve multilevel governance coordination between national, regional and local governments (OECD, 2010a; IEA, 2009b).

Some local governments have taken an active role in raising public awareness on green growth. The Green Start Movement, a nationwide movement focused on reducing non-industrial greenhouse gas emissions, mainly through voluntary citizen participation and actions is a good example. The Green Start Network, established in 2003 to support the "Green Start Movement" to spread a low-carbon lifestyle and now existing in over 200 cities and Guns, is composed of representatives from the media, industry, religious groups, and civil and governmental organisations. Local Green Networks emphasise green growth education and awareness events. Seoul in particular, operates an Eco Mileage programme, whereby citizens receive "eco-miles" for achieving reductions in GHG from electricity, water, and gas consumption. Eco-mileage can then be used to buy eco-friendly products, such as LEP lamps, energy-efficient appliances and hybrid vehicles. Changwon-si, a medium-sized city, has also developed a voluntary carbon mileage programme to encourage citizens to reduce emissions. Participating households and businesses receive tips for cutting emissions in daily operations and are then awarded vouchers for reducing their carbon consumption, based on historical electricity and water consumption records. The city plans to expand the programme to include gas and transportation consumption (C40 Cities, 2011).

The government's low-carbon, green village project aims to establish energy self-reliant villages by installing renewable energy-generating facilities (biomass, wind and water) in rural areas to provide power to the village. The green villages are expected to generate employment and boost local economies, meanwhile reducing energy consumption from fossil fuels. By 2010, four ministries or government agencies (Ministry of Environment, Ministry of Public Administration \& Security, Ministry of Food, Agriculture, Forestry and Fisheries and Korea Forest Service) had launched separate demonstration projects, which included feasible studies and public hearings. The pilot projects will be assessed by the government to help determine the next phase of the programme and the responsibilities of each ministry. Currently, the projects are financed by the national government, with varying amounts of financial support from local governments.

The Four Major Rivers Restoration project includes plan to develop a number of eco-tourism sites (Box 1). In their five-year plans, other metropolitan/do governments indicate plans to develop eco-tourism sites. Suncheon-si, a small city located on the southern coast of Jeollabuk-Do, has pursued wetlands restoration in the Suncheon Bay as a means of eco-tourism. While surrounding areas devoted wetlands to industrial purposes (petro-chemical plants and steel mills), Suncheon-si restored the wetlands to provide habitat for migratory birds and ecological tourist attractions. The conservation efforts have created 6400 jobs and USD 100 million in economic benefits from tourism (United Nations Economic and Social Commission for Asia and the Pacific, 2010).

(c) Enhance Korea's status as a global leader in green growth: a global institute for green growth and financing mechanisms for developing countries 
In an effort to enhance Korea's status as a global leader in green growth, Korea launched the Global Green Growth Institute (GGGI) in 2010. The Institute is envisioned as a global think tank for green growth in developed and developing countries. Supported by a global network of representatives from universities, international organisations, research institutions and interest groups, the GGGI is headquartered in Seoul, with regional offices to be opened in developed and developing countries. The Korean government hopes over time to transform the legal status of the GGI from a non-profit to an inter-governmental organisation. An initial USD 10 million annual investment is promised by the Korean government for the first three years (GGGI, 2010).

Korea will offer assistance and co-operation to neighbouring developing countries in Asia through the East Asia Climate Partnership. Korea will also increase the amount of official development assistance, and raise the share of green development assistance from $11 \%$ in 2007 to $20 \%$ in 2013 and $30 \%$ in 2020 . Contributions to multi-lateral organisations, such as the UN Global Environment Facility, will be expanded.

At the sub-national level, a handful of Korean cities have taken part in international networks of cities, such as the Clinton Foundation's C40 Climate Leadership Group, of which Seoul is a participating city and Changwon is an affiliate city.

\section{Challenges to advance an Urban Green Growth Agenda}

\section{An international leader in green growth with a clear recognition of the urban dimension}

Korea's vision for green growth stemmed from an acute recognition of the limits of the country's previous growth paradigm that was based on increasing environmental pressures and the over-exploitation of resources. The "Green New Deal" was hence conceived and implemented as a way for the country to foster long-term sustainable growth. Two strategies have been developed to achieve this objective, the first focusing on short-term recovery while the second is oriented to facilitate growth over the long term. The first focuses on the boosting of the labour market, with massive investments in infrastructure so as to facilitate the production switch towards less energy-intensive activities. This strategy was conceived as a short-term response to the financial crisis. The second strategy is a voluntary industrial policy to enable a structural change in Korea's economic development pathway by enhancing its global competiveness in the green technology sector, which has been identified as the future engine of sustainable growth.

Despite the difficulty in provoking structural change - especially in such a critical period for the global economy, which renders the net outcome of ambitious green growth policy plans uncertain - there is good confidence in the potential impacts of Korea's strategy on environmental and economic performance. Korea's integrated approach to green growth, which is structured around ten strategic axes which are in turn associated with concrete projects and corresponding evaluation methods, is a potential benchmark for similar policy initiatives. Korea's National Strategy for Green Growth combines several macro-areas of policy action into an integrated and coherent policy framework: an economic master plan, a set of environmental regulations, a climate agreement and a carbon tax proposal. This capacity to assemble a wealth of sensitive issues in the current political and economic debate can prove essential to pave the way toward a broader and more global paradigm shift.

While Korea's strategy is not the only attempt to foster greener growth worldwide, it certainly represents the first, largest and most organised policy approach to green growth thus far. Integrating the multiple dimensions of green growth into a single, coherent policy framework represents a truly innovative approach. Further, the massive investment capacity mobilised in the green technology sector signifies not only an important milestone toward more sustainable development for the country, but is especially aimed at increasing the competitiveness of the domestic economy in the rapidly growing international market for green technology. 
With the largest investment package dedicated to sustainability and green growth strategies among OECD countries, Korea has been instrumental in shaping the international green growth agenda and establishing itself as a green growth leader. In addition to the dedication of considerable financial resources, since the Presidential Decree in 2009 the government has laid the foundation for a comprehensive policy and institutional framework to enable the transition to low-carbon, green growth. Korea's national strategy, coupled with the Five-year Plan, combines both a long-term vision for green growth with short-term job creation programmes. Driven by strong political will at the national level, the green growth strategy enjoys broad support among ministries and the compliance of metropolitan city and provincial (Do) governments.

At the sub-national scale, Korea's national strategy has attached a strong emphasis on the local/spatial dimension of green growth by identifying urban planning, transport, buildings and infrastructure as key determinants of policy effectiveness toward green growth. In many countries, translating the multidimensional and often unwieldy concept of green growth into concrete actions at the local and regional scale, where action can be most concrete and effective, is a difficult one. With few exceptions, the spatial dimension of the economy tends to be underestimated as a driver of green growth in most OECD countries. Korea is nevertheless an exception that merits considerable attention.

Given that the implementation of Korea's National Strategy for Green Growth is still in its early stages, a robust assessment of its economic and environmental impacts at the local scale would be premature. This section will assess a set of policies and governance challenges that should be addressed to further advance Korea's urban green growth agenda, as defined in the three pillars of the strategy. First, it will focus on the economic instruments and planning policies for greening urban transportation and building - two key sectors for achieving green economic development - which can provide valuable responses to curb carbon emissions. Second, given the breadth of issues covered by the Korea green growth agenda, collaboration across and within different tiers of government is required, as is co-operation with the business community. The second part will thus discuss governance challenges to advancing an urban green growth agenda. We will use the OECD Multilevel Governance Framework ${ }^{11}$ adapted for an Urban Green Growth Agenda (OECD, 2011g, forthcoming) to discuss obstacles to effective implementation of the Korea Green Growth Agenda at the sub-national level.

\section{Strengthening the urban dimension in addressing transport and building}

Korea's National Strategy for Green Growth acknowledges the importance of focusing on a complementary, local approach to green growth and gives regional and urban policies the important role they deserve in achieving green growth. The sustainable use of land and space, particularly in terms of transportation planning and increased energy efficiency in the building sector, are at the core of this programme.

Urban land use and its functions can be shaped by a number of spatial policy instruments, notably land use zoning, which regulates density (and thus height) of buildings and investments in infrastructure. In addition, changes in the modal split, shifting from the use of private vehicles to energy-efficient transport modes like walking, biking and public transport, can lead to a reduction in transport-related GHG emissions and in the amount of energy required for heating. This section assesses the extent to which a range of economic instruments and policy tools to foster urban green economic development in the transportation and building sectors have been used in Korea, and provides policy recommendations for strengthening their effectiveness in realising economic and environmental objectives.

11. See OECD (2011f): Methodological note: Public policies in decentralised contexts: a multilevel governance approach. 
(i) Why the spatial dimension of transport and building matters for green growth

How cities grow and operate matters for energy and resource demand. It is not cities, or urbanisation per se, that contribute to greenhouse gas emissions and resource demand, but rather the way in which people move around the city, the sprawling spatial patterns they produce, the way in which people use energy at home, and how buildings are heated that make cities great consumers of energy and polluters. While urbanisation is linked to increased carbon emissions, not all urban areas contribute to emissions equally. Transportation demand, urban design and density, and spatial organisation are key factors that influence energy consumption and resulting GHG emissions.

Transport demand is shaped by both urban form and density, affecting travel distances in urban areas, mainly through commuting. Denser urban areas may experience higher levels of congestion, yet they also hold the potential for robust transportation linkages and the shift to more energy-efficient travel modes. In accordance with previous findings for the U.S. (Ryan and McNelly, 1995), recent empirical simulations on European cities reveal the potential for spatial planning at the urban scale to reduce average travel distance of $10 \%$ (25\% when increasing density to its maximum degree), which in turn would lead to reduce carbon emission from urban transport by 11\% (31\% under maximum density) (Box 8) (Grazi et al., 2008).

\section{Box 8. An empirical analysis of the impact of urban form on transport-related carbon emissions}

To measure the impact of urban form on individuals' travel behaviour and, consequently, environmental quality, Grazi, et al (2008) has performed an instrumental variable econometric analysis of the influence of urban density on greenhouse gas emissions related to commuting behavior.

The findings from this study indicate that a higher urban density is likely to lead to a change in travel behaviour. The magnitude and direction of this change are observed by modal shifts in individual travel choices, from motorised vehicle use to other transport modes, notably public transport, bicycling and walking. The estimates show that in locations where density is $30 \%$ higher, $\mathrm{CO}_{2}$ emissions from transport are on average $15 \%$ lower.

The main implication of this finding is that policies that try to enforce or stimulate a higher density of activities may have a favourable effect on reducing $\mathrm{CO}_{2}$ emissions. For instance, if targeted urban policies resulted in $10 \%$ of the workforce settling in high-density areas in lieu of low-density areas, the reduction in $\mathrm{CO}_{2}$ would be about $5 \%$. To achieve more substantial changes in density, indirect or general equilibrium type of effects may have to be taken into consideration.

Urban form, and policies that affect urban form, such as land use and transportation planning, deserve more attention in climate policy debates because they can contribute to significant reductions in greenhouse gases.

Source: Grazi et al. (2008).

In the building sector, residential and commercial settlement patterns impact the size of dwellings and office buildings. For a given urbanised area, a higher population density implies less available space for individuals. This, in turn, influences the type and amount of energy required for daily activities (heating, cooling, etc.). At the same time, scarce aeration due to the physical proximity of buildings, coupled with the replacement of vegetation by impermeable surfaces that retain heat (such as asphalt) can also contribute to the urban heat island effect, in which urban areas become warmer than nearby rural areas, particularly at night. Urban land use and its functions are shaped by a number of spatial policy instruments, notably through zoning, regulating density and building height, and infrastructure investments (in roads, public transportation or amenities for cycling and walking). In addition, changes in modal split, which shift the scales from private vehicle use in favour of energy-efficient transport modes like walking, biking and public transport, can reduce transport-related GHG emissions, as well as the energy required for heating. 
Modelling and analysis of the impacts of climate change policies on emissions reduction have long been dominated by aggregate approaches with a national and international perspective. The role of spatial organisation, including land use planning and urban form, has often been neglected in these macroanalyses, along with its impacts on transport. Nevertheless, a growing body of research affirms that land use and transportation are inextricably linked. Research in the U.S. provides evidence that transportation investments and policies influence development patterns, particularly development that occurs along highway corridors or at interchanges. At the same time, development patterns shape travel patterns, insofar as the design of suburban areas makes transit and walking a challenge or the separation between land uses in low-density developments makes driving a necessity (Handy, 2005). As a result, transportation investments can contribute to sprawl, as evidenced in the case of highway development, but can also potentially be used as strategies to help fight sprawl (with investments in public transit, for example). Efforts to reduce energy use and greenhouse emissions benefit from dense urban form. As density increases, $\mathrm{CO}_{2}$ emissions from transport go down, as does per capita electricity demand (OECD, 2010c).

Integrated transportation and land use planning efforts can lead to significant reductions in greenhouse gas emissions. A number of policy tools exist to facilitate compact development, through mixing landuses, improving mass transit services and providing urban amenities. These include reducing existing regulatory barriers to more compact development, including barriers to mixed-use, transit-oriented and brownfields development, accompanied by fiscal reform that internalises environmental and public services costs incurred by new development and concentrates urban amenities and services in priority growth areas. These instruments, and the extent to which they are relevant to the case of Korean cities, are examined in further detail below.

\section{(ii) Policy instruments for greening urban transportation in Korea}

As mentioned in the first section of this paper, energy use from the transportation sector in Korea accounted for $19.7 \%$ of total domestic energy demand in 2009 (KEEI, 2011). From an aggregate national policy standpoint, Korea's National Strategy for Green Growth proposes to cut transport-related emissions by enhancing energy efficiency and developing new and renewable energies. In particular, renewable fuel standards are to be developed in order to make bio-diesel and biogas available for private and public vehicles, with the goal of biodiesel reaching $3 \%$ of fuel demand in the transportation sector by 2012, and $7 \%$ by 2020 (UNEP, 2009).

While the promotion of renewable energy sources will be crucial to meeting the stabilisation target of transport-related emissions in Korea, complementary, local transportation and land-use measures will also be necessary. First, Korea aims to increase the share of public transit to 55\% of all transport activity by 2013 (Presidential Commission on Green Growth in Korea, 2009). Green transportation interventions include the planned expansion of the railroad networks, with the objective of increasing train ridership from $18 \%$ in 2009 to $22 \%$ in 2013, in addition to the construction of multi-modal transportation centres in urban areas. The greening of the transportation network will be possible due to relevant investment capacity (around USD 8.5 billion) and is expected to create 16000 new jobs (Cho, 2009). Land-use zoning changes and densification policies are expected to reduce average commuting distances and travel time, thus encouraging individuals to switch from private vehicles to public transportation. Finally, to increase the rate of bicycle use from $1.5 \%$ in 2009 to $5 \%$ by 2013, the government plans to construct $3114 \mathrm{~km}$ of new bike lanes in urban areas (PCGG, 2009).

This section examines a range of market-based and nonmarket-based instruments that can be used to green the transportation sector. While market-based instruments tend to be effective in the short term (EPA, 2006; EEA, 2007), the role of complementary spatial planning and other regulatory measures may be important in the longer run. Moreover, a distinction should be made on the basis of the direct versus indirect impacts of the instruments on the target. On the one hand, some market-based instruments may 
directly reduce the average demand for transport in urban areas or promote a shift in modal split toward less energy-intensive travel modes (for commuting especially). On the other hand, acting on the spatial structure of the economy through physical planning can be seen as an indirect instrument to alter individuals' travel behaviour (Grazi and van den Bergh, 2009).

These measures can contribute to reductions in transport-related GHG emissions by inducing changes to the modal split, increasing the energy efficiency of vehicles and transport infrastructure, encouraging (or discouraging) the use of certain fuels, and reducing congestion and transport volume. In meeting this global objective, most options give rise to various co-benefits as well, in terms of reduced local pollution and improved quality of life and health impacts.

Market-based instruments. Market-based instruments, such as fees, tariffs, taxes or tradable permit schemes are generally cost-effectiveness tools to achieve environmental goals, such as emission reduction targets, as captured by equalisation among polluters of marginal abatement costs. What is more, pricing instruments can stimulate the search for new investments or innovation through $R \& D$, thereby reducing the monetary burden, e.g. the payment of an environmental tax (e.g., Perman et al., 2003).

In the context of curbing GHG emissions from urban transport we consider three different price instruments:

Parking tariffs. Parking tariffs can help stimulate the shift from private to public transport modes and/or discourage non-residents to use their automobiles, resulting in lower GHG emissions. Some parking tariff schemes increase the hourly cost of parking and/or limit the available parking time; others distinguish between residents and other users of public urban parking spaces (Calthorpe, 2000). In Korea, local governments have the authority to apply parking tariffs in cities. Most Korean local governments currently operate their own parking tariff policies, although the policy structure is relatively simple in most areas (e.g. single tariff charged in proportion to the time parked, with an exemption for the disabled). Changing the tariff policy is often met with opposition from residents. Depending on the source of the vehicles (e.g. residents or non-residents), one solution could be for local governments to consider more flexible parking policies that distinguish between residents and non-residents (as is the case in Paris, where residents are given the possibility to park longer than non-residents) or vary the pricing based on the location or time of day. Lower parking tariffs could be adopted for low-emission (hybrid and electric) vehicles, which may be effective in promoting the modal shift towards less pollutive modes of transport. In order to generate broader public support for parking tariff policies, this approach should be combined with other instruments and incentives that discourage private vehicle use and encourage public transit, walking and cycling.

Road charge. Taxing the use of roads is an old idea (Henderson, 1974) that has been implemented in different urban contexts: Singapore, Norwegian municipalities, and most recently London and Stockholm. Congestion pricing exists in different forms, but most commonly consists of setting a price on busy roads during peak hours or levying a charge to access a specific zone, such as the centre city. Seoul is the only city to have introduced road charging in Korea, with a limited approach that was launched in 1996 . The policy charges a fee to private cars (with less than three passengers) running through the Namsan 1st \& 3rd Tunnel, notorious for heavy traffic congestion. Although traffic data should be accumulated for a robust impacts analysis, a preliminary assessment of the policy suggests that it has been relatively successful in reducing traffic volumes in the tunnel, with only a slight increase in traffic volume on detour roads. Between 1996 and 2006, traffic volume of private vehicles decreased by 20.8\% in the tunnel and increased by $1.4 \%$ on detour roads, as drivers chose to take bypass roads in order to avoid the charge (Mo, 2009). At the same time, average traffic speed through the Namsan Tunnel increased by $115 \%$. 
This type of congestion charge could be expanded to other areas of Seoul, and to other cities. The Area License System, which charges a fee to traffic flows in and out of designated zone, in Singapore, Stockholm and London are strong examples. Further reductions in traffic volume in urban areas could be achieved through the implementation of a Vehicle Quota System to directly control the growth of the vehicle stock (as is the case in Singapore). To increase the political acceptability of these types of fiscal disincentives, complementary measures to improve public transport should also be implemented so as to limit redistributive inequities. Fees collected could be invested for improvements in public transit, as in London. Singapore promised revenue neutrality by reducing vehicle taxes, while the Dutch proposed to replace vehicle ownership-based charges with usage-based charges (ITF, 2010).

Land use tax. An increasing number of municipalities have replaced taxes on the value of buildings with taxes on the value of land sites, resulting in a decoupling of land value from the value of real estate improvements (Cohen and Coughlin, 2005). With the most famous example in Pittsburgh (Pennsylvania, U.S.) (Oates and Schwab, 1997), nowadays more than 700 cities worldwide use a "two-rate" taxation system, whereby the majority of property values is represented by land, whose value is often increased as a result of public investments in the surrounding area (e.g. attractive neighbourhoods and services). As a result, property owners benefit from an increased value for which they bore none of the cost. Empirical and theoretical studies have shown that the "two-rate" scheme can lead to higher quality of residential buildings, greater production output, higher rates of employment, increased urban security, less speculation, lower land prices, and ultimately higher population densities, which can contribute to reduced commuting distances and transport-related GHG emissions.

In Korea, under the central government's property tax scheme, local governments impose a "two-rate" property tax on land and buildings. However, a standard of assessment declared by the central government (the appraised value of land) and local governments (defined as a ratio multiplied to the appraised value of land) has been criticised for generating values that are too low relative to the market value (e.g. $23 \%$ of market value in 2003) or economic value, and focusing on the acquisition stage rather than possession (Ji, D. and S. Choi, 2003). The Korean government could make refinements to the property tax system by incorporating land value and the land tax scheme by using the state of Virginia's case, which estimates land use value by the productive potential of land.

Non-market-based instruments. Nonmarket-based instruments include command-and-control measures (such as standard setting and the enforcement of regulations) and integrated spatial and transportation planning. These types of instruments are rarely effective alone, but can be crucial complementary policies to the market-based instruments described above.

Command-and-control measures (e.g. land-use (zoning) regulations, fuel efficiency standards). Zoning regulations that limit vehicle access (or the access of certain types of vehicles, such as heavy trucks) in certain zones is a clear example of a command-and-control measure at the urban scale. These types of policies can be implemented to address externalities like noise and pollution intensity (including GHG emissions) associated with heavy ${ }^{12}$ cars and trucks. Zoning may influence the demand for transport volume, notably by reducing traffic by heavy cars in urban centres, which can in turn help to reduce GHG emissions per kilometre driven. Only recently, some metropolitan governments in Korea (for example, Daegu, Busan and Incheon) have introduced "Transit Mall Districts", which are only accessible to public transit and bicycles. The policy has been met with some resistance, however, due to uncertainty about the effect on congestion levels in nearby districts and on local businesses.

12. "Heavy" in terms of motor capacity and weight 
In order to expand this type of zoning and generate greater public support, cities could increase the flexibility of these instruments, for example by allowing low-emission cars to access the district during certain hours, and by committing to invest revenues from fines into public transportation improvements and urban amenities. London's Low Emission Zone (LEZ) is a good case. Since 2008, public authorities have operated a LEZ that prohibits access by most polluting heavy diesel vehicles, and plans to apply tighter standards in 2012, under which more vehicles would be affected (Transport for London, 2011).

Spatial planning. A number of studies have provided evidence of the positive role of physical (urban) planning in effectively curbing long-term urban GHG emissions (notably from transport), although this type of instrument has not been shown to be effective in the short term (Greene and Schafer, 2003; Rietveld 2006, Waisman et al., 2010). Cities' reactions to changes in the spatial structure (involving the relocation of activities, new buildings and new infrastructure) occur with a certain time lag. Mismatch between land use and transportation policies has all too often aggravated traffic congestions around metropolitan cities. For instance, the introduction of a beltway around Seoul in 1999 was succeeded by the construction of five new cities (Bundang, Ilsan, Pyeongchon, Sanbon, and Jungdong) around Seoul three years later, leading to considerable traffic congestion around Seoul. Another case is the development northwest of the Yong-in area. Nearly 250000 newly constructed homes were built in the area in 2006, but connected to Seoul via a single road (Route 23) and, at the time, no subway service (Jung et al. 2010). The resulting traffic jams were significant.

Korea could more actively pursue compact Transit-Oriented Development (TOD), which consists of higher density and mixed-use development near transportation stations, combined with public investment on mass-transit. In Curitiba, urban growth is channelled along structural axes based on mass transit routes and on modal interchange nodes through a combination of densification, intensification and mixed land use measures (Burgess, 2000).

The long-term effectiveness of physical planning relies upon the efficacy through which space is reorganised given the presence of economic activities. For example, in a time of low energy prices, planning of American cities as "car-dimensioned cities" has been effective in guaranteeing high flows of vehicle traffic and increased ownership rates (which both contribute significantly to GHG emissions).

Urban design and physical planning can help to discourage the use of energy-intensive private vehicles and promoting a modal shift by designing safe bike lanes and altering the functions and uses of old buildings. Projects aimed at reducing travel distances and thus increasing residential and employment density, accompanied by adequate mobility planning and transit supply, can be effective in decreasing the demand for transport as well as stimulating modal split toward less polluting modes. A number of empirical (mainly economic) studies confirm the positive effect of denser urban form on reducing travel distance per capita (e.g., Boarnet and Sarmiento, 1999; Bento, et al., 2005).

\section{(ii) Policy instruments for greening the building sector in Korea}

Korea's building sector has become a major focus for national greenhouse gas reduction efforts, given its high levels of energy consumption. As mentioned in the first section, building-related energy use accounts for approximately $24 \%$ of overall domestic energy demand, taking into account the building's life cycle (construction, operation and demolition). Efforts to cut emissions from this energy-intensive sector are expected on the national level by promoting green technologies in the building sector, developing renewable energy and establishing an energy efficiency rating certification system. The use of solar energy, thermal heat and wind power in new apartments and homes and larger public buildings (such as universities, which alone are responsible for $14 \%$ of total energy demand) is planned in phases and should help curtail overall energy use and associated GHG emissions. After building one million settlements following the renewable energy paradigm, another million homes and buildings will be gradually 
substituted by more energy efficient buildings starting 2010. The National Strategy for Green Growth moreover foresees the construction of 14 "Environment Energy Towns" and a total of 800 low-carbon green villages in eight distinct geographical zones of Korea. Finally, the standard illumination system in public buildings will be replaced by the light-emitting diode (LED) system. Investments are planned to be mobilised for a total of USD 7 billion and expected to generate 150000 employment opportunities.

A handful of market-based and nonmarket-based instruments can be used to reduce GHG emissions in the building sector. These measures can contribute to a greener building sector by altering the equipment demand in terms of both structural housing features (size and insulation) and household appliances; increasing the energy efficiency of buildings and household appliances; promoting renewable energy use (solar, geothermal energy or biomass); and reducing energy demand.

Market-based and regulation (command-and-control) instruments in the building sector are generally effective in the short to medium-term, whereas urban planning tends to generate results over the long term. These instruments also differ by the economic mechanisms through which they are employed: on the one hand, market-based policies can directly affect energy efficiency and building equipment through the investments in equipment, which in turn can slow down overall energy consumption. On the other hand, urban planning can indirectly shape individuals' energy consumption by altering the type and nature of the building stock.

Market-based instruments. A possible source of failure of energy policy may be represented by distortion in the market mechanisms that drives demand and supply of housing service away from optimum. This is the case of investment decisions by agents that are not necessarily the ultimate beneficiary of such an investment. For instance, landlords have little to any fiscal incentive to improve a building's energy efficiency if the tenants are footing the energy bill, and tenants, for their part, aren't often willing to make the necessary investments in a rental property. Market-based measures like grants, subsidies, tax cuts and credits are set in place to compensate for the extra cost of investing in energy efficiency appliances and projects, or to encourage actors to invest in energy efficiency products.

The Korean government could develop policies to provide landlord incentives. According to a recent OECD survey (2011e), homeowners are more likely to invest in energy-saving equipment than tenants. The Korean government could develop policies to target specific household groups with different incentives, for example to provide the homeowner incentives including direct subsidies to install energyefficient equipment, and at the same time rights to reclaim the costs for such investments (OECD, 2011e). Also, tax cuts for green building investment could be another useful policy instrument.

Non-market-based instruments. Nonmarket-based instruments include command-and-control measures for regulating actors' behaviour, such as energy performance requirements or pre-defined energy efficiency standards, which make energy-efficient choices compulsory. Examples of command and control measures implemented worldwide include building codes and standards, as it is the case of thermal regulations, appliance and equipment standards and mandatory energy performance certificates. Since 2007, an energy performance evaluation is required for each housing transaction in France, which has generated a need for specialised workers in the construction sector, leading to job creation. Korea has also introduced various regulatory policy instruments, such as reinforced building codes and the mandatory estimation of energy consumption and the submission of an energy savings plan when applying for a building permit. The government has also introduced the Eco-friendly Building Certificate and Energy Efficiency Grading instruments to provide the housing market with information about energy efficiency. However, challenges remain in determining how to efficiently regulate energy consumption behaviour of existing residences. In this case, multiple policy instruments such as incentives or disincentives, in addition to policies to increase consumer awareness, should be considered as essential elements of an integrated policy package. Seoul's "Eco Mileage programme" could complement regulatory measures. Under this 
programme, citizens who reduce $10 \%$ of GHG emissions from electricity, water, and gas consumption are entitled to 50000 miles, which can then be used to buy eco-friendly products.

Pursuing integrated transportation and land-use and spatial planning will be essential for Korea to achieve greener growth. A policy mix of both market-based and nonmarket-based instruments are needed to provide a coherent policy message that encourages sustainable transport modes and spatial and building form, while discouraging less efficient travel modes and urban settlement patterns. A compact, transitoriented development strategy can underpin complementary market-based measures, such as comprehensive road charging in cities and parking tariffs, and nonmarket-based interventions, such as energy efficiency labelling and more sustainable building codes.

\section{Implementation of the Green Growth Strategy: bridging the gaps in multi-level governance}

Diagnosis of co-ordination gaps in delivering a coherent response to current economic and environmental pressures represents one of the primary challenges in multi-level green growth governance. Several governance gaps can be observed in the context of green growth in Korean cities; gaps can exist in terms of administrative boundaries, policy, information, capacity, funding, objectives, accountability and the market (Table 20). 


\section{Table 20. Governance "gaps" for delivering green growth in Korean cities}

\begin{tabular}{|c|c|c|}
\hline Name of the Gap & What is it about? & How does this occur in Korea? \\
\hline Administrative gap & $\begin{array}{l}\text { Occurs when there is a geographical mismatch between the } \\
\text { green growth challenge or opportunity and administrative } \\
\text { boundaries. Most of the time, administrative boundaries } \\
\text { (municipalities, regions, and states) are not fixed according } \\
\text { to the greening challenge/opportunity logic and frontiers, } \\
\text { resulting in a mismatch at the sub-national level that hinders } \\
\text { the coherence of policymaking and makes the relationships } \\
\text { between elected representative, local authorities and end- } \\
\text { users more complex. }\end{array}$ & $\begin{array}{l}\text { Existing administrative boundaries do not always correspond to the } \\
\text { delimitations of functionally integrated economic regions. As a result, it } \\
\text { can be difficult to address air pollution sources that are generated } \\
\text { across administrative boundaries (e.g. in the transportation sector). }\end{array}$ \\
\hline Policy gap & $\begin{array}{l}\text { Refers to the sectoral fragmentation of policy tasks and } \\
\text { powers across ministries and public agencies within the } \\
\text { central government administration as well as among different } \\
\text { departments within sub-national government administrations. } \\
\text { Silo approaches in policymaking foster incoherence between } \\
\text { sub-national policy needs and national level policy initiatives } \\
\text { and reduces the possibility for cross-sectoral policy } \\
\text { coherence and implementation at the sub-national level. It } \\
\text { also creates uncertain market conditions that may inhibit } \\
\text { companies from entering the marketplace in this city-region, } \\
\text { or create conditions that make it difficult to obtain capital for } \\
\text { infrastructure investments, business operations or } \\
\text { expansion. }\end{array}$ & $\begin{array}{l}\text { Fragmentation of urban policies in general exists at the central level in } \\
\text { Korea, as well as for green growth-related tasks involving different } \\
\text { government ministries and agencies. } \\
\text { At the urban scale, there is also a need to harmonise emerging green } \\
\text { growth policies within the already fragmented local development policy } \\
\text { framework, a result of separate plans for municipal economic } \\
\text { development, spatial development and sectoral development. To a } \\
\text { limited extent, local and regional governments have incorporated green } \\
\text { growth goals and policies into regional economic development plans } \\
\text { and the development plans of Daily Living Spheres. For example, in } \\
2011 \text {, green growth was included as one of the ten major tasks for local } \\
\text { areas. However, economic development plans remain separate from } \\
\text { spatial development and sectoral plans, resulting in fragmented local } \\
\text { development policy. }\end{array}$ \\
\hline Information gap & $\begin{array}{l}\text { Happens when there is an asymmetry of information across } \\
\text { ministries, between levels of government and across local } \\
\text { actors involved in specific policy areas. An asymmetry of } \\
\text { information may also occur when national and sub-national } \\
\text { authorities do not share their knowledge of what is } \\
\text { happening "on the ground," creating win-lose situations by } \\
\text { specific use of information not in the possession of the other } \\
\text { party. }\end{array}$ & $\begin{array}{l}\text { Inconsistent, or nonexistent, methodologies for establishing local } \\
\text { emissions inventories hamper the ability of cities to assess progress } \\
\text { toward green growth over time and across locations. }\end{array}$ \\
\hline
\end{tabular}




\begin{tabular}{|c|c|c|}
\hline Name of the Gap & What is it about? & How does this occur in Korea? \\
\hline Capacity gap & $\begin{array}{l}\text { Is generated by insufficient scientific and technical expertise, } \\
\text { know-how and infrastructure to design and implement policy. } \\
\text { The capacity gap is particularly acute to issues related to } \\
\text { environment and green growth. When there is a difference } \\
\text { between the capacity required for carrying out certain } \\
\text { responsibilities, and the organizational, technical, procedural, } \\
\text { networking and infrastructure capacity available within the } \\
\text { local authority, impacts on the implementation of desired } \\
\text { policies are unavoidable. The capacity gap also applies to } \\
\text { the national level in terms of managing multi-level relations, } \\
\text { allocating responsibilities and funds, and ensuring } \\
\text { coordinated, coherent policy approaches among central level } \\
\text { actors. }\end{array}$ & $\begin{array}{l}\text { A lack of green growth expertise at the local level (especially in small } \\
\text { and medium-sized cities) hinders the effective implementation of green } \\
\text { growth strategies at the urban scale. }\end{array}$ \\
\hline $\begin{array}{l}\text { Funding (or fiscal) } \\
\text { gap }\end{array}$ & $\begin{array}{l}\text { Refers to the insufficient or unstable revenues to implement } \\
\text { policy across ministries and levels of government. This gap } \\
\text { reflects a mutual dependence between levels of government } \\
\text { where sub-national authorities depend on higher levels of } \\
\text { government for funding support, while central government } \\
\text { depends on sub-national authorities to deliver the policy } \\
\text { goals and meet both national and sub-national priorities. A } \\
\text { funding gap can also occur if private capital is too costly } \\
\text { because of perceived implementation risks or other factors } \\
\text { that make private lenders or investors wary of entering the } \\
\text { local marketplace. In the case of green growth initiatives, } \\
\text { there may also be a disconnect related to the return on } \\
\text { investment requirements of the project sponsor, who seeks a } \\
\text { shorter payback period than the project is capable of } \\
\text { delivering. }\end{array}$ & $\begin{array}{l}\text { Most green growth initiatives have been heavily financed by the central } \\
\text { government, given the generally low levels of self-reliance of local } \\
\text { governments. }\end{array}$ \\
\hline Objective gap & $\begin{array}{l}\text { Occurs when diverging or contradictory objectives between } \\
\text { levels of government or departments/ministries compromise } \\
\text { the adoption of convergent targets over the long run. } \\
\text { Frequently, when clear priorities are not formulated at the } \\
\text { highest political level, conflicting interests prevent any } \\
\text { consensus on common and aligned targets towards effective } \\
\text { policies. Overall, the objective gap underlines the difficulties } \\
\text { of governments to foster strategic and territorialised planning } \\
\text { engaging all relevant stakeholders over the long run, beyond } \\
\text { political changes and electoral calendars. The objective gap }\end{array}$ & $\begin{array}{l}\text { The dual economic and environmental aims of green growth can at } \\
\text { times lead to conflicting objectives. As mentioned previously, the design } \\
\text { of the Gangneung-si green city demonstration project was initially } \\
\text { hampered by conflicting objectives of the ministries involved in the } \\
\text { project, understandably due to differences in the scope of each } \\
\text { ministries' work: MOE wished to focus on environmental protection } \\
\text { while MLTM stressed the development process and maximisation of the } \\
\text { return on investment. }\end{array}$ \\
\hline
\end{tabular}




\begin{tabular}{|c|c|c|}
\hline Name of the Gap & What is it about? & How does this occur in Korea? \\
\hline & $\begin{array}{l}\text { may also arise if local political or policy interests do not align } \\
\text { with the interests or needs of private sector stakeholders, } \\
\text { causing them to exit the local market entirely or restrict } \\
\text { efforts to expand in the city/region. }\end{array}$ & \\
\hline Accountability gap & $\begin{array}{l}\text { Refers both to the lack of transparency in policymaking, } \\
\text { integrity and institutional quality issues. Ensuring } \\
\text { transparency practices across different constituencies is } \\
\text { crucial for effective implementation of policies. In addition, } \\
\text { with the development of private sector participation in some } \\
\text { sectors related to green growth, the traditional government } \\
\text { accountability is changing. In this context, the accountability } \\
\text { gap can be reflected in the market entry process, award } \\
\text { criteria, as well as contract provisions for unforeseen } \\
\text { contingencies. }\end{array}$ & $\begin{array}{l}\text { Although the Presidential Committee on Green Growth (PCGG) } \\
\text { includes a range of stakeholders, including representatives of the } \\
\text { private sector, non-governmental agencies, industries, universities and } \\
\text { civic groups, there are currently no representatives from local } \\
\text { governments, presenting a potential gap in the accountability of the } \\
\text { PCGG at the local scale. }\end{array}$ \\
\hline Market gap & $\begin{array}{l}\text { Arises when a policymaking goals or ambitions do not align } \\
\text { with the ability of private sector stakeholders to deliver on } \\
\text { these goals. The private sector is a critical partner in } \\
\text { horizontal co-ordination efforts to advance green growth, } \\
\text { because businesses serve many different roles in delivering } \\
\text { this growth such as :direct service providers contracted by } \\
\text { government to carry out certain greening functions (e.g. } \\
\text { transport provider, energy supplier, water treatment plant } \\
\text { operator, contractor responsible for energy efficiency or } \\
\text { climate adaptation upgrades, etc.) or innovator designed to } \\
\text { address green growth challenges or opportunities. To the } \\
\text { extent certain green business sectors are immature in a city- } \\
\text { region, that will inhibit the success of certain policy solutions } \\
\text { and clarify the need for policy action or improved } \\
\text { coordination between different governmental entities. } \\
\text { Include. }\end{array}$ & $\begin{array}{l}\text { The market for green technology is still at an early stage in Korea, and } \\
\text { could be hampered in the long run by the current limits of small and } \\
\text { medium-sized businesses to participate widely in the green growth } \\
\text { industry. }\end{array}$ \\
\hline
\end{tabular}


Although these gaps could apply more or less to all countries, in the case of Korea, we will focus on four main governance gaps: (i) the policy gap, (ii) the administrative gap; (iii) the fiscal gap; and (iv) the information and capacity gap.

\section{(i) Addressing the policy gap: the need for clear market signals and policy coherence}

In order for sub-national authorities to effectively implement the National Strategy for Green Growth, the central government will need to provide a more coherent policy message across all sectors and levels of government. This includes (a) establishing clear pricing signals on carbon and greenhouse gas emissions; (b) resolving inter-ministerial conflicts that have led to policy fragmentation; and (c) addressing fragmentation and inconsistencies of planning instruments at the regional and local levels.

(a) The establishment of clearer pricing signals can help guide investment in green growth at the sub-national scale. Putting a price on pollution or on the over-exploitation of a scarce resource through mechanisms such as taxes or tradable permit systems should be a central element of the green growth policy mix (OECD, 2011c). These policy instruments tend to minimise the costs of achieving a given objective and provide incentives for further efficiency gains and innovation. The OECD has previously recommended the introduction of a comprehensive cap-and-trade emissions trading system in Korea, combined with a carbon tax levied on households and offices to put a global price on greenhouse gases and contribute to achieving the mid-term emission reduction targets (Jones, R. and B. Yoo, 2010). To complement this strategy, Korea could also remove environmentally harmful direct subsidies for coal and the more indirect subsidy of selling electricity at prices below cost, notably in the agriculture sector.

(b) A comprehensive approach to urban development in Korea at the national level should be pursued to generate more effective green growth outcomes. An integrated approach to urban development has traditionally been stymied in Korea, as in many OECD countries. In particular, urban policy mandates are fragmented across many ministries, particularly those administrations responsible for public administration, regional development, transport, environment, public finance and budget, culture and protection of national heritage, higher education and health. The atomisation of administrative mandates across a wide range of central ministries with jurisdiction over urban issues is not always compatible with an effective, coherent, multi-sectoral approach to urban development. Harmonising urban development plans with economic development, environmental planning and sectoral plans can lead to conflicts.

The implementation of green growth policies has further aggravated inter-ministerial conflicts. For instance, climate change statistics relating to the environment, land use and sea levels and meteorological trends have historically been collected by a handful of different ministries, each of which is loath to share information with others. As a result, each ministry bases its climate change scenarios on different baseline information, resulting in at times conflicting policy measures (Lee et al, 2009). The establishment of the Greenhouse Gas and Energy Target Management System in 2010 was at the heart of a fierce struggle over which ministry would take charge of greenhouse gas emissions regulation. In the end, the Ministry of Environment was designated to co-ordinate the institution and collect data from four ministries, each of which was responsible for designating the "controlled entities" in their sectors of competency. As mentioned previously, tensions between competing ministries became evident early in the planning stages of the Gangneung Green City project. (Wang, K.I., 2010). Employing partnership development tools such as a Memorandum of Understanding, as was one of the solutions to moving forward with the Gangneung project, can help clarify roles and responsibilities. 
(c) At the urban scale, there is also a need to harmonise emerging green growth policies within the already fragmented local development policy framework, a result of separate plans for municipal economic development, spatial development and sectoral plans (Table 21). The Ministry of Land, Transportation and Maritime Affairs must approve provincial comprehensive and metropolitan area plans and ensure that any changes are in line with national legislation. At the local level, however, two different planning frameworks guide urban development: the urban master plan is a long-term plan (generally 20 years) that communicates the vision and direction of local development, while the urban management plan is for ten years, and unlike the urban master plan, includes enforcement mechanisms to ensure that administrative officials manage urban areas and protect them from uncontrolled development.

To a limited extent, local and regional governments have incorporated green growth goals and policies into regional economic development plans and the development plans of Daily Living Spheres (Table 21). ${ }^{13}$ For example, in 2011, green growth was included as one of the ten major tasks for local areas. However, economic development plans have been separate from spatial development and sectoral plans, resulting in fragmented local development policy. Policy coherence at the urban/regional level also requires pursuing integrated transportation and land use planning. A number of policy tools exist to facilitate compact development, through mixing land-uses, improving mass transit services and providing urban amenities. These include reducing existing regulatory barriers to more compact development, including barriers to mixed-use, transit-oriented and brownfields development, accompanied by fiscal reform that internalises environmental and public services costs incurred by new development and concentrates urban amenities and services in priority growth areas. To more effectively incorporate green growth policy tools into existing multi-layer urban planning, Korea could consider the policy instruments based on experiences in other OECD countries, for example the development of instruments like the Chartes d'objectifs and Contrats de Villes (France) or the creation of a Secretariat for Cities (Canada).

Table 21. Urban planning in Korea

\begin{tabular}{|l|l|l|l|}
\hline Type of plan & Purpose of plan & $\begin{array}{l}\text { Lead(s) for } \\
\text { implementation }\end{array}$ & $\begin{array}{l}\text { Lead(s) for } \\
\text { approval of } \\
\text { plans }\end{array}$ \\
\hline $\begin{array}{l}\text { National } \\
\text { Comprehensive Plan }\end{array}$ & $\begin{array}{l}\text { Direction for long term national } \\
\text { development } \\
\text { Strategies for improving industry and } \\
\text { balanced development }\end{array}$ & $\begin{array}{l}\text { Minister of Ministry of } \\
\text { Land, Transport and } \\
\text { Maritime Affairs (MLTM) }\end{array}$ & $\begin{array}{l}\text { President of } \\
\text { Korea }\end{array}$ \\
\hline $\begin{array}{l}\text { Provincial } \\
\text { Comprehensive Plan }\end{array}$ & $\begin{array}{l}\text { Direction for long term development } \\
\text { at regional level }\end{array}$ & Governor of province & $\begin{array}{l}\text { Minister of } \\
\text { MLTM }\end{array}$ \\
\hline $\begin{array}{l}\text { Metropolitan Area } \\
\text { Plan }\end{array}$ & $\begin{array}{l}\text { Common interest in spatial } \\
\text { development and inter-regional } \\
\text { infrastructures with adjacent local } \\
\text { authorities }\end{array}$ & $\begin{array}{l}\text { City mayor, governor of } \\
\text { province, or Minister of } \\
\text { MLTM }\end{array}$ & $\begin{array}{l}\text { Minister of } \\
\text { MLTM }\end{array}$ \\
\hline Urban Master Plan & $\begin{array}{l}\text { Direction of spatial development of } \\
\text { each local authority for a long term }\end{array}$ & $\begin{array}{l}\text { City mayor, county } \\
\text { governor, metropolitan city } \\
\text { mayor }\end{array}$ & $\begin{array}{l}\text { Governor of } \\
\text { province } \\
\text { Metropolitan city } \\
\text { mayor }\end{array}$ \\
\hline $\begin{array}{l}\text { Urban Management } \\
\text { Plan }\end{array}$ & Practical measures of urban policy & $\begin{array}{l}\text { City mayor, county } \\
\text { governor }\end{array}$ & $\begin{array}{l}\text { Governor of } \\
\text { province }\end{array}$ \\
\hline
\end{tabular}

13. A total of 161 cities (Sis) and counties (Guns), excluding the wards in Seoul and other metropolises, are eligible for developing Daily Living Sphere plans. These cities and counties accounted for $54 \%$ of the population in 2007. The scheme, which also may be reflected in local urban management plans, calls for both local government efforts to foster their growth potential and central government support to guarantee minimum living conditions 


\section{(ii) Addressing the administrative gap: fostering horizontal collaboration}

Enhanced horizontal co-ordination among local governments can enable local authorities to maximise financial and human resources, facilitate knowledge spillovers and help tackle congestion, air pollution, health problems and greenhouse gas emissions (OECD, 2010a). With varying levels of fiscal and technical capacity to respond to climate change, local leaders can assist each other. Knowledge spillovers can be enhanced by collaborative inter-urban frameworks to combat climate change. Hanover, a German metropolitan region with about four million inhabitants, benefits from a regional approach to mitigation and adaptation strategies with its Regional Climate Protection Agency (Klimaschutz-Agentur Region Hannover), which co-ordinates all climate protection activities throughout the region (OECD, 2010a).

Co-operation among local governments remains limited in Korea. Regional governments (provinces and metropolitan cities) tend to see each other as competitors more than as potential partners in development (OECD, 2011d forthcoming). As the country has moved toward greater decentralisation, local governments have been more concerned with how to use their newly devolved responsibilities and position themselves to attract businesses and national financial support. National programmes like the green growth demonstration projects can further exacerbate competition among local authorities, as municipalities compete to become one of the selected projects.

One solution to encourage voluntary modes of co-operation among adjacent municipalities could be to adopt a city-region policy framework to guide policy-making, particularly with respect to intermunicipal partnerships. Korea could benefit from a city-region policy framework, given the interconnectivity of municipalities in Korea and the promise of city-region arrangements to deliver services at a larger scale. City-regional arrangements have recently emerged in England to deliver services such as transport and training, across groups of municipalities within a single, economically integrated urban area. The city-region concept has gained traction there because a number of the underlying factors that shape the urban economy have changed. The ongoing effects of globalisation, increases in long-distance commuting, and expansion of the service and knowledge based economy have widened the scale at which urban economies function. Local authorities recognise that they can no longer tackle housing, transport and training issues within their own boundaries and instead need to collaborate more with their neighbouring authorities. Ultimately this allows city-regions to pool devolved funding with local resources to deliver transport, training and urban regeneration (Larkin and Marshall, 2008).

The various experiments with voluntary inter-municipal co-operation agreements governance in OECD countries show that the central state can play a dominant role in the process, often through the use of fiscal or legal instruments (OECD, 2010a). One such example is Canada, where much of the federal infrastructure programming requires that contiguous municipalities in a functional region, either urban or rural, to partner on joint infrastructure projects where appropriate. Each municipality, rather than ask for its own funding, pools its efforts with others to maximise investment efficiency in the functional region (for waste management or transit, for instance). This approach could be implemented for the implementation of national green growth objective in Korea, for instance, with programming terms and conditions including bonus schemes conditional to funding linked not only to infrastructure but also strategic policy planning. In particular, the central government could develop incentives to facilitate co-operation between metropolitan cites and provinces. Metropolitan cities and provinces could in turn encourage all-sized municipalities within or across their administrative boundaries to co-operate each other sm. Co-operation would be rewarded based on conditionality principle. 
As the green growth strategy includes a wide range of actions that should be implemented at different scales, such collaborative framework requires some flexibility. These types of collaborative arrangements should also be adapted to the different regional contexts to avoid a one-size-fits-all approach, an inherent risk to nationally-led programmes. For instance, the central government's efforts to promote green $\mathrm{R} \& \mathrm{D}$ and innovation at a wider regional scale have been criticised in some areas for failing to take into account the mismatch between the strong industrial base in Ulsan, Busan and Daegu and their poor capacities in R\&D. However, the Korean government has recently begun to develop more localised policy initiatives, such as the "600 Low Carbon Green Villages" project, which aims to establish energy self-reliant villages by installing facilities to generate biomass fuel and wind and water power in rural areas. According to the PCGG (2009), each project will be designed and developed individually, with consideration of the characteristics of each village.

\section{(iii) Addressing the financial gap: diversify funding sources}

With the vast majority of the overall green growth budget financed by the central state through grants or matching funds to local governments, the sustainability of local programmes is a considerable challenge, particularly in urban areas where local authorities rely heavily on central government support in general to fund the overall city budget. What is more, local public finance was severely hit by the recent global economic crisis (OECD, 2011h). The total balance of local government budgets plunged from a surplus of KRW 20.2 trillion in 2008 to a deficit of KRW 7.1 trillion in 2009. Meanwhile, the average fiscal autonomy of local governments decreased from $59.4 \%$ in 2000 to $53.6 \%$ in 2009 and $52.2 \%$ in 2010. In contrast to the capital region, which registers relatively good fiscal autonomy (over 90\% in Seoul, 75.9\% in Gyeonggi Province, $74.2 \%$ in Incheon in 2009), most provinces rely on the central government for two-thirds to three-quarters of their budgets (Figure 21).

Figure 21. Self-reliance ratio of finances in Korean metropolitan/do regions (2009)

Unit: \%

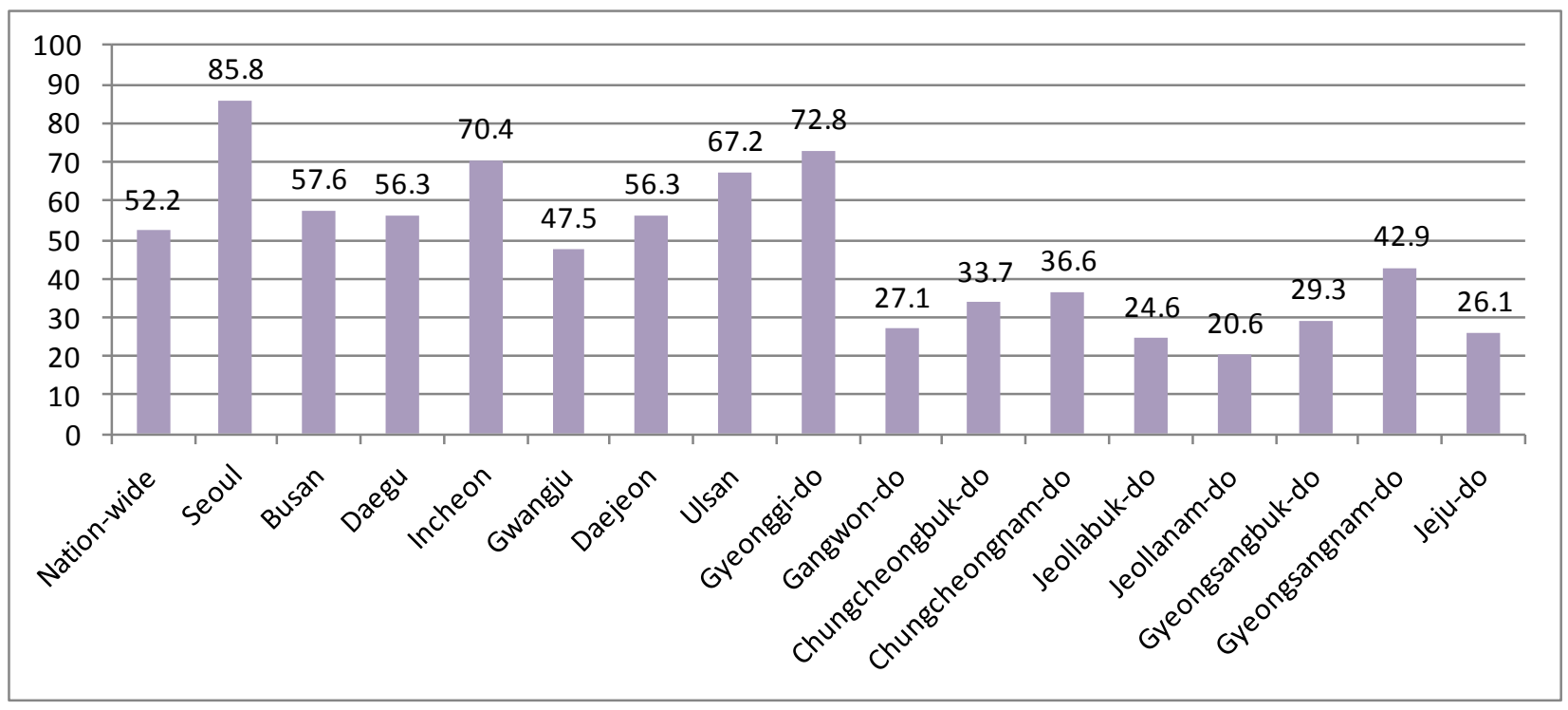

Source: Ministry of Public Administration and Security, 2010. 
Most local government green growth action plans include five-year investment plans, which range from KRW 2.6 trillion in total investment (Ulsan) to KRW 42.2 trillion (Gyeonggi-do) (Figure 22). The highest investment volumes as a portion of GRDP can be found in Gwangju (12.2\%), Jeju (11.6\%) and by Jeollanam-do (10.7\%). However, most local investment plans (Seoul is an exception) rely heavily on central government support in the form of grants and matching funds. The central government is responsible for over $80 \%$ of total green growth investments in Gyeongsanbukdo and approximately $72.4 \%$ in Chungcheongbuk-do.

Figure 22. Funding sources for local green growth plans (2009-2013)

Unit: Trillion KRW

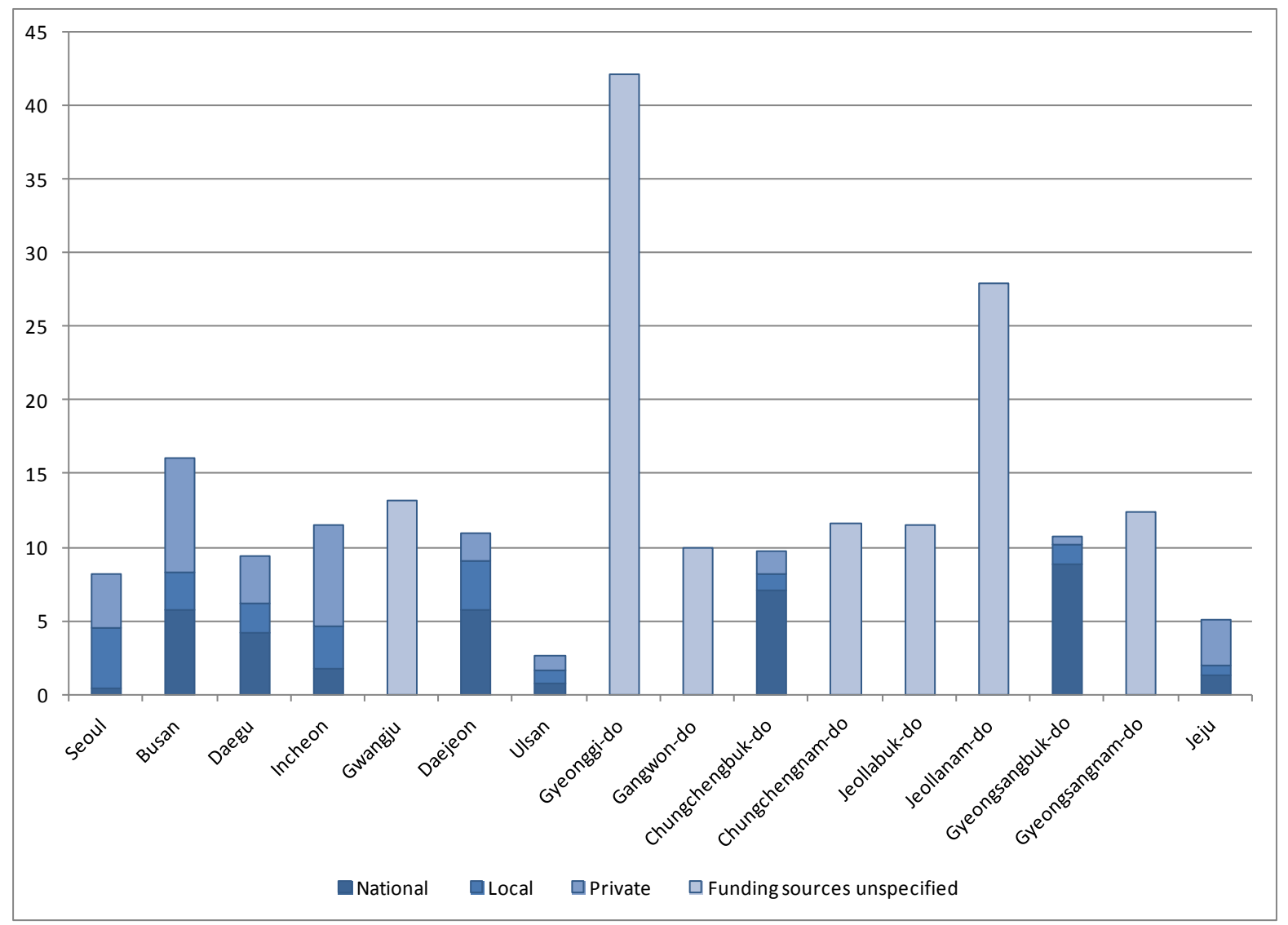

Note: The investment period of Seoul is from 2010 to 2014; 2) " $n$ " indicates that financial resources were not specified by the local authority.

Source: PCGG (2010) and responses to the OECD questionnaire to 16 Metropolitan cities and Provinces.

Limited local fiscal autonomy threatens the resiliency of local authorities because it limits their capacity to respond to the changing priorities of higher levels of government or sudden budget adjustments. Further, low self-reliance ratios render local authorities especially vulnerable to an eventual political regime shift, which could transfer power to an administration with limited or no support for green growth. Seoul, the most financially independent city in Korea, has for decades been a leader in sustainability and green growth policies. While the city benefits from a highly qualified labour force, among many other factors, its financial independence has enabled the city to initiate its own policies and programmes. There has been considerable discussion in Korea over increasing local fiscal autonomy, while focusing on building the revenue base of local taxation such as shifting a 
portion of the national VAT to local governments (OECD, 2005). However, this highly political debate, due to the inevitable sharing of authority that would be required among different level of governments, suggests that change may not be expected in the short term, suggesting that the central government will need to envision a more strategic approach.

Experiences in OECD countries show that national government can play a key role by greening existing urban revenue sources: as discussed previously, congestion charges and road taxes can reduce car travel by private vehicle and fund green infrastructure; and local energy fees that put a price on wasteful energy use can increase efficiency. National governments could also green urban finance by re-designing grants to sub-national governments to correct incentives for unsustainable behaviour and reward cities that create environmental benefits beyond their borders. While in some OECD countries there is room to redesign property taxes so as to stop favouring urban sprawl and start encouraging development in the urban core and around transportation linkages, the local property tax system is not thought to be conducive to sprawl in the case of Korea. In Korea, local property tax is a relatively marginal revenue source for local governments, which has become even more marginal since 2005 when the introduction of the Comprehensive Property Tax (CPT) at the central level was accompanied by a scaling back of the local property tax. A special feature of the property tax in Korea is its progressive character (it is only paid by $2 \%$ of households, mostly in three of the wealthiest wards in Seoul).

In addition to the local finance stream, new financial instruments will be needed to act on green growth in cities. Public-private partnerships, which have been increasingly used by cities in the last few decades, can bolster urban green growth goals under certain conditions. By sharing risks in innovative ways, PPPs can, under the right circumstances, provide better value for money, such as lower prices, than traditional infrastructure procurement. PPPs also have the potential to encourage private (and public) actors to take a more long-term view on spending by relating maintenance spending more closely to capital investment. PPPs can also stimulate energy efficiency in public buildings, given the potential for investments in energy efficiency to generate efficiency gains for the private operator. The use of PPPs can, however, be problematic. In many cases, only the annual PPPagreement payments are visible on government balance sheets, while the private party in a PPP can carry a number of the risks and thus be obliged to record the PPP on its balance sheet. In order to circumvent national or supra-national deficit and debt rules, cities thus might not be interested in assessing a project on its merits, but only on whether it can be done as a PPP, which undermines value for money and long-term fiscal sustainability. Some countries have tried to limit this problem by imposing more strict accounting rules, ensuring a mandated value-for-money process and imposing a maximum amount of transparency about the deal when it is struck.

The use of PPPs as a source of financing green growth actions could be further exploited by local authorities to diversify their funding sources. A survey of 300 companies undertaken by the Federation of Korean Industries revealed that $70 \%$ of the Korean private sector is supportive of green growth and $41.4 \%$ of surveyed firms expressed a willingness to invest in green growth projects (UNEP, 2009). Co-ordinated efforts may also be facilitated through private sector participation on the Presidential Committee for Green Growth, which includes a range of key private sector actors.

In Korea, recourse to the private sector and to private investment to finance and leverage public programmes is relatively recent. Innovation policy programmes so far have been fully funded by the executive branch. For example the Innovative Cluster City Programme had a budget of KRW 29.7 billion in 2005 and increased to KRW 46.2 billion in 2006. With the exception of corporate matching funds for the category technology projects of the industry, research and university, the project was almost entirely financed by the government. For example, business consulting costs for technology projects were entirely covered by the government whereas co-R\&D activities received 
government support only up to $75 \%$. Korea's policy to support industrial complexes tends to use subsidies and investment in hard infrastructure. In general initiatives are led by the public instead of the private sector.

Since the 1997 so-called IMF crisis, however, territorial cooperation through public/private partnerships (PPP) and formal consultation of the private sector have gained ground. Through the PPPs the public sector grants a contract to a private firm to setup an infrastructure and its management or for the supply of a service and its supervision. The private actor acts as the principal that builds and operates the infrastructure and offers a service. In Korea, firms are less reluctant to engage in investment when the government, which usually bears a large part of the risk, manages the partnership. In the period 2003-13 public funding of (hard) infrastructure is estimated to amount to USD 15-30 billion, which is less than estimated needs (OECD, 2005).

In certain infrastructural sectors, notably ICT, the government has been able to induce the private sector to make long-term investments. The central government launched large-scale programmes such as Cyber Korea 21 (1999-2002) and e-Korea vision (2002-07). A fund for the promotion of the information society was established to decouple investment trends from the budgetary constraints and endowed with USD 8 billion between 1993 and 2002 (40\% from public funds with the rest brought by private actors). In 2010, however, the government announced a super-broadband infrastructure that is expected to be completed by 2013. This plan is being developed as a PPP that mobilises USD 24 billion from public funds and USD 32 billion from the private sector. At an urban scale, PPPs are being used to as a supplement to local finances for greening urban area or new development. Pilot projects, including New Songdo City in Incheon, are being pursued in various metropolises, successfully attracting local business and international investment. However, PPPs can bear a high risk of failure if local governments rush into agreements with private partners, without full understanding of local economy, urban characteristics and resources. In order to maximise the possibilities of success, the central government could support local governments by providing sample business models, developing guidelines and reinforcing technical capacity at the local level. ,. Local governments could also provide incentives related to their competences, for example sharing the costs or offering infrastructure, in co-operation with the central government.

\section{iv) Addressing the information and capacity gap: developing measuring and monitoring tools}

To help cities become more effective in the design and delivery of locally tailored policy solutions to climate change, Korea could also pursue the development of harmonised city-scale emissions inventories so that mitigation performance can be monitored, supported and compared across urban jurisdictions. As previous OECD work has shown, at the international level, cities have been active in efforts to reduce greenhouse emissions for at least a decade and the level of ambition and scale of statements of intent to mitigate have grown with time. However, there is a need for cities to bring rigour and structure into their efforts to measure progress in achieving their mitigation goals (OECD, 2010). Harmonised urban inventory methods and reporting is essential to enable performance assessment and comparison across urban locations within a nation, for example, to assist national decision-makers to better understand the potential for, and overall mitigation progress made, at urban scale and to compare cost-effectiveness of policies. The OECD is currently contributing to international efforts to develop a harmonised urban GHG emissions inventory (see OECD, 2011i), although the adoption of a single international protocol is still likely years away. As a result, cities have taken different approaches in defining what sectors to include, in establishing the geographic boundaries of the area included, as well as in aggregating data in different ways, hampering comparison across existing inventories. 
Establishing a common framework for urban inventory remains a challenge in Korea. Emissions data is currently collected nationally, by sector, in each relevant ministry, which in turn submits to GIR "information and statistics about matters under [its] jurisdiction, such as energy, industrial process, agriculture, [waste] and forestry" (Framework Act, Article 45). At the local level, while the guidelines for greening cities developed by the Ministry of Land, Transportation and Maritime Affairs recommends that local jurisdictions establish these inventories from which to base localised action plans, a common framework is still lacking. Since many local jurisdictions lack the technical or financial capacity to develop such inventories, assistance from the national government will be needed to establish a common methodology and monitor progress on the environmental and employment impacts of green growth policies at the metropolitan level. Here, there is potential to expand the current responsibilities of the GIR to include the co-ordination of regional and local emissions data, in addition to the sectoral data it already collects from other relevant ministries. Nevertheless, the GIR should work closely with international bodies, such as the IPCC, to ensure that Korea's methodology corresponds to the approach adopted internationally. 


\section{BIBLIOGRAPHY}

Alussi, A. et al. (2011). "Sustainable Cities: Oxymoron or the Shape of the Future?" Working paper of the Harvard Business School, Boston.

Bank of Korea (2009), “Financial Stability report”, Bank of Korea, Seoul, Korea.

Bento, A., et al. (2005), The effects of urban spatial structure on travel demand in the US. The Review of Economics and Statistics 87, pp. 466-478.

Boarnet, M., and S. Sarmiento (1998), "Can land use policy really affect travel behavior? A study of the link between non-work travel and land use characteristics", Urban Studies 35(7), pp. 11551169 .

Burgess, R. (2000), “The Compact City Debate: A Global Perspective”, in Jenks, M. and R. Burgess (eds.) (2000) "Compact Cities: Sustainable Urban Forms for Developing Countries, Spon Press.

C40 Cities (2011) Best Practices - Energy, www.c40cities.org/docs/casestudies/energy/Changwon\%20-\%20Carbon\%20Mileage.pdf, accessed 25 Feb 2011.

Calthorp, E. (2000), “Parking Policies and Road Pricing”, Urban Studies 37(1), pp, 63-76.

Cho, Won-Dong (2009), "Green Growth National Strategy and Five Year Plan", presentation to the OECD, Paris, 9 September 2009.

Cho, G. N. (2009), "Green New deal and Regional/Urban Policies of Korea", discussion paper presented at the OECD roundtable Green Cities: New Approaches to Confronting Climate Change, Las Palmas de Gran Canaria, Spain, 11-12 June.

Cho, K.W, et al. (2009), Vulnerability Assessment of the Korean Coast due to Sea-level Rise and Appropriate Response Strategy, KEI, Seoul, Korea.

Choi. G., J. Choi. and H. Kim (2005), "The Impact of High Apparent Temperature on the Increase of Summertime Disease-related Mortality in Seoul: 1991-2000", J Prev Med Public Health 2005, Vol. 38, No. 3, Prev Med Public Health Association, Seoul, pp. 283-290.

Cohen, Jeffrey P., and Cletus C. Coughlin (2005), “An Introduction to Two-Rate Taxation of Land and Buildings," Federal Reserve Bank of St. Louis Review, May/June, pp. 359-74.

Debrezion, G., Pels, E. \& Rietveld, P. (2007), "The Effects of Railway Investments in a Polycentric City: A Comparison of Competitive and Segmented Land Markets", Environment and Planning A, 39, pp. 2048-2067. 
Desmedt, J., G. Vekemans, and D. Maes (2009), "Ensuring effectiveness of information to influence household behaviour", Journal of Cleaner Production, 17(4), pp. 455-462.

Dhakal, S. (2004), Urban Energy Use and Greenhouse Gas Emissions in Asian Mega-cities: Policies for a Sustainable Future, Institute for Global Environmental Strategies, Hayama, Japan.

The Economist Intelligence Unit (2009), European Green City Index, Siemens AG, Munich

The Economist Intelligence Unit (2010), Latin American Green City Index, Siemens AG, Munich.

The Economist Intelligence Unit (2011), Asian Green City Index, Siemens AG, Munich.

EEA (2007), “Transport and environment: on the way to a new common transport policy”, EEA Report No 1/2007, European Environment Agency, Copenhagen.

EKC (2009), "Life and Natural Sciences," in Lee, J.H. et al. (eds), Proceedings of the EU-Korea Conference on Science and Technology, Springer, p. 280.

Eom, J. and L. Shipper (2010), "Trends in passenger transport energy use in South Korea", Energy Policy, Vol. 38, pp. 3598-3607.

EPA (2006), Inventory of U.S. greenhouse gas emissions and sinks: 1990-2004, Environmental Protection Agency, Washington, D.C.

Gangwon-do (2010), "Plan to reinforce illegal disposal of waste" (in Korean), www.provin.gangwon.kr/dep/part08/sub02/sub02.asp?hb_Mode=readArticle\&hb_BoardManag er_ID=BDCCHH01\&hb_BoardItem_ID=126881, accessed 2 May 2011.

Global Green Growth Institute (2010), "Introduction of GGGI”, www.gggi.org.

Grazi, F., J.C.J.M. van den Bergh, and J.N. van Ommeren (2008), "An empirical analysis of urban form, transport, and global warming”, The Energy Journal. 29(4), pp. 97-107.

Grazi and van den Bergh, (2008). "Spatial organization, transport, and climate change: Comparing instruments of spatial planning and policy". Ecological Economics 67, pp. 630-639.

Greene, D.L., and A. Schafer (2003), "Reducing greenhouse gas emissions from U.S. transportation", Pew Center on Global Climate Change, Arlington, VA.

Hwang, Kee Yong and J.Y. Park. (2010), "Proactive National Transport Strategy for Low Carbon and Green Growth in Korea," Singapore Land Transport Authority.

Henderson, J.V. (1974), "Road congestion: a reconsideration of pricing theory", Journal of Urban Economics, 1(3), pp. 346-365.

IEA (2006), Energy technology perspectives: Scenario and strategies to 2050, OECD/IEA, Paris.

IEA (2008), World Energy Outlook 2008, OECD/IEA, Paris.

IEA (2009a), World Energy Outlook 2009, OECD/IEA, Paris. 
IEA (2009b), Innovations in Multi-Level Governance for Energy Efficiency: Sharing experience with multi-level governance to enhance energy efficiency, OECD/IEA, Paris.

IEA (2010a), Key World Energy Statistics: 2010 Edition, OECD/IEA, Paris.

IEA (2010b), Energy Balances of OECD Countries: 2010 Edition, OECD/IEA, Paris.

IPCC (2001), Climate Change 2001: Mitigation - Contribution of Working Group III to the Third Assessment Report of the Intergovernmental Panel on Climate Change (IPCC), Metz, B., et al. (eds.), Cambridge University Press, Cambridge.

IPCC (2007), Climate Change 2007: Impacts, Adaptation and Vulnerability. Contribution of Working Group II to the Fourth Assessment Report of the Intergovernmental Panel on Climate Change, Parry, M.L., et al. (eds.), Cambridge University Press, Cambridge.

International Transportation Forum (2010), "Implementing Congestion Charging; Summary and conclusions", JTRC Discussion Paper, ITF, Paris.

Jeong, J. (2011), "Green Jobs and Skills Development: from Korea's Experience and Perspectives", presentation by the Ministry of Employment and Labour at the OECD Green Growth Strategy Workshop, Paris, 11 February 2011.

Jeju Province (2011), “Jeju Smart Grid Test-bed”, http://smartgrid.jeju.go.kr/contents/index.php?mid=0202a, accessed 25 February 2011.

Ji, D. and S. Choi (2003), A Study on Readjusting and Improving Real-Estate Based Tax Systems, Korea Research Institute of Housing and Settlements (KRIHS), Gyeonggi-do.

Jones, R. and Byungseo Yoo (2010), "Korea's Green Growth Strategy: Mitigating Climate Change and Developing New Growth Engines", OECD Economics Department Working Papers No. 798, OECD, Paris.

Jun, M-J (2010), "Spatial transformation and regional disparity, housing, transportation and emissions", presentation at the joint workshop between Korea Planners' Association and the OECD in Seoul on 14 April 2010, Korea Planners' Association, Seoul.

Jung. I. H, et al. (2010), “The Enhancement of Linkage between Housing and Transportation policy: focusing on residential location and household trip patterns in Seoul metropolitan area", Korea Research Institute of Housing and Settlements (KRIHS), Gyeonggi-do.

Kim W-S (2003), “Air quality management in Seoul: development and implementation of strategic frameworks", in W-Y Kwon and K-J Kim (eds.) Urban management in Seoul, Seoul Development Institute, Seoul.

Kim, S., J. Sung and Y. Kim (2009), Changes in Flowering Times of the Woody Plant Species in the Hongneung Arboretum, Seoul: IUFRO conference proceedings, 19 May 2009, Quebec.

Korea Energy Economics Institute (KEEI) (2007), Energy Statistics Monthly, KEEI, Seoul.

Korea Energy Economics Institute (KEEI) (2011), Korean Energy Statistics Information, www.kesis.net, accessed 11 May 2011. 
Korea Institute of Construction Technology (2009), Energy Consumption in the Buildings Sector, Gyeonggi-do.

Korea Institute of Science and Technology Evaluation \& Planning (2010), Survey of Research and Development in Korea, Seoul.

Korea Meteorological Administration (2008), Understanding Climate Change and Taking Advantage of Climate Change Scenarios, Korea Meteorological Administration, Seoul.

Korea Statistics Office (2011), Korean Statistical Information System (in Korean), www.kosis.kr, accessed 1 March 2011.

Korea Transport Institute (KOTI) (2008), Calculation of Nation-wide Traffic Congestion Costs and Trend Analysis for 2007, Ilsan, Gyunggi-do.

Korean Intellectual Property Office (2011), Trends in Patent Applications (in Korean), www. Kipo.go.kr, accessed 19 April 2011.

Kwon W-Y (2001), "Globalization and Sustainability in Seoul”, in W-Y Kwon and K-J Kim (eds.) Urban management in Seoul, Seoul Development Institute, Seoul.

Lee K. H., et al. (2009), Research on cooperation among ministries for government projects, Korean Institute of Public Administration, Seoul.

Ministry of Environment (2009), Environment Statistics Yearbook, MOE, Gyeonggi-do.

Ministry of Environment (2010), 2009 Waste Generation and Disposal in Korea, MOE, Gyeonggi-do.

Ministry of Environment and National Institute of Environmental Research (2010), Korean Climate Change Assessment Report 2010, Ministry of Environment and National Institute of Environmental Research, Gyeonggi-do.

Ministry of Knowledge and Economy (2009), 2009 Yearbook of Regional Energy Statistics, Gyeonggi-do.

Ministry of Land, Transport and Maritime Affairs (MLTM) (2009), "Greening Urban and Building Initiative”, MLTM, Gyeonggi-do.

MLTM (2010), “The Multi-Modal Transfer Center Development Master Plan”, MLTM, Gyeonggi-do.

MLTM (2011a, forthcoming), Statistical Yearbook of MLTM: 2011, MLTM, Gyeonggi-do.

MLTM (2011b), "Innocity", http://innocity.mltm.go.kr/eng/public/public05.jsp, accessed 14 April 2011.

Ministry of Public Administration and Security (2009), Municipal yearbook of Korea (in Korean), MOPAS, Seoul.

Mo. C (2009), Study on Citizen's Policy Acceptance of Urban Congestion Pricing Scheme, KOTI, Gyeonggi-do. 
National Emergency Management Agency (2009), National Disaster Statistics Yearbook, NEMA, Korea.

National Institute of Environmental Research (2011), "National Air Pollutants Emissions System", www. Airemiss.nier.go.kr, accessed 16 March 2011.

Nicholls, R. J. et al. (2008), "Ranking Port Cities with High Exposure and Vulnerability to Climate Extremes: Exposure Estimates", OECD Environment Working Papers, No. 1, OECD, Paris.

Oates, W.E., and R.M. Schwab (1997), "The Impact of Urban Land Taxation: the Pittsburgh Experience", National Tax Journal, vol.50, pp. 121.

OECD (2004), Territorial Review of Pusan, Korea, OECD, Paris.

OECD (2005), Territorial Review of Seoul, Korea, OECD, Paris.

OECD (2006), OECD Environmental Performance Review of Korea, OECD, Paris

OECD (2007), "Literature Review on Climate Change Impacts on Urban City Centres: Initial Findings", OECD, Paris.

OECD (2008), "Eco-Innovation Policies in the Republic of Korea”, OECD, Environment Directorate, Paris.

OECD (2009), Green cities: New approaches to Confronting Climate Changes: OECD Workshop Proceedings, conference held 11-12 June 2009, Las Palmas de Gran Canaria, Spain.

OECD (2010a), Cities and Climate Change, OECD, Paris.

OECD (2010b), OECD Economic Surveys: Korea, OECD, Paris.

OECD (2010c), "Cities and Green Growth", Issues Paper for the Third Annual Meeting of the OECD Urban Roundtable of Mayors and Ministers, Paris, 25 May.

OECD (2011e), Greening Household Behaviour: The Role of Public Policy, OECD, Paris.

OECD (2011f, forthcoming), OECD Multilevel Governance Framework, OECD, Paris.

OECD (2011g, forthcoming) Cities and Green Growth: A Conceptual Paper, OECD, Paris.

OECD (2011h), "Making the Most of Public Investment in a Tight Fiscal Environment: Multilevel Governance Lessons from the Crisis", OECD, Paris.

OECD (2011i, forthcoming), “Towards Internationally Harmonised Methodologies to Inventory Urban Greenhouse Gas Emissions", OECD, Paris.

OECD (2011a, forthcoming), Regions at a Glance, OECD, Paris.

OECD (2011b), OECD Studies on Environmental Innovation Better Policies to Support EcoInnovation, OECD, Paris.

OECD (2011c,), Toward Green Growth, OECD, Paris. 
OECD (2011d, forthcoming), National Urban Policy Review of Korea, OECD, Paris.

Office of National River Restoration (2011), www.4rivers.go.kr/news/eng, accessed 18 March 2011.

Paju-si City (2010), "Utilization of Wasted Heat" (in Korean), www.paju.go.kr/open_content/paju_today/news/press/board.tdf?a=user.board.BoardApp \&c=2 002\&board_id=BD_WWW_03_04_02\&seq=11399, accessed 20 December 2010.

Perman, R., et al. (2003), Natural Resource and Environmental Economics, $3^{\text {rd }}$ ed., Addison Wesley, London.

The Presidential Committee on Green Growth (2009), Five Year Green Growth Action Plan, PCGG, Seoul.

The Presidential Committee on Green Growth (2010a), Framework Act for Low-carbon, Green Growth, PCGG, Seoul.

The Presidential Committee on Green Growth (2010b), "Summary of Local Climate Change Actions", based on submissions from local governments, PCGG, Seoul.

Pucher, John, et al (2005), "Public Transport in Seoul: Meeting Burgeoning Travel Demands of a Megacity”, Public Transport International, May/June 2005, Vol. 54, No. 3, pp. 54-61.

Rietveld, P. (2006), Transport and environment. The International Yearbook of Environmental and Resource Economics 2006/2007, Edward Elgar, Cheltenham, UK.

Ryan, S., and M.G. McNally (1995), "Accessibility and Neotraditional Neighborhoods: a Review of Design Concepts, Policies and Recent Literature", Transportation Research, 29(2), pp. 87-105.

Seoul Newspaper (2009), "Increasing Waste Generation" (in Korean), www.seoul.co.kr/news/newsView.php?id=20090915027017, accessed 2 May 2011.

SMBA (2011), "Introduction of Industry-University-Institute Collaboration for Technology Development Program in Korea", http://sanhak.smba.go.kr (in Korean), accessed 2 March 2011

Transportation for London (2011), "Low Emission Zone", www.tfl.gov.uk/roadusers/lez/, accessed 24 May 2011.

United Nations Economic and Social Commission for Asia and the Pacific (2010), Financing an Inclusive and Green Future: A Supportive Financial System and Green Growth for Achieving the Millennium Development Goals in Asia and the Pacific, United Nations, Bangkok.

United Nations Environmental Programme (UNEP) (2009), Global Green New Deal: an Update for the G20 Pittsburgh Summit, United Nations Environmental Program, Nairobi.

Verhoef, E.T., P. Nijkamp, and P. Rietveld (1997), “Tradable permits: their potential in the regulation of road transport externalities", Environment and Planning B 24, pp. 527-548.

Wang, K.I. (2009), “A Low-carbon Green City Project in Korea”, proceedings of the United Nations Project Office on Governance Session in the $5^{\text {th }}$ Initiative Conference: Governance Strategies for Pro-environmental Urban Policies in Developing Countries, Jeollabuk-do, 6 July. 
World Bank (2010), World Development Report: Development and Climate Change, World Bank, Washington, D.C.

World Bank (2011), "Representative Greenhouse Gas Baselines for Cities and their Respective Countries", http://go.worldbank.org/80LAWI7RX0, accessed 25 May 2011. 
Credits for cover photos (from left to right) are as follows:

Réf. 7782193 @ Kwest - Fotolia.com

Réf. 3066489 @ Mikael Damkier - Fotolia.com

Réf. 1300814 ( ) hassan bensliman - Fotolia.com 